Florida International University FIU Digital Commons

$11-9-2012$

\title{
Preservation of Nitric Oxide Availability as Nitrite and Nitrosothiols
}

\author{
Kumpal J. Madrasi \\ Florida International University, kmadr001@fiu.edu
}

DOI: $10.25148 /$ etd.FI12120508

Follow this and additional works at: https://digitalcommons.fiu.edu/etd

\section{Recommended Citation}

Madrasi, Kumpal J., "Preservation of Nitric Oxide Availability as Nitrite and Nitrosothiols" (2012). FIU Electronic Theses and Dissertations. 805.

https://digitalcommons.fiu.edu/etd/805 


\title{
FLORIDA INTERNATIONAL UNIVERSITY \\ Miami, Florida
}

\section{PRESERVATION OF NITRIC OXIDE AVAILABILITY AS NITRITE AND NITROSOTHIOLS}

\author{
A dissertation submitted in partial fulfillment of the \\ requirements for the degree of \\ DOCTOR OF PHILOSOPHY
}

in

BIOMEDICAL ENGINEERING

by

Kumpal J. Madrasi 
To: Dean Amir Mirmiran

College of Engineering and Computing

This dissertation, written by Kumpal J. Madrasi, and entitled Preservation of Nitric Oxide Availability as Nitrite and Nitrosothiols, having been approved in respect to style and intellectual content is referred to you for judgment.

We have read this dissertation and recommend that it be approved.

Chenzhong Li

Yen-Chih Huang

Watson Lees

Nikolaos Tsoukias, Major Professor

Date of Defense: November 9, 2012

The dissertation of Kumpal J. Madrasi is approved.

$\begin{array}{r}\text { Dean Amir Mirmiran } \\ \text { College of Engineering and Computing } \\ \hline \begin{array}{r}\text { Dean Lakshmi N. Reddi } \\ \text { University Graduate School }\end{array}\end{array}$

Florida International University, 2012 


\section{DEDICATION}

To my parents (late) Jagdish Jagmohandas Madrasi and Jaishree Jagdish Madrasi and to my maternal grandfather (late) Ramniklal Uttamram Ghariwala

\section{ॐ भूर्भवस्वः तत्सवितुर्वरिन्यम}

\section{भर्गोदेवस्य धीमहि धियोयोनः प्रचोदयात ।I (R.V. 3.62.10)}

"We meditate on the effulgent glory of the divine Light; may he inspire our understanding."

"Those who seek to achieve things should show no mercy." -- Kautilya 


\section{ACKNOWLEDGMENTS}

I will start off with a big hug to my once widowed mom who worked day and night as a tutor earning barely enough for my education and for inspiring in me the love of reading, without which I would never have been the science student that I became. I also thank my maternal grandfather for all the support he gave me during the start of my educational life, without whom I would have been left without any education or a home. And a special thanks to my step father who blended into the family pretty well and whose motivational support meant a lot to me during the course of my degree.

I would like to express my deepest appreciation to professor Nikolaos $\mathrm{M}$. Tsoukias, postdoctoral fellow Adam Kapela and research assistant professor Mahesh Joshi for giving me the opportunity and the freedom to pursue my intersts. Their guidance, continuous support and genuine concern played a critical role in the completion of this dissertation. It was a pleasure and a great experience to work under their supervision. I am also very grateful to professors Watson Lees, Chenzhong Li and YenChih Huang for their presence on my dissertation committee. I was extremely fortunate to attend their lectures and take their guidance on my research projects.

I gratefully acknowledge the financial support of the Florida International University for awarding me the Dissertation Year Fellowship without which life would have been a lot tougher and the National Institute of Health for funding my research projects.

I would like to thank my labmates: fellow graduate students Tushar Gadkari, Sridevi Nagaraja Shabnam Namin and Jaimit Parikh and undergraduate students Luis Alonzo, Konstantinos Sebekos Zenith Acosta, Carolina Bautista, Liset Hilares, Suset 
Rodriguez, Florencia Goluboff, Celisse Zabalo and Daniel Rodriguez for helping at various points with my research and for giving me a wholesome lab experience.

I also thank my high school, college and coaching class teachers (Murtuza Chashmai, Sabitha Menon, Bhavik Nathwani and many more) for being inspiring personalities and a guiding light for my career at various times. I can't forget Al Pacino's fantastic speech to the Miami Sharks in "Any given Sunday" for motivating me whenever I felt down and beaten. Finally, I thank the Indian community of South Florida for giving a second home away from home and a space to unwind and relax after a hard day's labor. 


\section{ABSTRACT OF THE DISSERTATION \\ PRESERVATION OF NITRIC OXIDE AVAILABILITY AS NITRITE AND \\ NITROSOTHIOLS}

by

Kumpal J. Madrasi

Florida International University, 2012

Miami, Florida

\section{Professor Nikolaos Tsoukias, Major Professor}

Nitric Oxide (NO) has been known for long to regulate vessel tone. However, the close proximity of the site of NO production to "sinks" of NO such as hemoglobin $(\mathrm{Hb})$ in blood suggest that blood will scavenge most of the NO produced. Therefore, it is unclear how NO is able to play its physiological roles. The current study deals with means by which this could be understood. Towards studying the role of nitrosothiols and nitrite in preserving NO availability, a study of the kinetics of glutathione (GSH) nitrosation by NO donors in aerated buffered solutions was undertaken first. Results suggest an increase in the rate of the corresponding nitrosothiol (GSNO) formation with an increase in $\mathrm{GSH}$ with a half-maximum constant $\mathrm{EC}_{50}$ that depends on $\mathrm{NO}$ concentration, thus indicating a significant contribution of $\mathrm{NO}_{2}$ mediated nitrosation in the production of GSNO. Next, the ability of nitrite to be reduced to NO in the smooth muscle cells was evaluated. The NO formed was inhibited by sGC inhibitors and accelerated by activators and was independent of $\mathrm{O}_{2}$ concentration. Nitrite transport mechanisms and effects of exogenous nitrate on transport and reduction of nitrite were examined. The results showed that $\mathrm{sGC}$ can mediate nitrite reduction to $\mathrm{NO}$ and nitrite is 
transported across the smooth muscle cell membrane via anion channels, both of which can be attenuated by nitrate. Finally, a 2 - D axisymmetric diffusion model was constructed to test the accumulation of NO in the smooth muscle layer from reduction of nitrite. It was observed that at the end of the simulation period with physiological concentrations of nitrite in the smooth muscle cells (SMC), a low sustained NO generated from nitrite reduction could maintain significant sGC activity and might affect vessel tone. The major nitrosating mechanism in the circulation at reduced $\mathrm{O}_{2}$ levels was found to be anaerobic and a $\mathrm{Cu}^{+}$dependent GSNO reduction activity was found to deliver minor amounts of NO from physiological GSNO levels in the tissue. 


\section{TABLE OF CONTENTS}

CHAPTER

PAGE

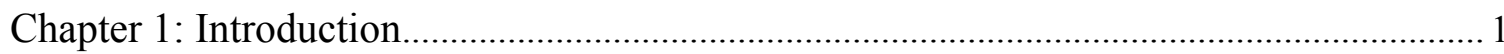

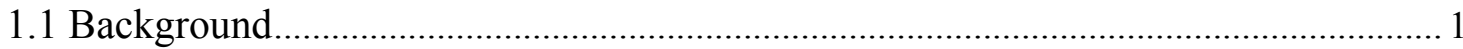

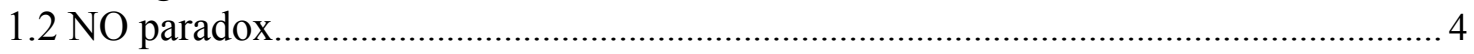

1.2.1 NO consumption reduced by RBCs ..............................................................

1.2.2 NO conservation as nitrosothiols and nitrites ...................................................... 6

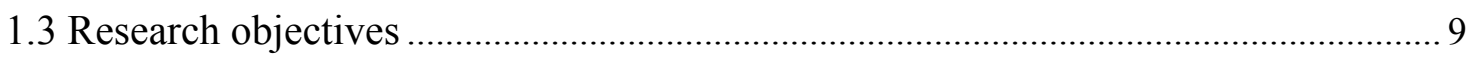

Chapter 2: Glutathiyl Radical as an Intermediate in the Glutathione Nitrosation .............. 11

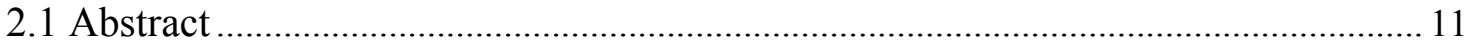

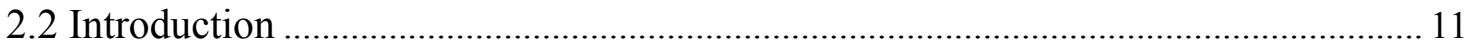

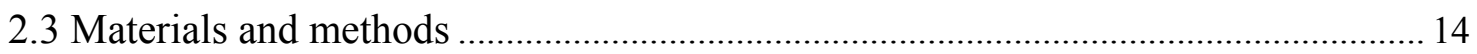

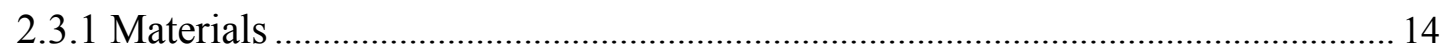

2.3.2 NO release by NO donor ......................................................................... 14

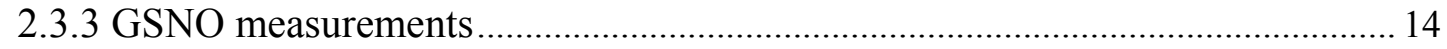

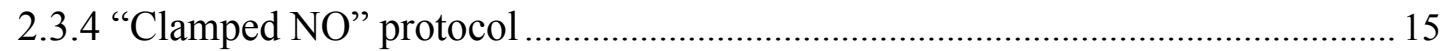

2.3.5 Pseudo steady state approximation .................................................................. 16

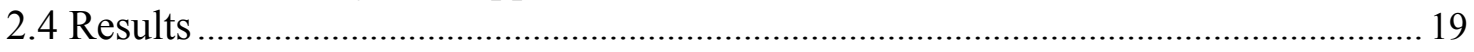

2.4.1 Dependence of [NO] on [NOdonor] ………………..................................... 19

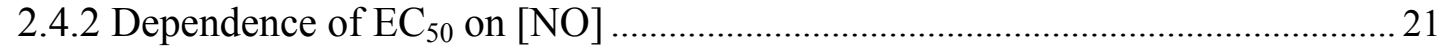

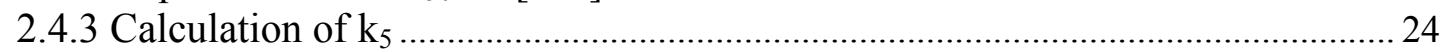

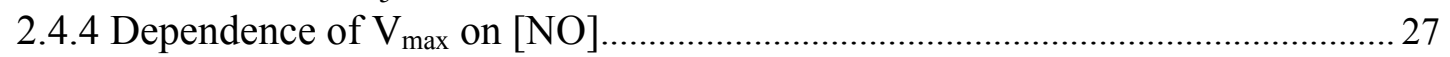

2.4.5 Validation of rate law and data fitting ........................................................... 28

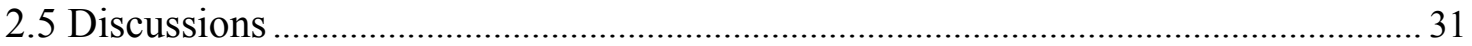

Chapter 3: Nitrite Transport and Reduction by sGC in Smooth Muscle Cells .................... 37

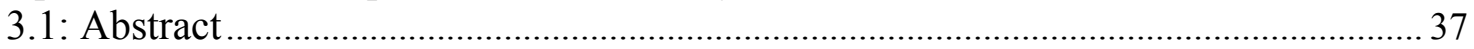

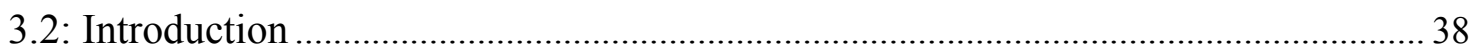

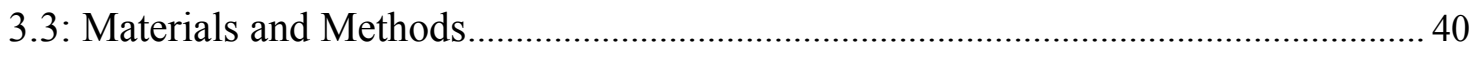

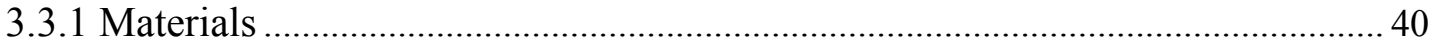

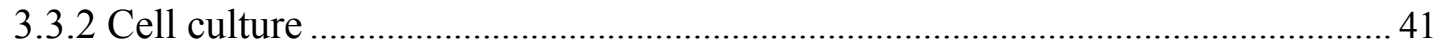

3.3.3 Fluorescence NO Imaging .......................................................................... 41

3.3.4 Chemiluminescence analysis ........................................................................ 41

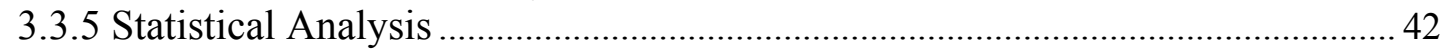

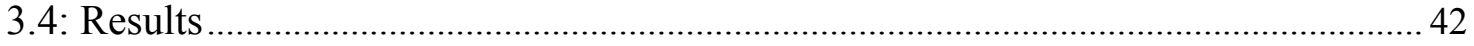

3.4.1 ODQ inhibited and YC-1 accelerated nitrite reduction to NO .......................... 42

3.4.2 Heat treatment and order of the reaction ............................................................. 45

3.4.3 CO and Allopurinol effects on nitrite reduction to NO...................................... 46

3.4.4 $\mathrm{O}_{2}$ dependence of nitrite reduction and transport ................................................. 49

3.4.5 Cellular nitrite transport via anion channels ......................................................5 50

3.4.6 Competitive inhibition of nitrite reduction and transport by nitrate ....................52

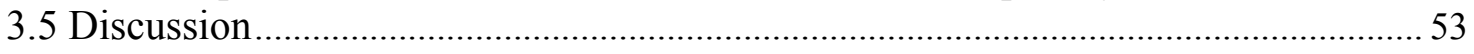


Chapter 4: Computational modeling of NO and NO oxidative species in the microcirculation: Reducing nitrite to NO in the smooth muscle cells vs. arteriolar lumen57

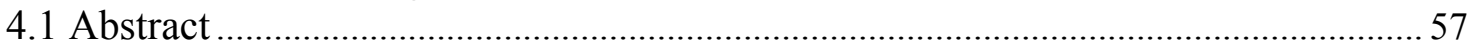

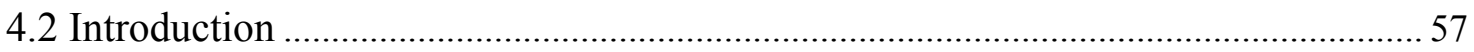

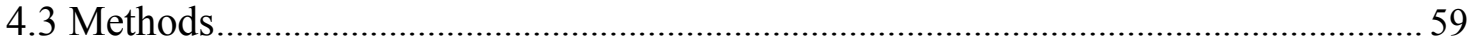

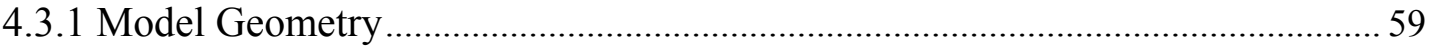

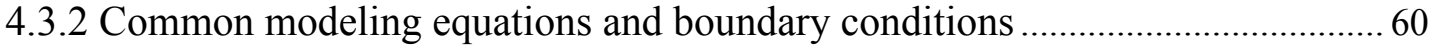

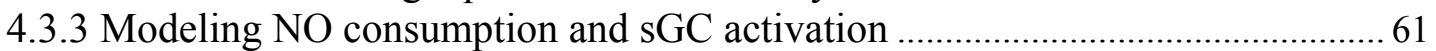

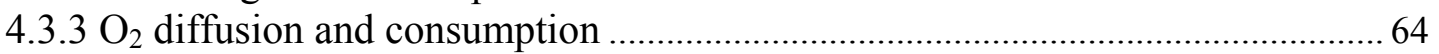

4.3.4 $\mathrm{NO}_{2}, \mathrm{~N}_{2} \mathrm{O}_{3}$, nitrite and nitrate formation, transport and consumption................. 65

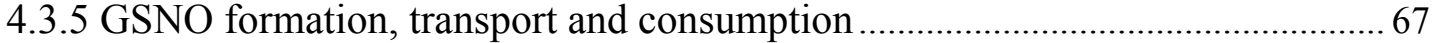

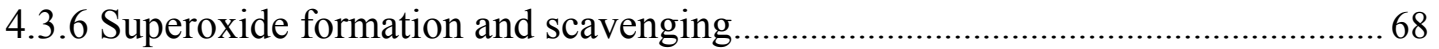

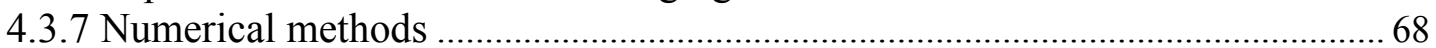

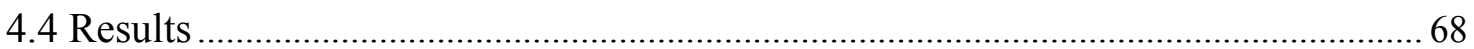

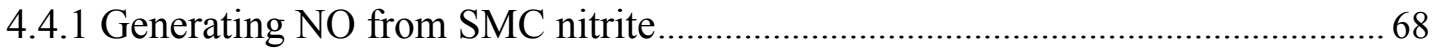

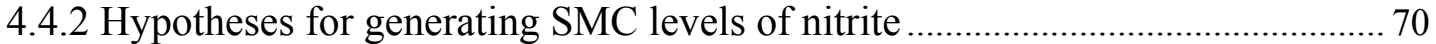

4.4.3 Generating NO from nitrite supplied in blood vessels ....................................... 71

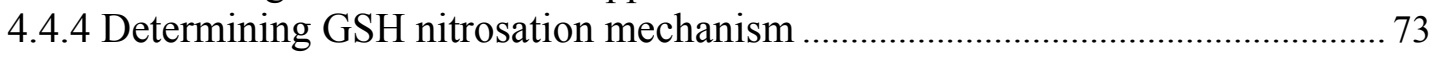

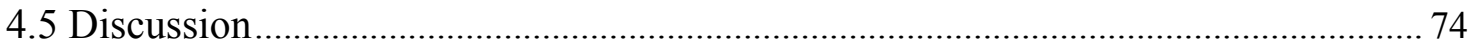

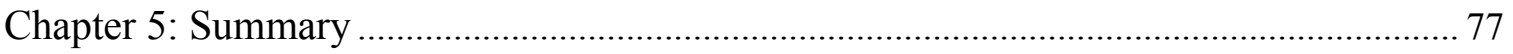

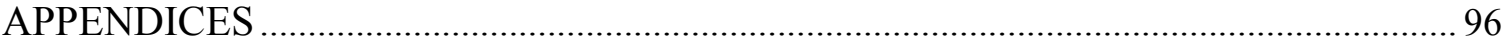

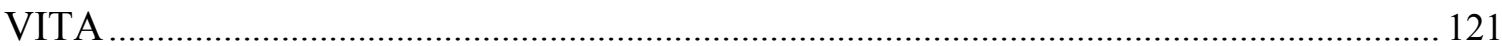




\section{LIST OF FIGURES}

FIGURE

PAGE

Fig 1.1: Schematic of NO production from NOS tracking the donation of oxygen atoms

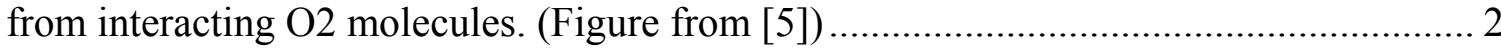

Fig 1.2: Schematic of blood flow in an arteriolar region. The arteriolar lumen has RBCs clustered in the center owing to laminar flow and a cell free layer adjacent to the endothelium. The endothelium and the smooth muscle layer are separated by an interstitial gap of connective tissues. Beyond the SMC lie a non-perfused region followed by a region perfused by capillaries (Figure from Tsoukias et al. [24])........................... 4

Fig 2.1: (A) Release of NO from PAPA/NO $(500 \mu \mathrm{M})$. NO concentration is monitored with a NO-sensitive electrode for $30 \mathrm{~min}$. After an initial accumulation period, NO levels remain relative steady for a significant time period. (B) log-log graph showing relation between maximum NO concentrations achieved at different PAPA/NO concentrations (n $=4)$. The slope of $0.51+0.04$ is not statistically different from $0.5(p=0.30)$. 20

Fig 2.2: (A) Representative data for GSNO formation as a function of time. GSNO concentration was monitored in a spectrophotometer at $338 \mathrm{~nm}$, following mixing of GSH $(250 \mu \mathrm{M})$ and PAPA/NO $(1 \mathrm{mM})$. Data were fitted by a $5^{\text {th }}$ order polynomial to remove noise (dashed black line). The maximum slope of the polynomial is identified (red circle) and corresponds to the GSNO formation rate at peak NO concentration. (B) Rates of nitrosation (V) at three different NO donor concentrations (500 $\mu \mathrm{M}$ (red), $1 \mathrm{mM}$ (blue) and $5 \mathrm{mM}$ (green)) are plotted against GSH concentrations. Inset shows $\mathrm{V}_{\max } / \mathrm{V}$ plotted against $1 / \mathrm{GSH}$. Slope of these lines indicate $\mathrm{EC}_{50}$ values. An increase in $\mathrm{EC}_{50}$ values is observed with increasing $\mathrm{NO}$ donor concentrations. 22

Fig 2.3: (A) A $\log$ - log graph of half maximum constant $\left(\mathrm{EC}_{50}\right)$ at different PAPA/NO concentrations. Average $\mathrm{EC}_{50}$ values $(\mathrm{n}=3)$ are presented. The slope of $0.5 \pm 0.2$ is not statistically different from $0.5(\mathrm{p}=0.946)$. The result suggests that $\mathrm{EC}_{50}$ is proportional to the square root of $\mathrm{NO}$ donor concentration and thus proportional to NO concentration. (B) A graph of $\mathrm{EC}_{50}$ vs. clamped $\mathrm{NO}$ values from $\mathrm{NO}$ electrode measurements in Fig 2.1B. The slope from a linear fit of the graph is $30.5 \pm 5.2 \mu \mathrm{M} \mathrm{GSH} / \mu \mathrm{M}$. 23

Fig 2.4: (A) A $\log$ - log graph of nitrosation rates at saturating GSH concentrations $\left(\mathrm{V}_{\mathrm{max}}\right)$ at different PAPA/NO concentrations. Average values with standard deviations (error bars) are presented. A linear fit gives a slope of $1.08 \pm 0.1$. The slope is not statistically different from $1(\mathrm{p}=0.09)$ and significantly different from 0.5 and $1.5(\mathrm{p}<<$ 0.05) suggesting a $\mathrm{V}_{\max }$ proportional to the $\mathrm{NO}$ donor concentration. (B) The linear dependence of $\mathrm{V}_{\max }$ on PAPA/NO concentration has a slope of $(7.5 \pm 0.5) \times 10^{-5} \mathrm{~s}^{-1} \ldots .28$

Fig 2.5: Comparison of GSNO formation rates as predicted by the proposed rate law of the simplified reaction scheme Eq. 2.2d (solid lines), the mathematical model of the 
complete reaction set (dotted lines) next to experimental data. Data using different PAPA/NO concentrations are presented $(500 \mu \mathrm{M}, 1 \mathrm{mM}, 3 \mathrm{mM}, 5 \mathrm{mM}$ and $10 \mathrm{mM})$. The corresponding NO concentration achieved were. Error bars show standard deviations ( $\mathrm{n}=$ $3)$.

Fig 3.1: Effect of ODQ on nitrite reduction to NO: Rat aortic smooth muscle cells loaded for 45 min with $10 \mu \mathrm{M} \mathrm{Cu}_{2}$ (FL2E) and treated with (A) Vehicle, (B) $30 \mathrm{mM}$ nitrite and (C) pretreatment with $10 \mu \mathrm{M}$ ODQ followed by $30 \mathrm{mM}$ nitrite for $10 \mathrm{~min}$. (D) Change in the ratio of arbitrary fluorescence units normalized with average of arbitrary fluorescence units of control $\left(\mathrm{afu} / \mathrm{afu} \mathrm{u}_{\mathrm{c}}\right)$ for $\mathrm{A}, \mathrm{B}$ and $\mathrm{C}$. 43

Fig 3.2: Effect of YC-1 on nitrite reduction to NO: Rat aortic smooth muscle cells loaded for 45 min with $10 \mu \mathrm{M} \mathrm{Cu}_{2}$ (FL2E) and treated with (A) Vehicle, (B) $30 \mathrm{mM}$ nitrite and (C) pretreatment with $20 \mu \mathrm{M} \mathrm{YC}-1$ followed by $30 \mathrm{mM}$ nitrite for $10 \mathrm{~min}$. (D) Change in the ratio of arbitrary fluorescence units normalized with average of arbitrary fluorescence units of control (afu/afu $)$ for $\mathrm{A}, \mathrm{B}$ and $\mathrm{C}$. 44

Fig 3.3: (A) Effect of heat on nitrite reduction to NO: Cell lysates were treated with either vehicle, $600 \mu \mathrm{M}$ nitrite or $600 \mu \mathrm{M}$ nitrite after heating the cell lysates in near boiling water for $30 \mathrm{~min}$. (B) Nitrite reduction from three doses of nitrite, $0.6,0.8$ and $2 \mathrm{mM}$ was measured and the initial rate of nitrite reduction (averaged over first 10 minutes of the experiment) was plotted against nitrite in a $\log -\log$ graph. The slope of the graph is 0.73 \pm 0.3 thus indicating first order kinetics for the reaction. $(\mathrm{n}=3$ and $* \mathrm{p}<0.05)$. 45

Fig 3.4: Effect of $\mathrm{CO}$ on nitrite reduction to NO: (A) Cell lysates were treated with either vehicle, $600 \mu \mathrm{M}$ nitrite, $600 \mu \mathrm{M}$ nitrite $+50 \mu \mathrm{M}$ CORM-2, and $600 \mu \mathrm{M}$ nitrite $+50 \mu \mathrm{M}$ CORM-2 $+10 \mu \mathrm{M}$ ODQ. (B) Cell lysates were treated with either vehicle, $600 \mu \mathrm{M}$ nitrite, $600 \mu \mathrm{M}$ nitrite $+50 \mu \mathrm{M}$ CORM-2, and $600 \mu \mathrm{M}$ nitrite $+50 \mu \mathrm{M}$ degraded CORM2. (C) Cell lysates were treated with either vehicle, $600 \mu \mathrm{M}$ nitrite $+50 \mu \mathrm{M}$ CORM-2 or $600 \mu \mathrm{M}$ nitrite $+50 \mu \mathrm{M}$ CORM-2 $+600 \mu \mathrm{M}$ CPTIO. (D) Effect of allopurinol on nitrite reduction to NO: Cell lysates were treated with either vehicle, $600 \mu \mathrm{M}$ nitrite, or $600 \mu \mathrm{M}$ nitrite $+100 \mu \mathrm{M}$ allopurinol for $10 \mathrm{~min}$ and $\mathrm{NO}$ measured by chemiluminescence. $(\mathrm{n}=3$ and $* \mathrm{p}<0.05, * * \mathrm{p}>0.05)$ 47

Fig 3.5: (A) Effect of oxygen on nitrite reduction to NO: Cell lysates were treated with $600 \mu \mathrm{M}$ nitrite either after purging with helium for $15 \mathrm{~min}$ (hypoxic) or with compressed air (normoxic). (B) Nitrite transport kinetics: Nitrite was added to cell cultures and intracellular nitrite measured by chemiluminescence upon cell lysis at different time intervals $(\mathrm{n}=3)$. (C) Cells were treated with either vehicle, $600 \mu \mathrm{M}$ nitrite (normoxia), or $600 \mu \mathrm{M}$ nitrite (hypoxia) $(\mathrm{n}=3$ and $* \mathrm{p}<0.05, * * \mathrm{p}>0.05)$.

Fig 3.6: Intracellular nitrite measurements by chemiluminescence: (A) Cell cultures were treated with either vehicle, $100 \mu \mathrm{M}$ DIDS, $600 \mu \mathrm{M}$ nitrite or $100 \mu \mathrm{M}$ DIDS $+600 \mu \mathrm{M}$ nitrite for $10 \mathrm{~min}$ and cell lysates used for nitrite measurements. (B) Cell cultures were 
treated with either vehicle, $75 \mu \mathrm{M}$ probenecid, $600 \mu \mathrm{M}$ nitrite, or $600 \mu \mathrm{M}$ nitrite +75 $\mu \mathrm{M}$ probenecid and cell lysates used for nitrite measurements. (C) Cell cultures were treated with either vehicle, $50 \mathrm{mM} \mathrm{K}^{+}$gluconate, $600 \mu \mathrm{M}$ nitrite or $600 \mu \mathrm{M}$ nitrite +50 $\mathrm{mM} \mathrm{K}^{+}$gluconate for $10 \mathrm{~min}$ and cell lysates used for nitrite measurements. (D) Cell cultures were treated with either vehicle, $10 \mu \mathrm{M}$ NPPB, $600 \mu \mathrm{M}$ nitrite, or $10 \mu \mathrm{M}$ NPPB $+600 \mu \mathrm{M}$ nitrite for $10 \mathrm{~min}$ and cell lysates used for nitrite measurements. $(\mathrm{n}=3$ and * $\mathrm{p}<0.05, * * \mathrm{p}>0.05)$

Fig 3.7: Effect of nitrate on nitrite reduction and nitrite transport. (A) Cell lysates were treated with either vehicle, $600 \mu \mathrm{M}$ nitrite, or $600 \mu \mathrm{M}$ nitrite $+300 \mu \mathrm{M}$ nitrate. (B) Cell cultures were treated with $600 \mu \mathrm{M}$ nitrite in the absence and presence of increasing concentration of nitrate for $10 \mathrm{~min}$ and intracellular nitrite measured by

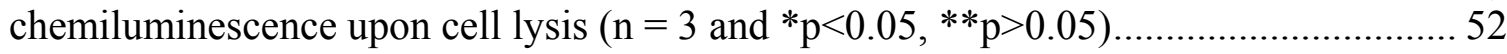

Fig 4.1: NO generated under steady state physiological nitrite conditions with NO consumption by blood and capillaries intact (A) NO from $10 \mu \mathrm{M}$ SMC nitrite (black line) and $20 \mu \mathrm{M}$ SMC nitrite (red line) for first order NO consumption in blood at an RBC permeability of $40 \mathrm{~cm} / \mathrm{s}$ and (B) NO from $10 \mu \mathrm{M}$ SMC nitrite (black line) and $20 \mu \mathrm{M}$ SMC nitrite (red line) for first order NO consumption in blood at an RBC permeability of $0.1 \mathrm{~cm} / \mathrm{s}$. Dashed lines in both instances indicate chosen constant $\mathrm{NO}_{2}{ }^{-}$concentrations. 69

Fig 4.2: A: Radial profiles of nitrite (black line) and nitrate (red line) in the modeled region. B: Radial profiles of nitrite under control (black line), 50 times less (red line) and 100 times less (green line) nitrite diffusivities 71

Fig 4.3: Supplying nitrite in the lumen A: NO generation solely by lumen nitrite for 200 $\mu \mathrm{M}$ (black line), $1 \mathrm{mM}$ (red line) and $5 \mathrm{mM}$ (green line) nitrite. B: GSNO generated solely by lumen nitrite for $200 \mu \mathrm{M}$ (black line), $1 \mathrm{mM}$ (red line) and $5 \mathrm{mM}$ (green line) nitrite. C: NO generation by lumen nitrite and SMC layer for $200 \mu \mathrm{M}$ (black line), $1 \mathrm{mM}$ (red line) and $5 \mathrm{mM}$ (green line) with equilibration across the arteriolar wall. Dashed lines in $\mathrm{A}, \mathrm{B}$ and $\mathrm{C}$ indicate chosen constant $\mathrm{NO}_{2}{ }^{-}$concentrations. 73

Fig 4.4: Change in GSNO concentration in the radial direction. A: through both pathways of nitrosation (red line) and without cytochrome $\mathrm{C}$ based GSNO production (black line) B: NO produced through constant GSNO concentrations: $20 \mathrm{nM}$ (black line), $40 \mathrm{nM}$ (red line) and $60 \mathrm{nM}$ (green line) 74

Fig A1.1: Comparison of the outcomes of the new (Eq. 2.2c) and simple (Eq. 2.2b) rate laws and the mathematical model. Dashed line indicates the simple rate law and solid line indicates the new rate law. Circles indicate outcomes of the mathematical model. Red, orange and green are for PAPA/NO concentrations of $0.5,1$ and $3 \mathrm{mM}$ respectively.... 99 


\section{LIST OF TABLES}

TABLE

PAGE

Table 2.1: Rate constants of reactions mentioned in the manuscript are as follows ........ 26

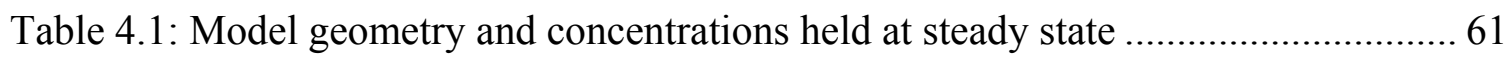

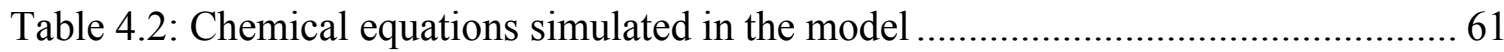

Table 4.3: Other rate constants and physical parameters used in the model ................... 63

Table A1.1: Detailed set of equations involved in the nitrosation of GSH are as follows 96 


\section{ABBREVIATIONS AND ACRONYMS}

Nitric Oxide

NO

Endothelium Derived Relaxing Factor

EDRF

Endothelial Nitric Oxide Synthase

eNOS

Neuronal Nitric Oxide Synthase

nNOS

Inducible Nitric Oxide Synthase

iNOS

Smooth Muscle Cells

SMC

soluble Guanylyl Cyclase

sGC

cyclic Guanosine Mono Phosphate

cGMP

Guanosine Tri Phosphate

GTP

Hemoglobin

$\mathrm{Hb}$

Red Blood Cells

$\mathrm{RBC}$

Hemoglobin Vesicles

$\mathrm{HbV}$

Hematocrit

Hct

Glutathione

GSH

Cysteine

Cys

S - Nitrosoglutathione

GSNO

S - Nitrosocysteine

CysNO

Pseudo Steady State Approximation

PSSA

Nitrogen dioxide radical

$\mathrm{NO}_{2}$

Dinitrogen Trioxide

$\mathrm{N}_{2} \mathrm{O}_{3}$

Propylamine Propylamine NONOate

$\mathrm{PAPA} / \mathrm{NO}$

Diethylamine NONOate

DEA/NO 
Oxygen

2-\{4,5-Bis[(6-(2-ethoxy-2-oxoethoxy)-2-methylquinolin-8-ylamino)methyl]-6hydroxy-3oxo-3H-xanthen-9-yl\} benzoic acid

2-(4-carboxyphenyl)-4,5-dihydro-4,4,5,5-tetramethyl-1H-imidazolyl-1-oxy-3-oxide, monopotassium salt 
Ferricytochrome C

CytFe(III)

Ferrocytochrome C

CytFe(II) 


\section{LIST OF SYMBOLS}

\begin{tabular}{|c|c|}
\hline $\mathrm{m}$ & meter \\
\hline$\mu \mathrm{m}$ & micrometer \\
\hline$[\mathrm{X}]$ & concentration of $X$ \\
\hline$\mu \mathrm{M}$ & micromolar \\
\hline $\mathrm{mM}$ & millimolar \\
\hline $\mathrm{nM}$ & nanomolar \\
\hline mol & moles \\
\hline $\mathrm{P}_{\mathrm{m}}$ & Membrane Permeability \\
\hline$\lambda$ & Partition coefficient \\
\hline $\mathrm{EC}_{50}$ & Half maximum effective concentration \\
\hline $\mathrm{V}_{\max }$ & Maximum rate of reaction \\
\hline afu & arbitrary fluorescence units \\
\hline $\mathrm{afu}_{\mathrm{c}}$ & average arbitrary fluorescence units of control \\
\hline s & second \\
\hline $\mathrm{pmol} / \mathrm{mg}$ & Picomoles/milligram of protein \\
\hline $\mathrm{nmol} / \mathrm{mg}$ & Nanomoles/milligram of protein \\
\hline $\mathrm{D}_{\mathrm{X}}$ & Diffusivity of $X$ \\
\hline $\mathrm{R}_{\mathrm{X}}$ & Consumption rate of $\mathrm{X}$ \\
\hline $\mathrm{QX}_{\mathrm{X}}$ & Production rate of $\mathrm{X}$ \\
\hline $\mathrm{k}_{\mathrm{x}}$ & Rate constant for reaction $\mathrm{x}$ \\
\hline $\mathrm{k}_{\mathrm{d}}$ & Dissociation constant \\
\hline $\mathrm{R}_{\text {init }}$ & Initial rate of reaction \\
\hline
\end{tabular}




\section{Chapter 1: Introduction}

\subsection{Background}

Nitric oxide (NO) has been known for decades [1] to be the Endothelium Derived Relaxing Factor (EDRF) that promotes vascular smooth muscle relaxation when it binds and activates soluble guanylyl cyclase (sGC). This has been followed by its implication in a wide array of biological functions from physiological events such as neurotransmission [2] and host immune system defense [3] to pathophysiological events such as ischemia, inflammation and neurodegeneration. Besides NO itself, products of NO oxidation such as nitrogen dioxide $\left(\mathrm{NO}_{2}\right)$, dinitrogen trioxide $\left(\mathrm{N}_{2} \mathrm{O}_{3}\right)$, peroxynitrite $\left(\mathrm{ONOO}^{-}\right)$, nitrite, nitrate and nitroxyl (HNO) also play important roles in both physio and pathophysiological processes [4].

In vivo, NO is produced by two constitutively expressed enzymes, endothelial Nitric Oxide Synthase (eNOS) and neuronal Nitric Oxide Synthase (nNOS) as well as the inducible enzyme inducible Nitric Oxide Synthase (iNOS). NOS enzymes produce NO by catalyzing a five electron oxidation of a guanidine nitrogen of L-arginine (L-Arg). Oxidation of L-Arg to L-Citrulline occurs via two successive monooxygenation reactions producing $\mathrm{N}^{\mathrm{G}}$ hydroxy L-arginine (NOHLA) as an intermediate. Two moles of oxygen $\left(\mathrm{O}_{2}\right)$ and 1.5 moles of NADPH are consumed per mole of NO formed [5]. For constitutive enzymes, in response to receptor or physical stimulation, there is an influx of $\mathrm{Ca}^{2+}$. This causes an increase in the concentration of intracellular inositol triphosphate $\left(\mathrm{IP}_{3}\right)$ which initiates the release of $\mathrm{Ca}^{2+}$ from the endoplasmic reticulum (ER). The $\mathrm{Ca}^{2+}$ then binds to calmodulin $(\mathrm{CaM})$ to activate the constitutive NOS to produce NO. For 
inducible enzymes, calmodulin is already bound to the enzyme [6] and it is independent of calcium influx. Four more cofactors/prosthetic groups: flavin adenine dinucleotide (FAD), flavin mononucleotide (FMN), heme iron (present on the NOS) and tetrahydrobiopterin $\left(\mathrm{BH}_{4}\right)$ are recruited to produce NO. Fig 1.1 shows a molecular representation of the NO production reaction.

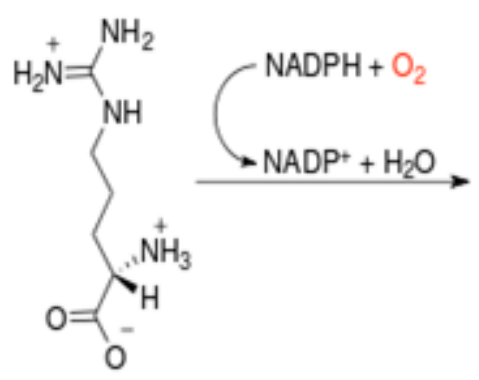

L-Arginine

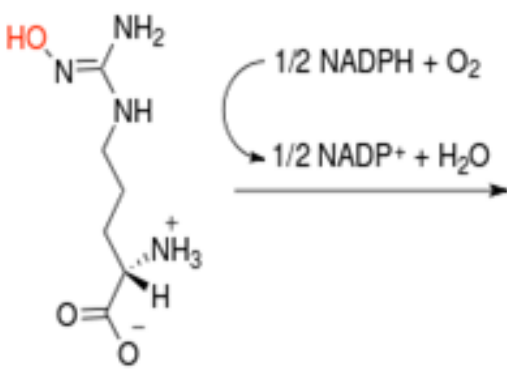

NOHLA

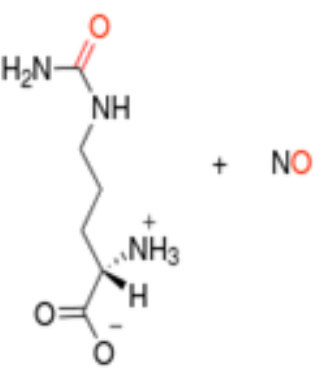

L-Citrulline

Fig 1.1: Schematic of NO production from NOS tracking the donation of oxygen atoms from interacting $\mathrm{O} 2$ molecules. (Figure from [5])

As it is a small diatomic molecule, NO then gets transported in all directions freely. For its physiological function, the following series of events has to happen in a chronological order: (1) NO binding to the heme moiety of sGC and activating the enzyme by inducing a conformational change that displaces iron out of the plane of the porphyrin ring [7], (2) sGC catalyzing the production of cyclic Guanosine Mono Phosphate (cGMP) from Guanosine Tri-Phosphate (GTP) to elevate cGMP and (3) cGMP causing a cascade of intracellular events that culminate in a reduction in calcium dependent vascular smooth muscle tone by inactivating myosin light chain kinase (MLCK) [8, 9] through phosphorylation by phospho kinase G (PKG). MLCK inactivation causes disruption of MLCK induced phosphorylation of the myosin light chain, which would have otherwise lead to contraction [10]. To complete this chain of 
events, sGC has to have an exposure to NO concentrations in the range of $23-120 \mathrm{nM}$ [11-14]. But the environment in which NO is produced is replete with NO scavengers which are as follows:

1) Molecular oxygen: In the presence of oxygen, NO undergoes a second order oxidation reaction to produce nitrite and a small proportion of nitrate as end products. This is usually characterized as a slow process but recent work has suggested that the reaction might be accelerated in hydrophobic components [15-17]. In addition, an enzyme Ceruloplasmin has been found in the plasma accelerating NO oxidation [18] along with the hydration reaction of an $\mathrm{NO}$ - ferricytochrome c complex in the mitochondria $[19,20]$.

2) Superoxide anion: Under diseased conditions, lack of availability of NOS cofactors can lead to NOS uncoupling. In such instances, there is a drop in the NO output of NOS enzymes and superoxide is produced. The superoxide produced has a high affinity for $\mathrm{NO}$ and can consume it to produce peroxynitrite anions (ONOO$\left.{ }^{-}\right)$which further reduces NO availability.

3) Metalloproteins: Blood flowing in the vessel lumen has about $2 \mathrm{mM}$ hemoglobin $(\mathrm{Hb})$ encapsulated in RBCs, which is a very potent NO scavenger. Moreover, we have various heme compounds in tissues, such as myoglobin and cytochrome c oxidase which are also known NO scavengers [21, 22].

As a result of the above mentioned possibilities for the consumption of NO, NO has a short half-life in vivo (spanning a few seconds). This has led to questions [23] on 
how NO gets transported to the smooth muscle cell and whether or not, enough is transported to allow for the proposed NO functioning as EDRF.

\subsection{NO paradox}

These questions are known in the field as the 'NO paradox'. In order to address the 'NO paradox', several theoretical and experimental studies have been made till date. These have approached the NO paradox from two sides: (1) suggesting NO consumption is reduced in the blood by mechanisms side stepping the high $\mathrm{NO}$ affinity for $\mathrm{Hb}$ observed in in vitro reactions and (2) suggesting that NO is conserved in compounds that don't have as high an affinity for heme groups as NO, such as nitrosothiols (RSNOs), nitrite anions and dinitrogen trioxide $\left(\mathrm{N}_{2} \mathrm{O}_{3}\right)$, thus affording these compounds a longer half-life in vivo and enabling NO transport. Fig 1.2 shows the key players in the 'NO paradox', viz. RBCs, endothelium and smooth muscle layer.

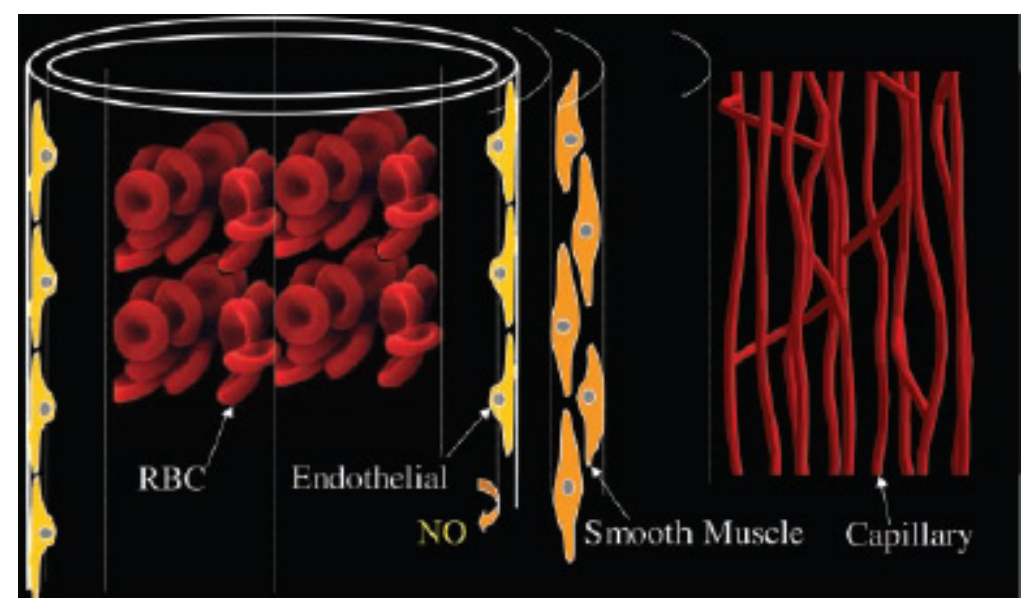

Fig 1.2: Schematic of blood flow in an arteriolar region. The arteriolar lumen has RBCs clustered in the center owing to laminar flow and a cell free layer adjacent to the endothelium. The endothelium and the smooth muscle layer are separated by an interstitial gap of connective tissues. Beyond the SMC lie a non-perfused region followed by a region perfused by capillaries (Figure from Tsoukias et al. [24]) 


\subsubsection{NO consumption reduced by RBCs}

Theoretical simulations run by Lancaster et al. [23] had shown that $2 \mathrm{mM}$ of hemoglobin flowing through a $20 \mu \mathrm{m}$ diameter arteriole would scavenge most NO, thus lowering availability of NO to the arteriolar smooth muscle. Butler et al [25] and Vaughn et al [26] added to this model a cell free layer in the arteriole and showed that NO diffusion towards the smooth muscle can increase. Subsequent work by Liu et al. [27] at $1 \%$ hematocrit (Hct) suggested that NO consumption rate was 650 times less than that of free $\mathrm{Hb}$. They attributed this reduction in NO consumption to an $\mathrm{NO}$ gradient created in the vicinity of a red blood cell (RBC) by rapid consumption of NO by the RBC. They supposed that NO consumed in the neighborhood of an $\mathrm{RBC}$ is fast enough for $\mathrm{NO}$ diffusion to not be able to replenish it. The resulting layer of low NO concentration surrounding an RBC was termed as an extracellular diffusion layer by them. Tsoukias et al [28] developed an elaborate model for analyzing factors causing resistance to NO consumption and also arrived at the conclusion that major resistance to NO uptake is through extracellular diffusion. The genesis of this idea lies in the works by Huxley et al. [29] and Coin et al. [30] who observed significant diffusion boundary layer surrounding the $\mathrm{RBC}$ that provides a resistance in $\mathrm{O}_{2}$ uptake by $\mathrm{RBCs}$. This is said to be a result of $\mathrm{O}_{2}$ rapidly depleting in the area around the $\mathrm{RBC}$, which is faster than the rate of replenishment by diffusion or possible mixing of the surrounding. It has been proposed that the same conditions must also apply to $\mathrm{NO}$ because $\mathrm{NO}$ and $\mathrm{O}_{2}$ have similar diffusivities across the RBCs and moreover, $\mathrm{NO}$ is consumed by the RBCs faster than $\mathrm{O}_{2}$.

A few competing theories to the above mentioned idea exist. A prominent one of these is the idea that NO consumption is inhibited by the RBC membrane as proposed by 
Vaughn et al. [31, 32]. While they found that the rate of NO consumption by RBCs is about 1000 fold slower than that by an equivalent concentration of free $\mathrm{Hb}$, they attributed this observation to $\mathrm{RBC}$ membrane and cytoskeleton associated $\mathrm{NO}$ inert proteins that provide a barrier for NO diffusion [33]. They proposed a RBC membrane permeability for NO that was 1000 fold smaller than previously thought. Membrane limited NO uptake has also been proposed by Deonikar et al. [34] recently although they do acknowledge a significant role for extracellular diffusivity in prohibiting NO uptake by RBCs.

Sakai et al [35] analyzed lipid encapsulated hemoglobin vesicles (HbVs) with different vesicle diameters using stopped flow spectrophotometry. Their experimental and theoretical work suggest that intracellular $\mathrm{Hb}$ concentrations have a major role to play in prohibiting NO uptake, while extracellular diffusion resistance has a minor influence. The apparent binding constant of $\mathrm{HbV}$ with $\mathrm{NO}$ from their simulations was found to be close to the values reported from stopped flow spectrometry for RBCs for $\mathrm{HbVs}$ of similar size. Consequently, they extend the applicability of their findings to RBCs as well. Thus, we see that there are three existing schools of thought on how NO consumption by RBCs is inhibited and the field is yet to arrive at a final conclusion about this.

\subsubsection{NO conservation as nitrosothiols and nitrites \\ 1.2.2.1 NO conservation as nitrosothiols}

Ignarro et al [36] had found that low molecular weight thiols that react readily with nitrogen oxides to form S-nitrosothiols are more stable than NO itself, and are 
potent vasodilators and platelet inhibitors. Stamler et al [37] had conducted experiments on different protein thiols in the blood, and had shown that they can be S-nitrosylated, thus raising a possibility of their playing a role as intermediates in the cellular metabolism or bioactivity of $\mathrm{NO}$ and that their formation may represent an important cellular regulatory mechanism.

There is also a school of thought which believes that the EDRF itself could also be an S-nitrosothiol. Serum albumin is an abundant protein in blood plasma and it also contains a single free sulfhydryl group. When nitrosated to S-nitroso albumin, it is relatively more stable than $\mathrm{NO}$ (half-life of approximately 24 hours in a $\mathrm{pH}$ of 7.6). Concentration in plasma for S-nitroso-albumin is $5 \mu \mathrm{M}$, which is much higher than the 4 $\mathrm{nM}$ for free NO. Administration of exogenous S-nitroso albumin in animals has led to NO like effects whereas NOS inhibition has led to dropping of S-nitroso albumin concentrations. It has been proposed that NO transfer from S-nitroso-albumin occurs through transnitrosation of smaller thiols such as glutathione (GSH) or cysteine (Cys) to S-nitrosoglutathione (GSNO) and S-nitrosocysteine (CysNO). GSNO and CysNO have been detected in the plasma at concentrations of 0.1 and $0.3 \mu \mathrm{M}$ respectively. The transport of these species to the cells could follow the suggestion from Satoh et al. [38] who had shown it is easier for CysNO to get transported across cell membranes through the amino acid transport system L-AT. A case similar to the above mentioned thiols has been made for hemoglobin - that it acts as an NO carrier in the form of S-nitrosohemoglobin [39]. A gradient of S-nitroso hemoglobin is observed from arterial to venous blood $(0.3 \mu \mathrm{M}$ to $0.03 \mu \mathrm{M})$ which prompts many to say that it could have a role in NO 
transport. The theory of NO transport by nitrosothiols however was contradicted in a work by Zhang et al. [40] in which they suggested that S-nitrosothiols do not act as NO donors as they are conventionally thought of and have a distinct biochemistry from NO. Thus, work on S-nitrosothiols as a probable source of NO is still in progress and no firm conclusion is in sight.

\subsubsection{NO conservation as the nitrite anion}

The other way NO can be 'stored' is through the nitrite anion. In vivo plasma levels of nitrite are in the range of $0.3-1 \mu \mathrm{M}$ [41], and in some places like the aortic ring tissue, this concentration is in the range of $10-20 \mu \mathrm{M}[41,42]$. Under acidic conditions, nitrite will be converted to NO, which might involve enzymatic reduction with xanthine oxidoreductase (XOR) or nonenzymatic disproportionation [43-46] or by deoxyHb [47]. In vivo, these would occur in vascular regions with low $\mathrm{pH}$ and low partial pressure of oxygen.

Alzawahra et al [48] investigated the effect of nitrite bioactivation in vessels in in vivo hemodynamics in rats and in in vitro vasorelaxation in isolated rat aorta under aerobic conditions. They found that in anesthetized rats, nitrite dose decreased both systolic and diastolic blood pressure with a threshold doses of $10 \mu \mathrm{M}$ and a dose of 10 $\mu \mathrm{M}-2 \mathrm{mM}$ caused vasorelaxation of aortic rings. The sGC inhibitor $1 \mathrm{H}-(1,2,4)$ oxadiazolo (4,3-a) quinoxaline 1-one (ODQ) inhibited nitrite mediated NO production. They thus suggested that sGC catalyzes the reduction of nitrite to NO in the vessel wall. The prospect of sGC reducing nitrite to NO is interesting since NO could be regenerated 
right where it is needed and not much nitrite would be required to activate sGC as compared to suggestions from other schemes of nitrite reduction.

\subsection{Research objectives}

To summarize the above background, after Furchgott et al. [49] proposed endothelium dependent vasorelaxation of blood vessels, Ignarro et al. [1] and Palmer et al. [50] had found that the chemical species responsible is NO. NO in the vasculature is produced by eNOS in the endothelial cell layer, reaches the smooth muscle cells $\&$ reacts with sGC. This leads to cGMP production, which in turn leads to activation of intracellular protein kinases that cause vasorelaxation. However, there is considerable doubt as to how NO produced in the endothelium reaches the smooth muscle cell layer and in what concentrations owing to its low half-life resulting from its affinity for superoxide anion and heme [51,52]. To answer this doubt, we first conducted a study with the help of mathematical modeling to understand the uptake of NO by hemoglobin vesicles, which are proposed as RBC supplements. This was followed by a study on NO nitrosation kinetics in in vitro systems and a determination of the nitrosating intermediate. Further, the nitrite reductase activity of sGC in the smooth muscle cells was verified. In the end, a finite element model was created to study transport of NO conserving species in the microcirculation. Specifically, the following objectives were accomplished: 
- Study of NO consumption by erythrocytes:

○ Analyzing the mathematical model for NO consumption by erythrocytes and validation of results by comparing it with reaction rate constants from other experiments.

○ Analyze design of current $\mathrm{Hb}$ vesicles and suggest guidelines for design.

- Study of GSH nitrosation kinetics:

- Analyze the kinetics of nitrosothiol formation.

- Study activation of smooth muscle cell layer by nitrite and nitrosothiols:

- Study the release of intracellular NO from nitrite and nitrosothiols in smooth muscle cells subjected to aerobic and anaerobic environments.

○ Verify the role of sGC in nitrite reduction. 


\section{Chapter 2: Glutathiyl Radical as an Intermediate in the Glutathione Nitrosation}

This chapter was published with only slight modifications as: Madrasi K, Joshi M.S., Gadkari T., Kavallieratos K. and Tsoukias N.M. 2012, "Glutathiyl radical as an intermediate in glutathione nitrosation." Free Radic. Biol. Med., http://dx.doi.org/10.1016/j.freeradbiomed.2012.08.013

\subsection{Abstract}

Nitrosation of thiols is thought to be mediated by dinitrogen trioxide $\left(\mathrm{N}_{2} \mathrm{O}_{3}\right)$ or by nitrogen dioxide radical $\left(\mathrm{NO}_{2}\right)$. A kinetic study of Glutathione (GSH) nitrosation by $\mathrm{NO}$ donors in aerated buffered solutions was undertaken. S-nitrosoglutathione (GSNO) formation was assessed spectrophotometrically and by chemiluminescence. Results suggest an increase in the rate of GSNO formation with an increase in GSH with a halfmaximum constant $\mathrm{EC}_{50}$ that depends on $\mathrm{NO}$ concentration. Our observed increase in $\mathrm{EC}_{50}$ with $\mathrm{NO}$ concentration suggests a significant contribution of $\mathrm{NO}_{2}$ mediated nitrosation with the glutathiyl radical as an intermediate in the production of GSNO.

Keywords: Glutathione, nitric oxide, thiyl radical, kinetics

\subsection{Introduction}

Blood vessel dilation [1], signal conduction in nervous system [2], and cytotoxic activity against microbes [3] are amongst the important physiological roles played by NO. For free NO to perform these functions, it should be able to reach its sites of action without being scavenged through its reaction with heme proteins [23]. Formation of nitrosothiols can increase the half - life of NO in the vasculature and thus can enhance its biological functions. The formation of $\beta-93$ cysteine nitrosothiols on the hemoglobin molecule [39] and the combination of NO with low molecular weight thiols are two 
candidate pathways for NO preservation [36]. Nitrosothiols have been found to be potent vasodilators and inhibitors of platelet aggregation and may also play important roles in signaling pathways. In view of the importance of nitrosothiols in biological systems, it is of interest to elucidate the kinetic mechanism and assess the rate of their formation. Of particular interest is the nitrosation of glutathione due to its abundance in biological tissues [53]. Glutathione nitrosation has been proposed to occur via an initial reaction of $\mathrm{NO}$ with $\mathrm{O}_{2}$ and the subsequent formation of $\mathrm{N}_{2} \mathrm{O}_{3}$, which acts as the nitrosating agent for GSH. The suggested reaction mechanism for this route of nitrosation is as follows [5457]:

$2 \mathrm{NO}+\mathrm{O}_{2} \stackrel{k_{1}}{\longrightarrow} 2 \mathrm{NO}_{2}$ Reaction 2.1

$\mathrm{NO}_{2}+\mathrm{NO} \underset{k_{-2}}{\stackrel{k_{2}}{\leftrightarrow}} N_{2} \mathrm{O}_{3}$

Reaction 2.2

$\mathrm{GSH}+\mathrm{N}_{2} \mathrm{O}_{3} \stackrel{k_{3}}{\longrightarrow} \mathrm{GSNO}+\mathrm{NO}_{2}^{-}+\mathrm{H}^{+}$

Reaction 2.3

$\mathrm{N}_{2} \mathrm{O}_{3}+\mathrm{H}_{2} \mathrm{O} \stackrel{k_{4}}{\longrightarrow} 2 \mathrm{NO}_{2}^{-}+2 \mathrm{H}^{+}$

Reaction 2.4

Recent evidence shows that in adequately oxygenated solutions the $\mathrm{NO}_{2}$ can oxidize the GSH to form the glutathiyl radical (GS') which reacts with NO to form GSNO [58-61]. This scheme would include the same rate limiting step (Reaction 2.1) as well as Reactions 2.2 and 2.4. However, nitrosation would proceed through Reactions 2.5 and 2.6 instead of 2.3 .
$\mathrm{NO}_{2}+\mathrm{GSH} \stackrel{k_{5}}{\longrightarrow} \mathrm{GS}+\mathrm{NO}_{2}^{-}$
Reaction 2.5
$G S+N O \stackrel{k_{6}}{\longrightarrow} G S N O$
Reaction 2.6 
Thus, according to the second kinetic mechanism the $\mathrm{NO}_{2}$ can react with $\mathrm{GSH}$ to give GSNO (Reaction 2.5), but also reacts with $\mathrm{NO}$ to form $\mathrm{N}_{2} \mathrm{O}_{3}$ (Reaction 2.2). This cross talk between the two alternative pathways poses a significant obstacle in determining the relative contribution of the two mechanisms. Thus, despite recent evidence that propose $\mathrm{NO}_{2}$ as the active intermediate for nitrosation [58-61], the importance of $\mathrm{N}_{2} \mathrm{O}_{3}$ vs $\mathrm{NO}_{2}$ in thiol nitrosation has not been conclusively determined [54-57]. In this study, we have followed the kinetics of the GSH nitrosation reaction in an attempt to elucidate the reaction mechanism and to identify the role of $\mathrm{N}_{2} \mathrm{O}_{3}$ and $\mathrm{NO}_{2}$ as nitrosating intermediates.

Recent data [59] has documented significant GSSG formation during the nitrosation of GSH by NO donors, which involves the formation of the thiyl radical. This essentially validates the second reaction mechanism above, since the presence of GSSG means that there has been formation of the glutathiyl radical (GS). One potential route of GSSG formation is through the following series of reactions:

$$
\begin{aligned}
& G S H \stackrel{k_{7}}{\leftrightarrow} G S^{-}+H^{+} \\
& G S+G S^{-} \underset{k_{-8}}{\stackrel{k_{8}}{\hookrightarrow}} G S S G^{-} \\
& G S S G^{-}+O_{2} \stackrel{k_{9}}{\longrightarrow} G S S G+O_{2}^{-}
\end{aligned}
$$

Alternatively, GSSG can be formed from GSNO according to Reaction 2.10 [45].

$G S+G S N O \stackrel{k_{10}}{\longrightarrow} G S S G+N O$ Reaction 2.10 
The proposed, simplified kinetic mechanisms do not consider a number of relevant reactions including alternative reactions for GSSG formation as well other reactions that are involved in GSH and NO oxidation chemistry. In the Appendix A1, we present a mathematical model of 25 relevant reactions and we compare model predictions for GSNO formation rate against the output of the two simplified reaction schemes.

\subsection{Materials and methods}

\subsubsection{Materials}

Glutathione (GSH), N-Ethyl Maleimide (NEM), and Diethylene Triamine Pentaacetic Acid (DTPA) were obtained from Sigma Aldrich Co (St. Louis, MO). NO donors Propylamine Propylamine NONOate and Diethylamine NONOate (PAPA/NO and DEA/NO) and S-nitrosoglutathione were obtained from Cayman Chemical Co (Ann Arbor, MI).

\subsubsection{NO release by NO donor}

NO donors were chosen with an appropriate half - life; a suitably long half - life confers on them the ability to generate steady NO levels over the duration of the experiment (see results section). At $20-25{ }^{\circ} \mathrm{C}$ PAPA/NO and DEA/NO have a half - life of approximately $77 \mathrm{~min}$ and $16 \mathrm{~min}$ respectively. To validate theoretical predictions for the pattern of $\mathrm{NO}$ release from $\mathrm{NO}$ donors, we used different concentrations of PAPA/NO ranging from $500 \mu \mathrm{M}$ to $10 \mathrm{mM}$ in a $\mathrm{pH}$ of 7.4 and measured NO release using a commercially available NO-sensitive electrode (WPI, Sarasota, FL).

\subsubsection{GSNO measurements}

UV-visible spectro-photometry was carried out by a Cary 100 Bio UV-Vis spectrophotometer. GSH concentrations ranged from $200 \mu \mathrm{M}$ to $5 \mathrm{mM}$ and PAPA/NO 
concentrations from $500 \mu \mathrm{M}$ to $10 \mathrm{mM}$. Reactions were carried out in $1 \mathrm{~mL}$ size quartz cuvettes as in Field et al. [62]. GSNO formation in a mixture of GSH and PAPA/NO was followed at $338 \mathrm{~nm}$ (molar absorptivity of $900 \mathrm{M}^{-1} \mathrm{~cm}^{-1}$ ) [63]. We also measured GSNO formed using chemiluminescence analysis. The Copper (I) Chloride and Cysteine (2C) assay method was used to measure GSNO through a chemiluminescence analyzer (Sievers 280i NOA) as described in earlier works [63-67]. Different GSH concentrations (200 $\mu \mathrm{M}$ to $7.5 \mathrm{mM})$ and DEA/NO $(31.25 \mu \mathrm{M}$ to $500 \mu \mathrm{M})$ were incubated in Eppendorf tubes. Reactions were stopped with $10 \mathrm{mM}$ NEM at 2, 3 and 4 minutes. The solutions were left at room temperature in the dark for about an hour for the NO donor to completely decay, so as to avoid any NO signal in the assay from the NO donor. Following this period, GSNO content in our samples was analyzed. All reactions followed by spectrophotometry or by chemiluminescence were performed in $40 \mathrm{mM}$ phosphate buffer $(\mathrm{pH}=7.4)$ supplemented by $50 \mu \mathrm{M}$ DTPA at $20-25{ }^{\circ} \mathrm{C}$. To check for interference from other NO-derived species, samples were incubated with $2.5 \mathrm{mM} \mathrm{HgCl} 2$ for half an hour to abolish GSNO content [68] prior to the $2 \mathrm{C}$ assay.

\subsection{4 "Clamped NO" protocol}

A combination of an NO donor and an NO scavenger (i.e. CPTIO) has been previously utilized to maintain steady levels of NO in solution (i.e. "clamped NO protocol" [69]). We hypothesized that a similar "clamped NO" condition can be achieved in aerated solutions of $\mathrm{NO}$ donors where $\mathrm{O}_{2}$ will be the predominant $\mathrm{NO}$ scavenger. Thus, a relative steady NO concentration is expected as a result of the balance between NO release by the donor and consumption by the oxygen content of the solution. We also refer to this as the "clamped NO concentration" similar to Griffith et al. [69]. 
Assuming that every mole of NO donor releases $\mathrm{n}$ moles of NO, the NO release rate by the NO donor is given by Eq. 2.1a.

$S=n k_{d}[$ NOdonor $] e^{-k_{d} t}$

where $\mathrm{k}_{\mathrm{d}}=\ln (2) / \mathrm{t}_{1 / 2}$ and $\mathrm{t}_{1 / 2}$ is the half - life of the NO donor. For times less than $1 / 10$ of the half - life of the NO donor the release rate remains relatively constant and can be approximated by:

$S=n k_{d}[$ NOdonor $]$

In the absence of other NO scavengers NO is consumed through the reaction with dissolved $\mathrm{O}_{2}$ (Reaction 1) and through Reaction 2. Reaction 1 is the rate-limiting reaction and thus total NO consumption can be approximated by:

$R=4 k_{1}\left[O_{2}\right][N O]^{2}$

At equilibrium, the balance between Eq. $1 \mathrm{~b}$ and Eq. 1c yields a steady NO level:

$[N O]=\sqrt{\frac{n k_{d}}{4 k_{1}\left[O_{2}\right]}} \sqrt{[\text { NOdonor }]}$

Thus, NO levels should remain relatively constant and concentrations should increase proportionally to the square root of the NO donor concentration.

\subsubsection{Pseudo steady state approximation}

A pseudo steady state approximation has been previously employed by Kharitonov

et al. to simplify the kinetic mechanism (Reactions $2.1-2.4$ ) [55]. Assuming small 
concentration of unstable intermediates $\mathrm{NO}_{2}, \mathrm{~N}_{2} \mathrm{O}_{3}$ and thus negligible rates of change (for details, see Appendix A2) for these complexes we get:

$$
\frac{d[G S N O]}{d t}=\frac{2 k_{1}[N O]^{2}\left[O_{2}\right][G S H]}{[G S H]+\frac{k_{4}}{k_{3}}}
$$

On the other hand, the pseudo steady state approximation (for details, see Appendix A2) for the Reactions 2.1, 2.2, 2.4 - 2.6 gives us the rate of nitrosation as:

$$
\frac{d[G S N O]}{d t}=\frac{2 k_{1}[N O]^{2}\left[O_{2}\right][G S H]}{[G S H]+\frac{k_{2} k_{4}[N O]}{\left[k_{-2}+k_{4}\right] k_{5}}}
$$

Note that Eq. 2.2b in agreement with Eq. 2.2a suggests saturation kinetics with respect to the concentration of GSH. In Eq. 2.2b, however, the half-maximum constant $\mathrm{EC}_{50}$ is dependent on the NO concentration. Thus, an effective $\mathrm{EC}_{50}$ value equal to $\frac{k_{2} k_{4}[N O]}{\left[k_{-2}+k_{4}\right] k_{5}}$ is predicted. Experimentation will test the saturation kinetics of this rate law. Thus the rate of GSNO formation will be equal to the product of the maximum rate at saturating concentrations $\left(\mathrm{V}_{\max }=2 \mathrm{k}_{1}[\mathrm{NO}]^{2}\left[\mathrm{O}_{2}\right]\right)$ times a factor $m$ that differs between the two proposed mechanisms. According to the first mechanism (Eq. 2.2a), $\mathrm{m}_{1}=\frac{k_{3}[G S H]}{k_{3}[G S H]+k_{4}}$ while based on Eq. 2.2b, $\mathrm{m}_{2}=\frac{k_{5}[G S H]}{k_{5}[G S H]+\frac{k_{2} k_{4}[N O]}{\left(k_{-2}+k_{4}\right)}}$. Eq. 2.2a and 2.2b simply state that the rate is limited by the rate of $\mathrm{NO}$ oxidation (Reaction 1) and the fraction of $\mathrm{N}_{2} \mathrm{O}_{3}$ or 
$\mathrm{NO}_{2}$ utilized in GSH nitrosation $\left(\mathrm{m}_{1}=\frac{R x n 3}{R x n 3+R x n 4}, \mathrm{~m}_{2}=\frac{R x n 5}{R x n 5+R x n 2}\right)$. The functional difference between the two mechanisms arise from the NO dependency in the scavenging of the active intermediate in mechanism 2 (i.e. $\mathrm{NO}_{2}$ scavenging through Reaction 2.2) vs the NO-independent consumption of the active intermediate in mechanism 1 (i.e. $\mathrm{N}_{2} \mathrm{O}_{3}$ scavenging through Reaction 2.4). Based on Eq. 2.2b, $\mathrm{EC}_{50}$ will increase with $\mathrm{NO}$ concentration, if $\mathrm{NO}_{2}$ is the major nitrosating intermediate. On the other hand, based on Eq. 2.2a, an $\mathrm{EC}_{50}$ value that remains relative steady at different levels of $\mathrm{NO}$, is indicative of $\mathrm{N}_{2} \mathrm{O}_{3}$ as the nitrosating intermediate.

When we incorporate Reactions $2.7-2.9$ into kinetic mechanism 2 to account for the formation of GSSG, PSSA yields:

$$
\frac{d[G S N O]}{d t}=\frac{2 k_{1}[N O]^{2}\left[O_{2}\right][G S H]}{[G S H]+\frac{k_{2} k_{4}[N O]}{\left[k_{-2}+k_{4}\right] k_{5}}} \times \frac{k_{6}[N O]}{k_{6}[N O]+\frac{k_{8} k_{7}}{k_{-7}}[G S H]}
$$

The difference between Eq. $2.2 \mathrm{c}$ and $2.2 \mathrm{~b}$ is a correction factor $\mathrm{f}=$ $\frac{k_{6}[N O]}{k_{6}[N O]+\frac{k_{8} k_{7}}{k_{-7}}[G S H]}$ that accounts for the fraction of total GS utilized in the formation of GSNO (i.e. $\mathrm{f}=\frac{R x n 6}{R x n 6+R x n 8}$ ). Eq. $2.2 \mathrm{c}$ reduces to Eq. $2.2 \mathrm{~b}$ when $\frac{[N O]}{[G S H]}>>\frac{k_{8} k_{7}}{k_{6} k_{-7}}$. Incorporating Reaction $2.7-2.10$ to the simplified kinetic mechanism 2 and applying PSSA yields: 


$$
\frac{d[G S N O]}{d t}=\frac{2 k_{1}[N O]^{2}\left[O_{2}\right][G S H]}{[G S H]+\frac{k_{2} k_{4}[N O]}{\left[k_{-2}+k_{4}\right] k_{5}}} \times \frac{k_{6}[N O]-k_{10}[G S N O]}{k_{6}[N O]+\frac{k_{8} k_{7}}{k_{-7}}[G S H]+k_{10}[G S N O]}
$$

For low GSNO levels (i.e. [GSNO] $<<\mathrm{k}_{6} / \mathrm{k}_{10}$ [NO]) Eq. $2.2 \mathrm{~d}$ reduces to Eq 2.2c, thus Reaction 2.10 should not affect initial formation rates. However, Eq. 2.2d suggests that in a "clamped NO" condition, GSNO accumulation will lead to an equilibrium point with steady GSNO levels i.e. [GSNO] $=\mathrm{k}_{6} / \mathrm{k}_{10}[\mathrm{NO}]$.

\subsection{Results}

\subsubsection{Dependence of [NO] on [NOdonor]}

First, we investigated the pattern of NO release by NO donors to confirm our theoretical predictions (Eq. 2.1d). NO release was measured with varying concentrations of PAPA/NO (500 $\mu \mathrm{M}$ to $10 \mathrm{mM})$ electrochemically using an NO electrode. A sample reading is shown in Fig 2.1A. As NO release occurs, concentration levels rise to a peak value before reaching a slowly decaying plateau. As expected, decay in NO concentration occurs as a result of NO donor consumption over time. The long half - life of the NO donor allows for a relative steady level of $\mathrm{NO}$ over an adequate time frame. Peak NO concentrations from $\mathrm{NO}$ recordings at different $\mathrm{NO}$ donor concentrations were used to generate a $\log -\log$ graph of $[\mathrm{NO}]$ vs. [PAPA/NO] $(\mathrm{n}=4)$. The result is shown in Fig

2.1B. The linear relationship between $\log [\mathrm{NO}]$ and $\log [\mathrm{PAPA} / \mathrm{NO}]$ has a slope of $0.51 \pm$ 0.04 and it is not statistically different from $1 / 2(p=0.30)$. As expected, based on Eq. 2.1d, established NO levels are proportional to the square root of the utilized NO donor concentration, i.e. $[N O] \propto \sqrt{[\text { NOdonor }]}$. 

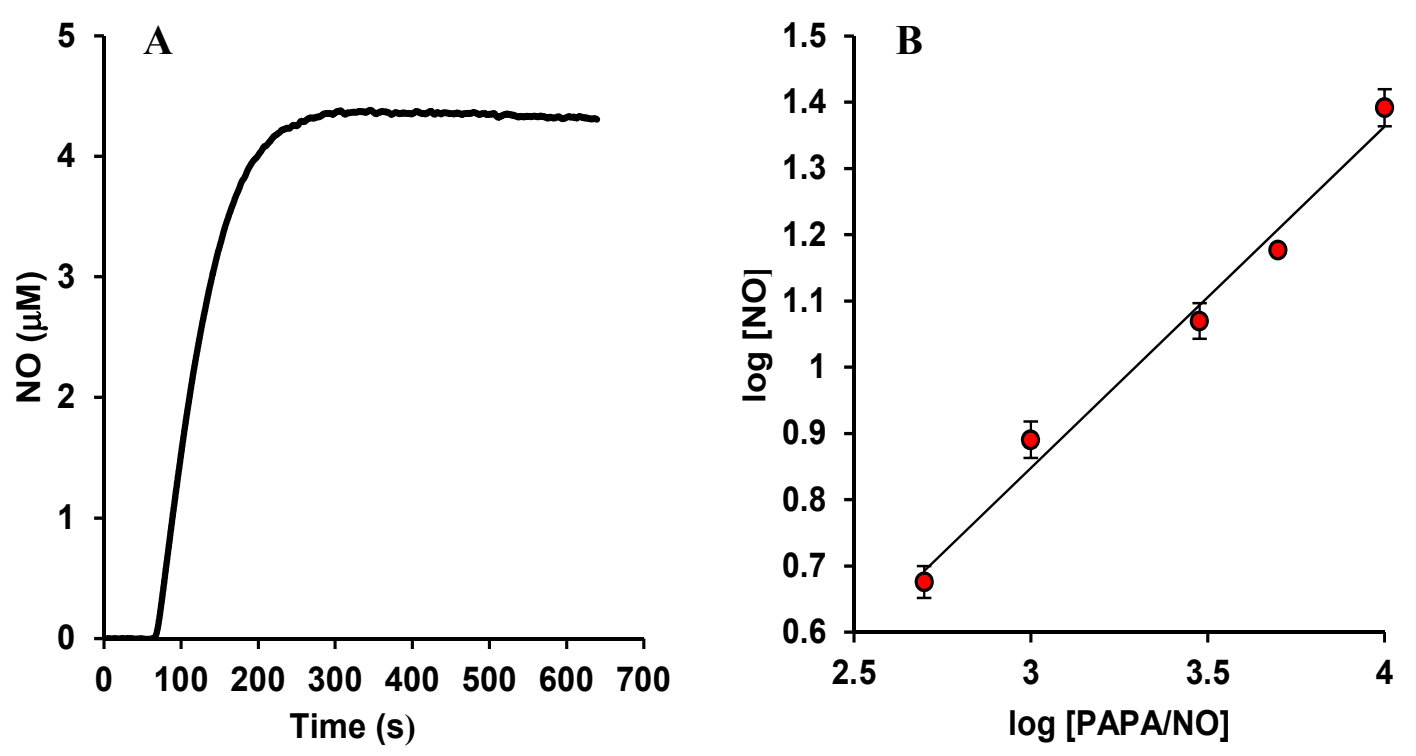

Fig 2.1: (A) Release of NO from PAPA/NO $(500 \mu \mathrm{M})$. NO concentration is monitored with a NO-sensitive electrode for $30 \mathrm{~min}$. After an initial accumulation period, NO levels remain relative steady for a significant time period. (B) log-log graph showing relation between maximum NO concentrations achieved at different PAPA/NO concentrations (n $=4)$. The slope of $0.51 \pm 0.04$ is not statistically different from $0.5(p=0.30)$.

Electrode data thus yield the following linear relationship between clamped [NO] and

$$
\begin{aligned}
& \sqrt{[P A P A / N O]} \\
& {[N O]=0.23 \pm 0.02 \sqrt{[P A P A / N O]}}
\end{aligned}
$$

This result would be in agreement with Eq. $2.1 \mathrm{~d}$ for $\mathrm{n} \times \mathrm{k}_{\mathrm{d}}=1.58 \pm 0.03 \times 10^{-4} \mathrm{~s}^{-1}$ for PAPA/NO under the conditions of our experiment. (Reported stoichiometry $(n=2)$ and half - life $\left(\mathrm{t}_{1 / 2}=77\right.$ minutes $)[70,71]$ for PAPA/NO at room temperature yield $\mathrm{n} \times \mathrm{k}_{\mathrm{d}}$ $=3 \times 10^{-4} \mathrm{~s}^{-1}$ but these values may change with experimental conditions $\left.[72,73]\right) . \mathrm{We}$ use Eq. 2.3 to better predict [NO] for every [PAPA/NO] in further analysis rather than using Eq. 2.1d with the reported half - life of PAPA/NO. 


\subsubsection{Dependence of $\mathrm{EC}_{50}$ on [NO]}

Fig 2.2A shows a representative recording of GSNO formation in the spectrophotometer for a particular GSH $(250 \mu \mathrm{M})$ and NO donor concentration (PAPA/NO; 1mM). Recordings show a relative constant rate of GSNO formation over a period of a few minutes. The slope of this tracing where NO concentration would have peaked was recorded (red circle in Fig 2.2A) and corresponds to the maximum rate of GSH nitrosation at the particular NO donor and GSH concentration. The use of this slope rather than initial slope is necessitated to account for the time required for $\mathrm{NO}$ to evolve. We ensure that peak/plateau NO concentration is reached fast after mixing with GSH and thus GSH concentration has not changed significantly from initial time and formation of GSNO is low (i.e. $[\mathrm{GSNO}]<<\mathrm{k}_{6} / \mathrm{k}_{10}$ [NO]). Experiments were repeated for different GSH concentrations at each NO donor concentration and the results are summarized in Fig 2.2B for three PAPA/NO concentrations $(500 \mu \mathrm{M}, 1 \mathrm{mM}$ and $5 \mathrm{mM})$. In the inset, $\mathrm{V}_{\max } / \mathrm{V}$ vs. 1/GSH plots were made (' $\mathrm{V}$ ' indicates the rate of nitrosation). Linear least square fittings followed by taking the slope yields $\mathrm{EC}_{50}$ values at each $\mathrm{NO}$ donor concentration. We observe a $\mathrm{NO}$ concentration dependent shift in $\mathrm{EC}_{50}$ values. As the $\mathrm{NO}$ donor concentration increases the $\mathrm{EC}_{50}$ value also increases. 

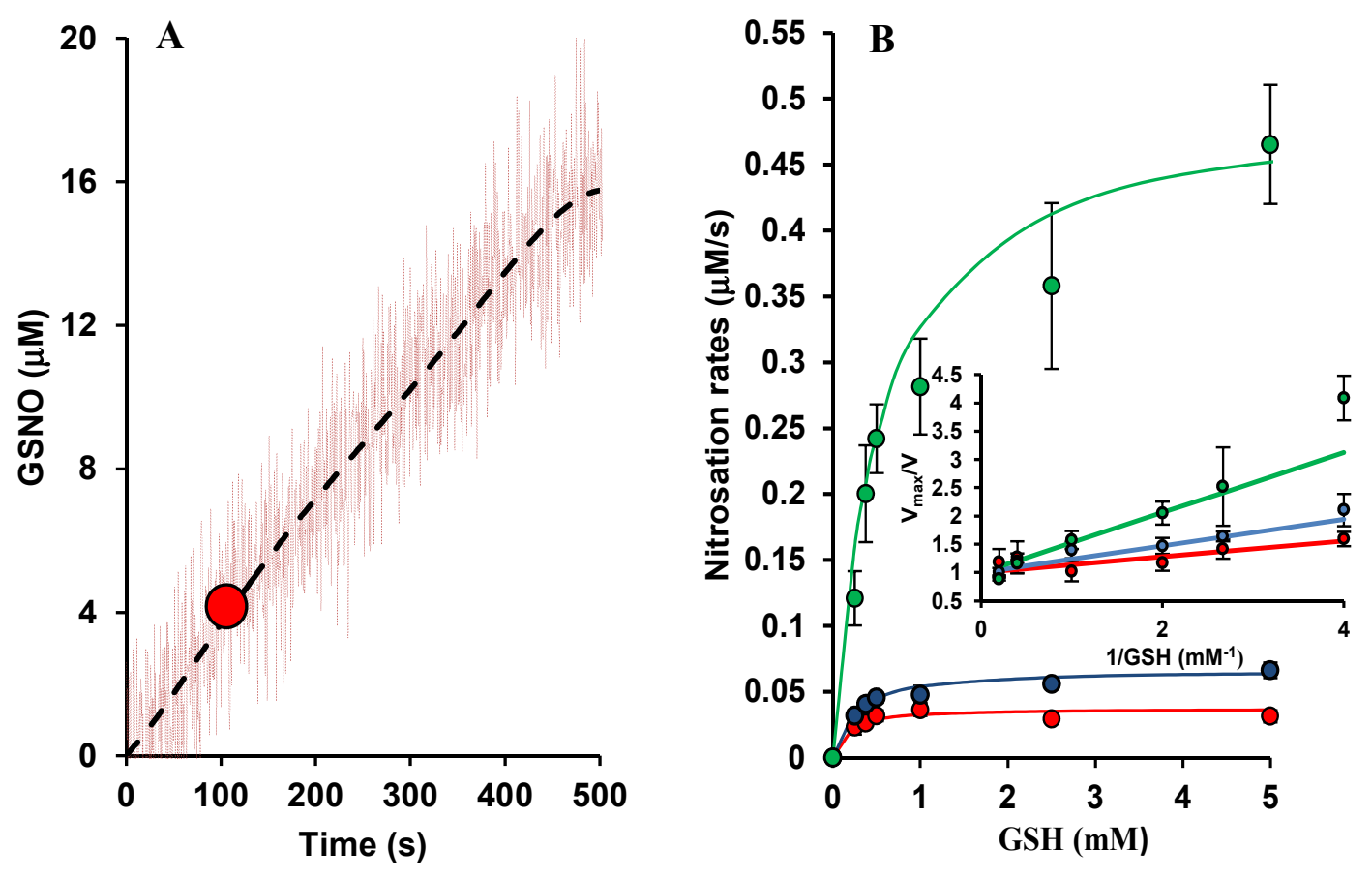

Fig 2.2: (A) Representative data for GSNO formation as a function of time. GSNO concentration was monitored in a spectrophotometer at $338 \mathrm{~nm}$, following mixing of GSH $(250 \mu \mathrm{M})$ and PAPA/NO $(1 \mathrm{mM})$. Data were fitted by a $5^{\text {th }}$ order polynomial to remove noise (dashed black line). The maximum slope of the polynomial is identified (red circle) and corresponds to the GSNO formation rate at peak NO concentration. (B) Rates of nitrosation (V) at three different NO donor concentrations (500 $\mu \mathrm{M}$ (red), $1 \mathrm{mM}$ (blue) and $5 \mathrm{mM}$ (green)) are plotted against GSH concentrations. Inset shows $\mathrm{V}_{\max } / \mathrm{V}$ plotted against $1 / \mathrm{GSH}$. Slope of these lines indicate $\mathrm{EC}_{50}$ values. An increase in $\mathrm{EC}_{50}$ values is observed with increasing $\mathrm{NO}$ donor concentrations.

Fig 2.3A depicts the dependence of the half maximum constant $\mathrm{EC}_{50}$ as a function of the NO donor concentration in a $\log -\log$ plot. $\mathrm{EC}_{50}$ values are averaged over $\mathrm{n} \geq 3$ experiments. A linear fit of the dependence of $\log \left(\mathrm{EC}_{50}\right)$ vs. $\log (\mathrm{PAPA} / \mathrm{NO})$ reveals a slope of $0.5 \pm 0.2$ which is not statistically different from $1 / 2(p=0.946)$. The above data point towards an $\mathrm{EC}_{50}$ value proportional to the square root of the NO donor (PAPA/NO) i.e. $E C_{50} \propto \sqrt{[\text { NOdonor }]}$. Thus, experiments point towards an $\mathrm{EC}_{50}$ value that is linearly 
dependent on the square root of NO donor and as a result proportional to the clamped NO concentration, i.e. $E C_{50} \propto[N O]$.

NO donor concentrations were related to NO concentrations using experimental data from Fig 2.1B. (Alternatively, one can use Eq. 2.1d if the stoichiometry and half life of the $\mathrm{NO}$ donor is known). We then can plot $\mathrm{EC}_{50}$ values from Fig 2.3A as a function of [NO] (Fig 2.3B). A linear dependence is observed in Fig 2.3B with a slope of $30.5 \pm 5.2 \mu \mathrm{M} \mathrm{GSH} / \mu \mathrm{M}$ NO.

$\mathrm{EC}_{50}=30.5[\mathrm{NO}]$
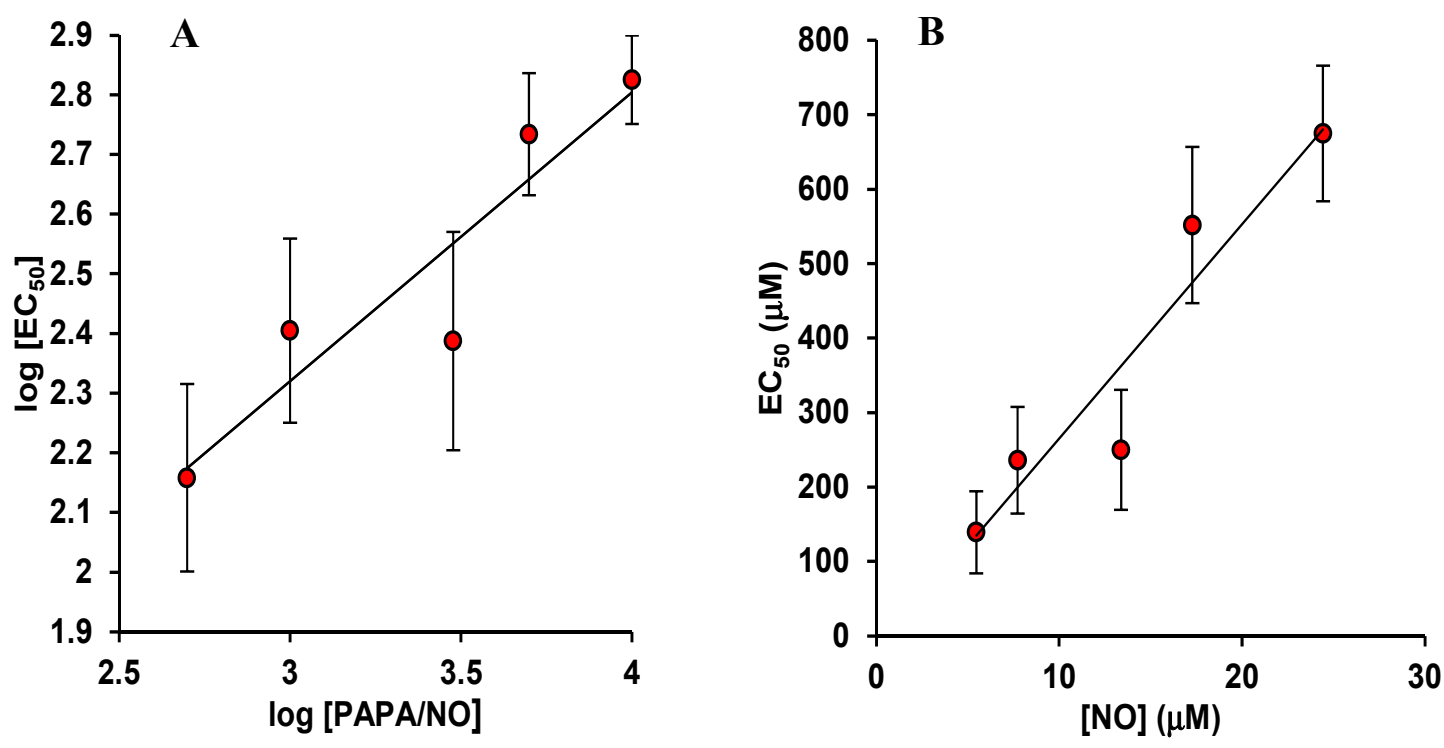

Fig 2.3: (A) A $\log -\log$ graph of half maximum constant $\left(\mathrm{EC}_{50}\right)$ at different PAPA/NO concentrations. Average $\mathrm{EC}_{50}$ values $(\mathrm{n}=3)$ are presented. The slope of $0.5 \pm 0.2$ is not statistically different from $0.5(\mathrm{p}=0.946)$. The result suggests that $\mathrm{EC}_{50}$ is proportional to the square root of $\mathrm{NO}$ donor concentration and thus proportional to NO concentration. (B) A graph of $\mathrm{EC}_{50}$ vs. clamped $\mathrm{NO}$ values from $\mathrm{NO}$ electrode measurements in Fig 2.1B. The slope from a linear fit of the graph is $30.5 \pm 5.2 \mu \mathrm{M} \mathrm{GSH} / \mu \mathrm{M}$. 
Experiments were repeated in a chemiluminescence analyzer following the $2 \mathrm{C}$ assay method from Gaston et al. [65] using different DEA/NO and GSH concentrations. This NO donor had a reasonably short half - life so as to allow both for a "clamped NO" condition (over a short period of time), and provide an early elimination of NO donor from the solution. The latter condition is needed to avoid interferences in the chemiluminescence device due to NO release by the donor when GSNO levels are measured. Recordings were collected for each GSH and NO donor concentration and were compared against a predetermined calibration curve prepared from known concentrations of GSNO (data not shown). Rates of GSNO formation were obtained by dividing GSNO concentrations by the corresponding incubation/reaction times. The control experiments where GSNO content was abolished with $\mathrm{HgCl}_{2}$ showed zero signal, hence confirming that the signal obtained was from GSNO. The estimated GSNO production rates were used to calculate $\mathrm{EC}_{50}$ using curve fitting similar to Fig 2.2B. A slope of $0.38 \pm 0.07$ in the $\log \mathrm{EC}_{50} \mathrm{vs} \log [\mathrm{DEA} / \mathrm{NO}]$ data was estimated $(\mathrm{n}=3)$. This is slightly different than the slope of approximately 0.5 from the earlier method. This may be attributed to some GSNO scavenging during the hour-long post reaction incubation time (see methods section). However, the alternative explanation for participation of $\mathrm{N}_{2} \mathrm{O}_{3}$ in nitrosation of GSH cannot be excluded.

\subsubsection{Calculation of $\mathbf{k}_{5}$}

This constant applies to the overall reaction of $\mathrm{NO}_{2}$ with both the thiol and the thiolate anion and it is pH dependent [74] (See also table 2.1). Based on our analysis the

dependence of $\mathrm{EC}_{50}$ on $[\mathrm{NO}]$ is linear with a slope that is equal to $\frac{k_{4} k_{2}}{\left(k_{-2}+k_{4}\right) k_{5}}$. Then 
assuming the values for the other kinetic constants $\left(\mathrm{k}_{2}, \mathrm{k}_{-2}, \mathrm{k}_{4}\right)$ from Table 2.1 and a slope of $30.5 \mu \mathrm{M} \mathrm{GSH} / \mu \mathrm{M}$ NO from Eq. 2.3 a value for $\mathrm{k}_{5}$ of $1.15 \times 10^{7} \mathrm{M}^{-1} \mathrm{~s}^{-1}$ is predicted. This is essentially the same as the experimentally observed value by Ford et al. [74], (derived from Fig 2 in [74] for $\mathrm{pH}=7.4$ ), and reasonably close to their corrected estimate of $2 \times 10^{7} \mathrm{M}^{-1} \mathrm{~s}^{-1}$ which takes account the reduction of GS at higher $\mathrm{pH}$ values in their analysis. The rate constant of $\mathrm{N}_{2} \mathrm{O}_{3}$ hydrolysis (Reaction 4) was determined from Eq. 2.9 and accounts for catalysis by $40 \mathrm{mM}$ of phosphate $[75,76]$, i.e. $k_{4}=\left(530+k_{p}[P i]\right)$ where $\mathrm{k}_{\mathrm{p}}=9.4 \times 10^{5} \mathrm{M}^{-1} \mathrm{~s}^{-1}[75,76]$. 
Table 2.1: Rate constants of reactions mentioned in the manuscript are as follows

\begin{tabular}{|c|c|c|c|}
\hline $\begin{array}{l}\text { Reactio } \\
\text { n No. }\end{array}$ & Reaction & Rate constant & $\begin{array}{l}\text { Referenc } \\
\text { e }\end{array}$ \\
\hline 1 & $2 \mathrm{NO}+\mathrm{O}_{2} \stackrel{k_{1}}{\longrightarrow} 2 \mathrm{NO}_{2}$ & $\mathrm{k}_{1}=2.9 \times 10^{6} \mathrm{M}^{-2} \mathrm{~s}^{-1}$ & {$[76,77]$} \\
\hline 2 & $\mathrm{NO}+\mathrm{NO}_{2} \underset{k_{-2}}{\stackrel{k_{2}}{\leftrightarrow}} \mathrm{N}_{2} \mathrm{O}_{3}$ & $\begin{array}{l}\mathrm{k}_{2}=1.1 \times 10^{9} \mathrm{M}^{-1} \mathrm{~s}^{-1} \\
\mathrm{k}_{-2}=8.1 \times 10^{4} \mathrm{~s}^{-1}\end{array}$ & [78] \\
\hline 3 & $\mathrm{~N}_{2} \mathrm{O}_{3}+\mathrm{GSH} \stackrel{k_{3}}{\longrightarrow} G S N O+\mathrm{NO}_{2}^{-}+H^{+}$ & $\mathrm{k}_{3}=6.6 \times 10^{7} \mathrm{M}^{-1} \mathrm{~s}^{-1}$ & [54] \\
\hline 4 & $\mathrm{~N}_{2} \mathrm{O}_{3}+\mathrm{H}_{2} \mathrm{O} \stackrel{k_{4}}{\longrightarrow} 2 \mathrm{NO}_{2}^{-}+2 \mathrm{H}^{+}$ & $\mathrm{k}_{4}=3.8 \times 10^{4} \mathrm{~s}^{-1}$ & [75] \\
\hline 5 & $\begin{array}{l}\mathrm{NO}_{2}+G S H \stackrel{k_{s^{\prime}}}{\longrightarrow} N O_{2}^{-}+G S+H^{+} \\
N O_{2}+G S^{-} \stackrel{k_{s^{\prime \prime}}}{\longrightarrow} N O_{2}^{-}+G S\end{array}$ & $\begin{array}{l}\mathrm{k}_{5}=1.15 \times 10^{7} \mathrm{M}^{-1} \mathrm{~s}^{-1} \\
\left(k_{5}=k_{5^{\prime}}+k_{5^{\prime \prime}} \frac{\left[G S^{-}\right]}{[G S H}\right)\end{array}$ & $\begin{array}{l}\text { Estimated } \\
\text { See also } \\
{[74]}\end{array}$ \\
\hline 6 & $G S+N O \stackrel{k_{6}}{\longrightarrow} G S N O$ & $\mathrm{k}_{6}=3 \times 10^{9} \mathrm{M}^{-1} \mathrm{~s}^{-1}$ & [79] \\
\hline 7 & $G S H \underset{k_{-7}}{\stackrel{k_{7}}{\leftrightarrow}} G S^{-}+H^{+}$ & $\begin{array}{l}\mathrm{k}_{7}=63 \mathrm{~s}^{-1} \\
\mathrm{k}_{-7}=0.1 \times 10^{10} \mathrm{M}^{-1} \mathrm{~s}^{-1}\end{array}$ & $\begin{array}{l}{[80]} \\
{[80]^{*}}\end{array}$ \\
\hline 8 & $G S^{-}+G S^{-} \underset{k_{-8}}{\stackrel{k_{8}}{\leftrightarrow}} G S S G^{-}$ & $\begin{array}{l}\mathrm{k}_{8}=9.6 \times 10^{6} \mathrm{M}^{-1} \mathrm{~s}^{-1} \\
\mathrm{k}_{-8}=1.6 \times 10^{5} \mathrm{~s}^{-1}\end{array}$ & $\begin{array}{l}{[81]} \\
{[82]}\end{array}$ \\
\hline 9 & $G S S G^{-}+O_{2} \stackrel{k_{9}}{\longrightarrow} G S S G+O_{2}^{--}$ & $\mathrm{k}_{9}=5 \times 10^{9} \mathrm{M}^{-1} \mathrm{~s}^{-1}$ & [82] \\
\hline 10 & $G S+G S N O \stackrel{k_{10}}{\longrightarrow} G S S G+N O$ & $\mathrm{k}_{10}=1.7 \times 10^{9} \mathrm{M}^{-1} \mathrm{~s}^{-1}$ & [83] \\
\hline
\end{tabular}

$* \mathrm{pH}=7.4$ 


\subsubsection{Dependence of $\mathbf{V}_{\max }$ on [NO]}

In Fig 2.4A, we plot $\mathrm{V}_{\max }$ against PAPA/NO concentrations in a $\log -\log$ plot. A slope of $1.09 \pm 0.1$ in the $\log -\log$ plot suggests a linear dependence between $V_{\max }$ and [PAPA/NO] (i.e. a square dependence on $[\mathrm{NO}]$ in agreement with both kinetic mechanisms). A linear plot of $\mathrm{V}_{\max } \mathrm{VS}[\mathrm{PAPA} / \mathrm{NO}]$ reveals a slope of $(7.5 \pm 0.5) \times 10^{-5} \mathrm{~s}^{-1}$ (Fig 2.4B).

$\mathrm{V}_{\max }=7.5 \times 10^{-5}[\mathrm{PAPA} / \mathrm{NO}]$

Based on both kinetic mechanisms (Eq. 3.2a or 3.2b) $\mathrm{V}_{\max }=2 \mathrm{k}_{1}[\mathrm{NO}]^{2}\left[\mathrm{O}_{2}\right]$. [Note: Eqs $2.2 \mathrm{c} \& 2.2 \mathrm{~d}$ predict different $\mathrm{V}_{\max }$ dependence on $\mathrm{NO}$ and differences with Eq. 2.2b can become significant at high GSH or GSNO concentrations. However, experimental data and model simulations (see below) suggest that under our experimental conditions these differences are negligible].

Using Eq. $2.1 \mathrm{~d}$, and the previously determined value for $\mathrm{n} \times \mathrm{k}_{\mathrm{d}}=1.58 \pm 0.03 \times 10^{-4} \mathrm{~s}^{-1}$ from the electrode data, we predict that:

$V_{\max }=2 k_{1}[N O]^{2}\left[O_{2}\right]=\frac{n k_{d}}{2}[$ NOdonor $]=7.9 \times 10^{-5}[P A P A / N O]$

Thus, the observed dependence of $\mathrm{V}_{\max }$ on PAPA/NO is in agreement with theoretical analysis for both kinetic mechanisms. 

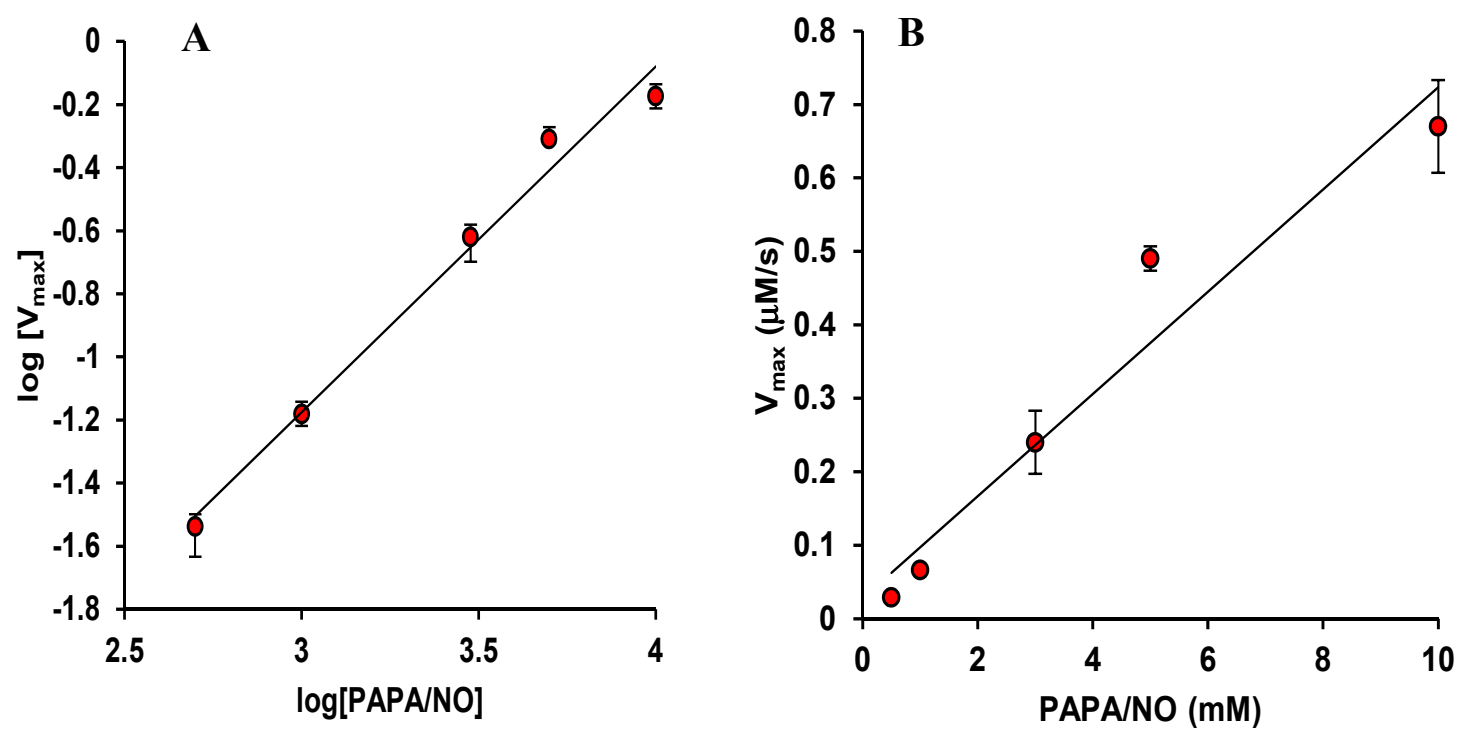

Fig 2.4: (A) A log - log graph of nitrosation rates at saturating GSH concentrations $\left(\mathrm{V}_{\max }\right)$ at different PAPA/NO concentrations. Average values with standard deviations (error bars) are presented. A linear fit gives a slope of $1.08 \pm 0.1$. The slope is not statistically different from $1(\mathrm{p}=0.09)$ and significantly different from 0.5 and $1.5(\mathrm{p}<<$ 0.05) suggesting a $\mathrm{V}_{\max }$ proportional to the NO donor concentration. (B) The linear dependence of $\mathrm{V}_{\max }$ on PAPA/NO concentration has a slope of $(7.5 \pm 0.5) \times 10^{-5} \mathrm{~s}^{-1}$.

\subsubsection{Validation of rate law and data fitting}

To validate the assumptions in the pseudo steady state approximation, we compared the proposed rate law (Eq. 2.2b) with the numerical solution of the complete set of ordinary differential equations describing the second kinetic mechanism (Reactions 2.1, 2.2, $2.4-6)$ and assuming values for kinetic constants from Table 2.1. Rate law and numerical solution provide essentially identical results (data not shown). Thus, Eq. 2.2b accurately describes the behavior of the second kinetic mechanism.

We further validated the proposed rate laws (Eq. 2.2b - 2.2d) against our experimental data and we tested if measured GSNO formation rates are in agreement with predicted rates from the rate laws. Previously determined values for reaction rate 
constants were assumed (Table 2.1). Each NO donor concentration was related to the corresponding clamped NO concentration based on Eq. 2.3. In Fig 2.5 rate law predictions are presented as solid lines and experimental data with different symbols for each NO donor (or NO) concentration. Dotted lines depict model simulations of the set of all 25 reactions presented in the Appendix A1. From the three rate laws, only Eq. $2.2 \mathrm{~d}$ is shown. Eq. $2.2 \mathrm{~b}$ and $2.2 \mathrm{c}$ yield similar results as $2.2 \mathrm{~d}$ over the range of GSH examined, and hence they were omitted from Fig 2.5. There is close agreement between rate law, model simulations and experimental data over a wide range of $\mathrm{NO}$ and $\mathrm{GSH}$ concentrations. There is a difference between rate law and model for high NO indicating that additional reactions that have not been incorporated in the simplified kinetic mechanism become more important as NO concentration increases. The accuracy of the experimental data does not allow confirming this limitation of the rate law at high NO concentrations.

Eq. 2.2c suggests that when the ratio of $[\mathrm{NO}]$ to $[\mathrm{GSH}]$ is not much greater than $\frac{k_{8} k_{7}}{k_{6} k_{-7}}$ reactions $2.7-2.9$ become important. Based on previous estimates for constants $\mathrm{k}_{6}, \mathrm{k}_{7}, \mathrm{k}_{-7}$, and $\mathrm{k}_{8}$ (Table 3.1 ) this ratio should be equal to $5 \times 10^{-4} \mu \mathrm{M} \mathrm{NO} / \mu \mathrm{M}$ GSH. In the experimental results presented in Fig 2.5, the ratios of $[\mathrm{NO}] /[\mathrm{GSH}]$ were between $10^{-3}-10^{-}$ ${ }^{1}$ thus, these reactions should not have affected GSNO formation. In the Appendix A1, we present model simulations for higher GSH concentrations (Fig A1.1). GSNO formations rates show a decrease at high [GSH] that cannot be captured by the rate law of Eq. 2.2b. On the contrary, Eq. 2.2c is in agreement with model simulations suggesting that this effect is attributed to Reactions $2.7-2.9$. 
Eq. $2.2 \mathrm{~d}$ suggests that when $[\mathrm{GSNO}]<<\frac{\mathrm{k}_{6}}{\mathrm{k}_{10}}[\mathrm{NO}]$ Reaction 2.10 does not affect formation rate. By measuring formation rates within a few seconds after mixing of the reactants we can minimize the effect of this reaction. At longer times, when [GSNO] approaches $\frac{\mathrm{k}_{6}}{\mathrm{k}_{10}}[\mathrm{NO}]$, an effect of this reaction can be observed (data not shown). Thus, under our experimental conditions and for the range of NO and GSH concentrations examined Reactions $2.1,2.2,2.4-6$ are the ones that mostly determine GSNO formation rate.

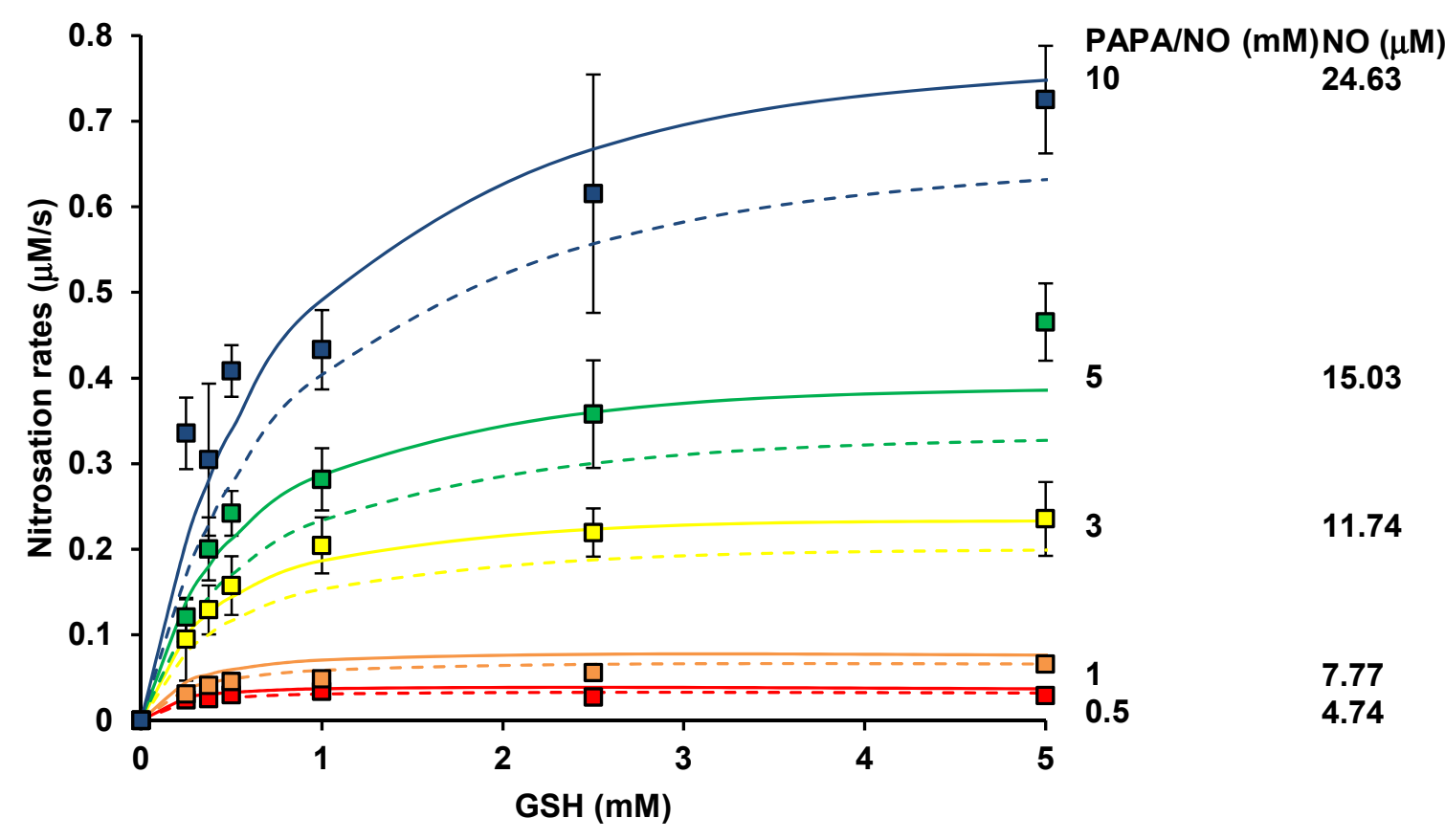

Fig 2.5: Comparison of GSNO formation rates as predicted by the proposed rate law of the simplified reaction scheme Eq. 2.2d (solid lines), the mathematical model of the complete reaction set (dotted lines) next to experimental data. Data using different PAPA/NO concentrations are presented $(500 \mu \mathrm{M}, 1 \mathrm{mM}, 3 \mathrm{mM}, 5 \mathrm{mM}$ and $10 \mathrm{mM})$. The corresponding NO concentration achieved were. Error bars show standard deviations ( $\mathrm{n}=$ 3). 


\subsection{Discussions}

Recent evidence for contribution of $\mathrm{NO}_{2}$ radical in the nitrosation of thiols [5861] provided the incentive to revisit an earlier proposed kinetic law by Kharitonov et al. [55] for the nitrosation of thiols. We followed a similar theoretical analysis (i.e. PSSA) with this earlier study for two alternative reaction schemes; one where $\mathrm{N}_{2} \mathrm{O}_{3}$ is the nitrosating intermediate and one where $\mathrm{NO}_{2}$ plays this role. Earlier experimental data have confirmed saturation kinetics of the nitrosation rate on GSH concentration [54-57]. This is in agreement with both kinetic mechanisms. Previous studies however, did not examine if the $\mathrm{GSH}$ concentration for half-maximum rate (i.e. $\mathrm{EC}_{50}$ ) remains constant at different $\mathrm{NO}$ concentration levels. Theoretical analysis suggests that unlike in $\mathrm{N}_{2} \mathrm{O}_{3}$ based nitrosation, in a primarily $\mathrm{NO}_{2}$ - based nitrosation the $\mathrm{EC}_{50}$ will increase as the $\mathrm{NO}$ concentration increases.

Experimental findings in this study confirm such dependence and argue for significant contribution of the second kinetic mechanism in GSH nitrosation. Our data show that GSNO formation rate follows saturation kinetics with respect to GSH concentration and $\mathrm{EC}_{50}$ increases with $\mathrm{NO}$ donor concentration. Data suggests an $\mathrm{EC}_{50}$ that is proportional to [NO] (Fig 2.3). This is in agreement with $\mathrm{NO}_{2}$ based nitrosation (Eq. 2.2b).

Theoretical considerations corroborated by experimental data show that in aerated slow-releasing NO donor solutions, NO levels remain relatively steady with a concentration that increases proportionally to the square root of the NO donor concentration (Fig 2.1). This enables us to monitor the reaction over longer periods of time (i.e. no need for rapid mixing in a stop-flow apparatus) and to relate the rate of 
GSNO formation to the NO concentration. [Caution however is advised since at later times conversion of GSNO to GSSG might influence GSNO formation rate]. We utilized two alternative methods to assess GSNO concentration. With the spectrophotometrical method, GSNO is measured continuously during the reaction, while chemiluminescence requires stopping the reaction at different time points and assess GSNO after a long incubation time to release excess NO from the system. As a result, rates estimated with the second method may have less accuracy.

Goldstein et al [75] has previously suggested that $\mathrm{NO}_{2}$ can act as an active intermediate for GSH nitrosation. They presented kinetic laws that propose a functional difference between $\mathrm{NO}_{2}$ and $\mathrm{N}_{2} \mathrm{O}_{3}$ mechanisms similar to this study (Note: Eq. 21 and 22 in [75] propose similar saturation kinetics but for the nitrosation yield instead of the reaction rate). These two quantities should follow a similar dependence on GSH and NO, at initial times. This functional difference was tested for some thiols (NAPenSH) showing dependence characteristic of the $\mathrm{N}_{2} \mathrm{O}_{3}$ based pathway. The authors concluded that both $\mathrm{NO}_{2}$ and $\mathrm{N}_{2} \mathrm{O}_{3}$ can play the role of active intermediate in thiol nitrosation.

Schrammel et al [61] have provided evidence for $\mathrm{NO}_{2}$ as the main nitrosating intermediate for GSH and albumin. The nitrosation was partially inhibited in the presence of thiyl scavengers (ascorbate and TEMPOL) and EPR spectroscopy revealed intermediate formation of glutathionyl radicals. They concluded that GSNO formation by $\mathrm{NO} / \mathrm{O}_{2}$ is predominantly mediated by $\mathrm{NO}_{2}$. However, TEMPOL may not impact solely the thiyl radical since scavenging of $\mathrm{NO}_{2}$ has also been suggested [84]. This would presumably interfere with the $\mathrm{N}_{2} \mathrm{O}_{3}$ pathway as well (Reaction 2.3). Jourd'heuil et al. [58] have also provided evidence for $\mathrm{NO}_{2}$ over $\mathrm{N}_{2} \mathrm{O}_{3}$ as the nitrosating intermediate. 
Inhibition of thiyl radical-mediated GSNO and GSSG formation by the thiyl radical trap 5,5-dimethyl-1-pyrroline N-oxide (DMPO) was demonstrated. However, nitrosation was shown to be insensitive to DMPO in an earlier study [85]. Thus, although the recent use of spin traps has provided evidence for a significant role of $\mathrm{NO}_{2}$ in thiol nitrosation, the relative importance of the two alternative intermediates remains a topic of continuing investigations. A recent study by Keszler et al [59] utilizes theoretical analysis and experimentation and suggests involvement of both intermediates in nitrosation. Simplified rate laws were provided for $\mathrm{N}_{2} \mathrm{O}_{3}$ but not for $\mathrm{NO}_{2}$ nitrosation. A detailed kinetic model that includes 20 relevant reactions was proposed and was fitted to the experimental data. Evidence for $\mathrm{N}_{2} \mathrm{O}_{3}$ contribution is provided by the reported decrease in GSNO formation when $\mathrm{N}_{2} \mathrm{O}_{3}$ hydrolysis is enhanced. A 10-fold increase in the rate of $\mathrm{N}_{2} \mathrm{O}_{3}$ mediated nitrosation (Reaction 2.3) than previously reported was actually suggested to explain a decrease in GSSG with a concomitant increase in GSNO when a thiyl radical trap (DMPO) was utilized. This allows for significant increase in GSNO formation through mechanism $1\left(\mathrm{~N}_{2} \mathrm{O}_{3}\right.$ based nitrosation scheme) when mechanism $2\left(\mathrm{NO}_{2}\right.$ based nitrosation scheme) is inhibited. Thus, there is conflicting evidence for the effect of thiyl radical scavenging on GSNO formation with some studies reporting a decrease [58, 61], while others an increase $[59,86]$. However, as pointed out in [59], cross talk between the two pathways makes difficult the interpretation of the results and to conclusively determine which is the dominant mechanism.

There is a good agreement between our estimated kinetic constant for thiol oxidation by $\mathrm{NO}_{2}$ (i.e. $\mathrm{k}_{5}=1.15 \times 10^{7} \mathrm{M}^{-1} \mathrm{~s}^{-1}$ ) and the constant provided by Ford et al. [74] (i.e. $1 \times 10^{7} \mathrm{M}^{-1} \mathrm{~s}^{-1}$ and $2 \times 10^{7} \mathrm{M}^{-1} \mathrm{~s}^{-1}$ after correction for a side reaction). Based on this 
value the authors in this earlier study argued, that there is small likelihood for significant generation of $\mathrm{N}_{2} \mathrm{O}_{3}$ (Reaction 2.2) compared to the loss of $\mathrm{NO}_{2}$ via reaction such as Reaction 2.5, and thus, a substantial fraction of any $\mathrm{NO}_{2}$ produced should not be channeled to nitrosative chemistry involving $\mathrm{N}_{2} \mathrm{O}_{3}$. This suggests a dominant role of $\mathrm{NO}_{2}$ in nitrosation of thiols and a lesser role for $\mathrm{N}_{2} \mathrm{O}_{3}$. Our theoretical analysis demonstrates this point in a system containing a significant number of the most relevant reactions.

An important observation in previous studies $[58,59,85,86]$ is the significant generation of GSSG. Reactants and active intermediates may be utilized for the generation of GSSG and this utilization can affect GSNO formation rate. This represents a serious threat for the accuracy of the proposed simplified rate laws (Eq. 2.2a and Eq. 2.2b) presented here or in previous studies. The reaction scheme presented in the Appendix A1 proposes four alternative pathways for GSSG formation (Reactions 2.8, $2.10,2.11,2.18$ ) out of which Reactions 2.8 and 2.10 are the most important based on the assumed values for the kinetic constants. Interestingly, Reaction 2.8 becomes important for low $[\mathrm{NO}] /[\mathrm{GSH}]$ ratios while Reaction 2.10 is important after significant GSNO accumulations and thus high $[\mathrm{GSNO}] /[\mathrm{NO}]$ ratios. Thus, the proposed rate law in Eq. $2.2 \mathrm{~b}$ can adequately describe our data since the high $[\mathrm{NO}] /[\mathrm{GSH}]$ ratio and the estimation of GSNO formation rate early (i.e. low [GSNO]/[NO] ratio) should provide conditions for low GSSG formation rate. [Note that previous studies $[58,59,85,86]$ have often used lower $[\mathrm{NO}] /[\mathrm{GSH}]$ ratios and reaction is followed for several minutes]. Interference from Reaction 2.8 will occur at low $[\mathrm{NO}] /[\mathrm{GSH}]$ ratios and will be documented with a decrease in GSNO formation rate as GSH concentration increases (Fig A1.1). 
Interference from Reaction 2.10 will appear after significant GSNO accumulation and will be documented with a saturation of GSNO concentration with time. In this study, the nitrosation mechanism was tested only for glutathione. Previous studies have shown similar kinetic behavior in the nitrosation of Cysteine, whereas for other thiols like Nacetyl Penicillamine (NAPenSH), captopril (CapSH) and N-nitrosomorpholine (MorNNO) the oxidizing reaction through $\mathrm{NO}_{2}$ has been found to be too slow and Reaction 2.2 was found to outcompete their oxidation by $\mathrm{NO}_{2}[75]$.

In vivo, the nitrosation pathway could be affected by the slow NO oxidation and other reaction pathways could become important. It has been previously suggested [15$17,60,87,88]$ that catalysis of nitric oxide oxidation in hydrophobic environments is possible which might accelerate formation rate. The physiological relevance of the nitrosation process and the ability of thiols to transport and preserve NO might hinge on acceleration of nitrosation in hydrophobic environments (owing to $<1 \mu \mathrm{M}[\mathrm{NO}]$ in vivo and the slow NO oxidation process in aqueous solution), and thus this needs further study. In addition, the effects of transition metal ions [89], cellular antioxidants [90] and lipid radical species [91] and $\mathrm{pH}$ variations [74] need to be further examined. There is also a possibility of a heme enzyme dependent nitrosation [92]. Glutathione may bind to ferricytochrome $\mathrm{c}$ followed by a combination of NO to form a ferric cyt-c GSNOH complex. Subsequent electron donation from NO to heme would then, yield ferrocytochrome c and GSNO. Experimental evidence with isolated enzymes and in cells corroborate this hypothesis [93]. Besides ferricytochrome c, other heme enzymes and iron complexes may serve similar functions [94-97]. 
In summary, recent studies point towards a role of $\mathrm{NO}_{2}$ in thiol nitrosation. However, the relative contribution of $\mathrm{N}_{2} \mathrm{O}_{3}$ and $\mathrm{NO}_{2}$ has been difficult to elucidate so far, as a result of crosstalk between the two alternative mechanisms. In this study, theoretical analysis suggests a functional difference in the rate laws between $\mathrm{N}_{2} \mathrm{O}_{3}$ and $\mathrm{NO}_{2}$ mediated nitrosation (Eq. 2.2a and 2.2b) and experimental data suggest a predominant role for $\mathrm{NO}_{2}$ in the nitrosation of GSH by $\mathrm{NO}$ donors in aerated solutions. In vivo, a series of factors may interfere with the nitrosation pathway and the relative importance of the two intermediates needs to be further investigated.

\section{Acknowledgements:}

This work was funded by National Institutes of Health Grant SC1HL095101 (NT). 


\section{Chapter 3: Nitrite Transport and Reduction by sGC in Smooth Muscle Cells}

This chapter has been submitted with only slight modifications as: Madrasi K, Joshi M.S. and Tsoukias N.M. 2012, "Nitrite Transport and Reduction by sGC in Smooth Muscle Cells” Free Radic. Biol. Med. (Manuscript submitted)

\section{1: Abstract}

Several heme proteins including hemoglobin and nitric oxide synthase (NOS) have been documented to serve as nitrite reductase under anoxia. Since sGC is also a heme protein and an important signaling biomolecule, we tested if it may function as a nitrite reductase in cultured aortic smooth muscle cells (SMCs) under normoxic conditions. Millimolar levels of nitrite were required to detect cellular NO using a novel NO specific fluorescent dye $\left(\mathrm{Cu}_{2} \mathrm{FL} 2 \mathrm{E}\right)$. However, in chemiluminescence analyses of cell lysates, addition of $400-600 \mu \mathrm{M}$ nitrite was sufficient to detect measurable NO synthesis that was independent of $\mathrm{O}_{2}$ concentration. The $\mathrm{NO}$ formation was inhibited by $\mathrm{sGC}$ inhibitor, ODQ and sGC activators, $\mathrm{YC}-1$ and $\mathrm{CO}$ significantly enhanced the nitrite reduction, documenting the $\mathrm{sGC}$-mediated nitrite reduction. The enzymatic nitrite reduction was demonstrated by the first-order reaction of NO generation. The cellular uptake of nitrite was attenuated by different anion channel blockers (Diisothiocyanatostilbene-2,2'-disulfonic acid (DIDS), probenecid, $\mathrm{K}^{+}$gluconate and 5Nitro-2-(3-phenylpropylamino)benzoic acid (NPPB)) demonstrating the participation of SMC anion channels in nitrite transport. Exogenous nitrate significantly inhibited both the nitrite influx and reduction, thus illustrating the modulation of nitrite activity by nitrate. These results show that $\mathrm{sGC}$ can mediate nitrite reduction to $\mathrm{NO}$ and nitrite is transported across the smooth muscle cell membrane via anion channels, which is attenuated by nitrate.

Keywords: ion channels, nitric oxide, nitrite, reductase, sGC 


\section{2: Introduction}

The biological sources of nitrite consist of as an oxidation product of NO and that acquired through diet. Recently accumulated evidence points to endogenous nitrite as a signaling agent along physiological and pathophysiological oxygen gradient. Nitrite serves as a stable storage form of NO in the vasculature as it is not readily consumed by known scavengers like oxyhemoglobin and superoxide. Nitrite can thus traverse the system without being consumed and may be readily available for local biotransformation to vasoactive NO. This unique property has attracted recent investigations into the conditions that favor nitrite reduction to $\mathrm{NO}$ and facilitate vasorelaxation. A number of nitrite reductases have been identified that when activated mediate vasorelaxation. For example, various globins (neuroglobin [98], deoxyhemoglobin and deoxymyoglobin [99]) and molybdenum enzymes (XOR [100] and aldehyde oxidase [101]), carbonic anhydrase [102], cytochrome c oxidase [103] and cytochrome P450 [104] are demonstrated to act as nitrite reductases. However, vasodilating actions of nitrite are observed mainly under low oxygen conditions - a phenomenon termed 'hypoxic vasodilation'. In other words, nitrite dependent relaxation is activated only when NOS activity was repressed due to low $\mathrm{O}_{2}$ supply. Nitrite was illustrated to be cytoprotective against ischemic damage in wide range of tissues by providing an alternative to NOS as the NO generator $[105,106]$.

Significant evidence has been presented to show that deoxyhemoglobin in blood mediates nitrite reduction to NO [107, 108]. This allosterically regulated reaction is proposed to participate in hypoxic vasodilation. A major challenge to NO signaling (via nitrite reduction by deoxyHb in $\mathrm{RBC}$ ) is the scavenging of $\mathrm{NO}$ before it escapes from 
cells and as a consequence sufficient NO may not be reaching smooth muscle to initiate the vasodilation. This obstacle to vasodilation can be overcome provided the smooth muscle cells generate local NO pool. Therefore, we speculated that sGC in SMC of vascular wall may serve the purpose by acting as nitrite reductase. This assumption is reinforced by the observed tissue nitrite levels being far greater than in plasma [42]. In support of this speculation Alzawahra et al [48] have documented attenuation of nitrite mediated aorta relaxation with ODQ. Based on these studies they have speculated the possibility of a heme protein acting as nitrite reductase. We have carried out a detailed investigation to test the hypothesis that $\mathrm{sGC}$ in $\mathrm{SMC}$, which is a heme protein, reduces nitrite to $\mathrm{NO}$ and thus providing a local source of vasodilator.

Since nitrite occurs in anionic form at physiologic $\mathrm{pH}$, the participation of cell membrane in nitrite transport attains particular significance. Nitrite uptake across the cell membrane could be a rate-limiting step prior to its intracellular conversion to NO. It is not known whether nitrite traverses the smooth muscle cell membrane via anion channels and/or diffuses as $\mathrm{HNO}_{2}$ through lipid bilayer. Smooth muscle cells are known to possess different classes of anion channels including $\mathrm{Cl}^{-}[109], \mathrm{Cl}^{-}: \mathrm{HCO}_{3}^{-}$antiporter channels AE2 and AE3 [110], and urate [111]. These ion channels are proposed to participate mainly in the maintenance of intracellular $\mathrm{pH}$ regulating vascular tone. A role for anion exchanger AE1 was suggested in the export of nitrite in $\mathrm{RBC}$ wherein the reactions were modulated by low $\mathrm{O}_{2}$ tensions [112]. So it is possible that nitrite could be using any of the known anion channels in SMC as proposed in the present investigations. However, a larger physiologically relevant question to be elucidated is how the movement of nitrite 
across the membrane gets modulated. Since nitrate is an anion like nitrite, it could be competitively inhibiting nitrite influx and subsequent reduction by reductase(s). The blood and tissue nitrate concentrations are significantly higher than nitrite and thus may serve a regulator role. To our knowledge there are no reports of inorganic nitrate modulating nitrite activity in mammalian system. However, nitrate was shown to depress the active uptake of nitrite in alga [113]. In this report, using rat aortic smooth muscle cells we have demonstrated that sGC serves as nitrite reductase that is independent of $\mathrm{O}_{2}$ tension. Nitrite appears to use several anion membrane transport mechanisms, which was modulated by nitrate.

\section{3: Materials and Methods}

\subsubsection{Materials}

A7r5 rat aortic smooth muscle cells, Dulbecco's Modified Eagle Medium (DMEM), Fetal Bovine Serum (FBS) and DMSO were acquired from ATCC (Manassas, VA, USA). Sodium Nitrite, Sodium Nitrate, 4,4'-Diisothiocyanatostilbene-2,2'-disulfonic acid disodium salt hydrate (DIDS), p-(Dipropylsulfamoyl)benzoic acid (Probenecid), Copper (II) Chloride $\left(\mathrm{CuCl}_{2}\right)$, Tricarbonyldichlororuthenium (II) dimer (CORM-2), $1 \mathrm{H}$ Pyrazolo(3,4-d) pyrimidin-4-ol (Allopurinol), and Penicillin - Streptomycin were obtained from Sigma Aldrich (St. Louis, MO, USA). 5-Nitro-2-(3phenylpropylamino)benzoic acid (NPPB) was obtained from Tocris Bioscience (Bristol, UK). Methylamine hexamethylene methylamine NONOate (MAHMA/NO), $1 \mathrm{H}-[1,2,4]$ oxadiazolo [4,3-a] quinoxalin-1-one (ODQ), and 5-[1-(phenylmethyl)-1H-indazol-3-yl]2-furanmethanol (YC-1) were obtained from Cayman chemicals (Ann Arbor, MI, USA). D-potassium gluconate, tissue culture flasks and dishes were obtained from Fisher 
scientific (Atlanta, GA, USA). Trypsin (0.25\% EDTA), DMEM:F-12K 1:1 medium and PBS were obtained from Invitrogen (Carlsbad, CA, USA). Protein assay reagents were from Bio-Rad (Hercules, CA, USA). $\mathrm{Cu}_{2}$ (FL2E) was prepared as described [114].

\subsubsection{Cell culture}

Cell culture protocols used are described in appendix A3 - A5. Cells were grown (passage 4 -10) in DMEM supplemented with 10\% FBS and 1\% penicillin-streptomycin in a humidified tissue culture incubator at $37{ }^{\circ} \mathrm{C}$ equilibrated with $95 \%$ air $5 \% \mathrm{CO}_{2}$. For experimentation, cells were cultured in $35 \times 10 \mathrm{~mm}$ dishes seeded with $2 \times 10^{5}$ cells and used at $60-80 \%$ confluency.

\subsubsection{Fluorescence NO Imaging}

After loading with $\mathrm{Cu}_{2}(\mathrm{FL} 2 \mathrm{E})(10 \mu \mathrm{M}$ for $45 \mathrm{~min})$ cells were analyzed for fluorescence due to $\mathrm{NO}$ synthesis in response to $30 \mathrm{mM}$ nitrite at $37^{\circ} \mathrm{C}$. Images were acquired with a fluorescence microscope (Olympus IX 81 fitted with a CCD camera (Qimaging)) and the data were analyzed with IPLAB software (BioVision Technologies).

\subsubsection{Chemiluminescence analysis}

Cells suspended in PBS were lysed with a sonicator (4 bursts of $10 \mathrm{sec}$ each) and cell lysates used for analysis of NO production in response to the nitrite injection in a deoxygenated purge vessel. The head space NO concentration was measured by using continuous sampling with ozone chemiluminescence (Sievers, NOA 280i). The NO produced (pmoles/mg protein) was estimated from the area under the curve based on a calibration curve from MAHMA/NO injections under identical conditions. Nitrite in cell lysates, upon deproteinization, was quantified (nmoles/mg) by reductive denitrosation with a mixture of iodine/iodide in glacial acetic acid and subsequent detection of 
liberated NO by gas phase chemiluminescence reaction with ozone as described [115]. The protein in cell lysates was determined by the Bradford method [116].

\subsubsection{Statistical Analysis}

All data have been represented as mean \pm SE with $n$ representing independent treatments. Data were analyzed using paired t-tests in MATLAB (MathWorks) and Pvalues $\leq 0.05$ were considered significant.

\section{4: Results}

\subsubsection{ODQ inhibited and YC-1 accelerated nitrite reduction to NO}

The SMCs loaded with a novel cell-trappable $\mathrm{NO}$ sensitive dye, $\mathrm{Cu}_{2}(\mathrm{FL} 2 \mathrm{E})$ were treated with saturating concentrations of nitrite $(30 \mathrm{mM})$ in the presence and absence of ODQ (sGC inhibitor) and intracellular fluorescence was measured. Significant increase in fluorescence was observed with nitrite treatment (Fig 3.1B), which was inhibited by 10 $\mu \mathrm{M}$ ODQ (Fig 3.1C). The arbitrary fluorescence units from our observations were normalized with average of arbitrary fluorescence units of control $\left(\mathrm{afu} / \mathrm{afu} \mathrm{c}_{\mathrm{c}}\right)$ and plotted (Fig 3.1D). When the cells were treated with saturating concentrations of nitrite $(30 \mathrm{mM})$ in the presence and absence of sGC agonist $\mathrm{YC}-1$, the increased fluorescence with nitrite treatment (Fig 3.2B) was enhanced further in the presence of $20 \mu \mathrm{M} \mathrm{YC}-1$ (Fig 3.2C and Fig 3.2D). ODQ and YC-1 added alone to the cells did not have any effect on intracellular fluorescence (data not shown). These results provide evidence for the sGC participation in nitrite reduction. 

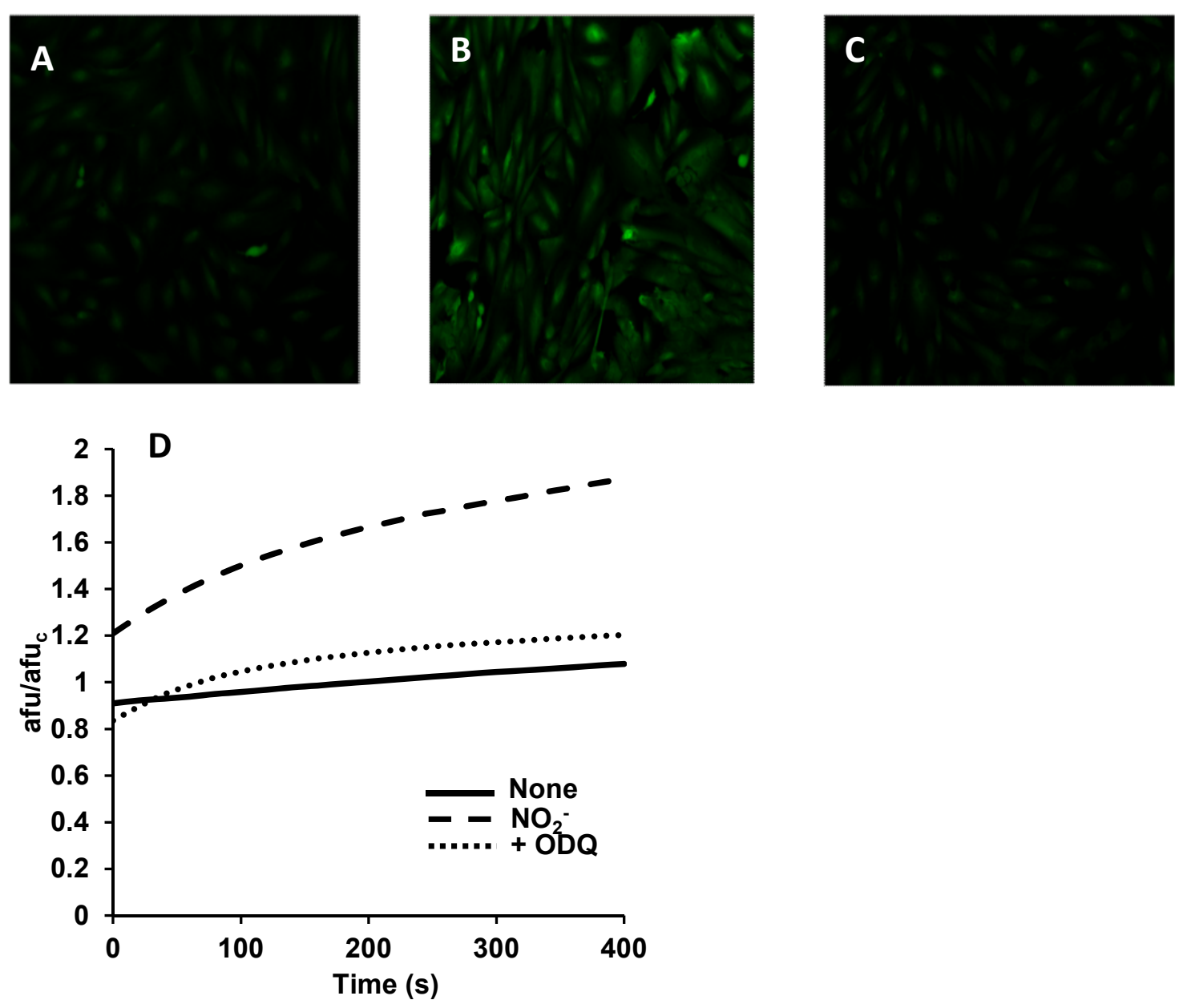

Fig 3.1: Effect of ODQ on nitrite reduction to NO: Rat aortic smooth muscle cells loaded for $45 \mathrm{~min}$ with $10 \mu \mathrm{M} \mathrm{Cu}_{2}$ (FL2E) and treated with (A) Vehicle, (B) $30 \mathrm{mM}$ nitrite and (C) pretreatment with $10 \mu \mathrm{M}$ ODQ followed by $30 \mathrm{mM}$ nitrite for $10 \mathrm{~min}$. (D) Change in the ratio of arbitrary fluorescence units normalized with average of arbitrary fluorescence units of control (afu/afu $\mathrm{c}_{\mathrm{c}}$ ) for $\mathrm{A}, \mathrm{B}$ and $\mathrm{C}$.
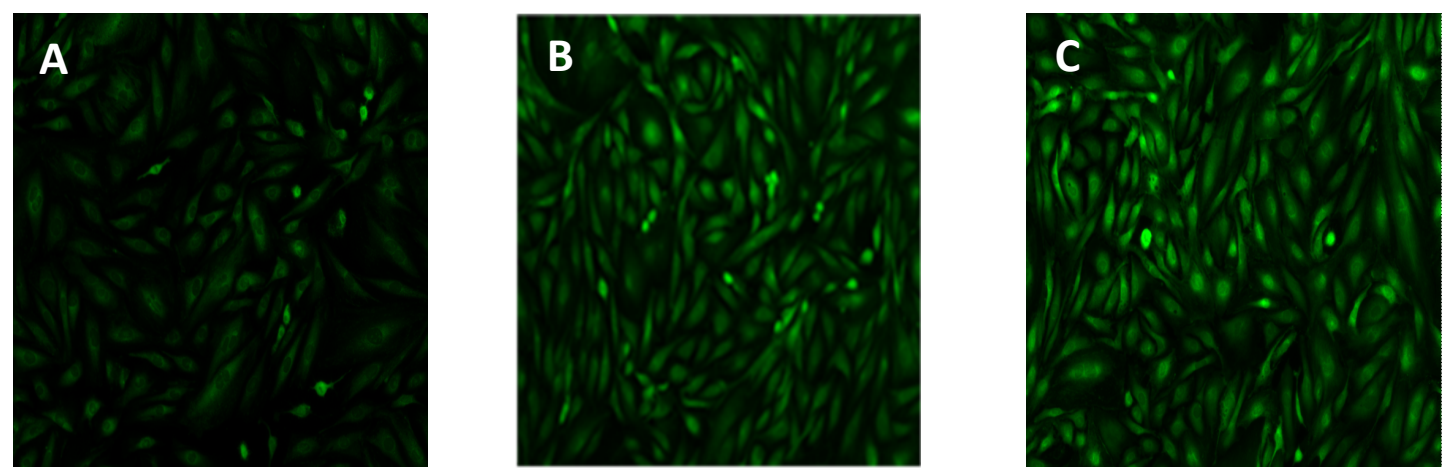


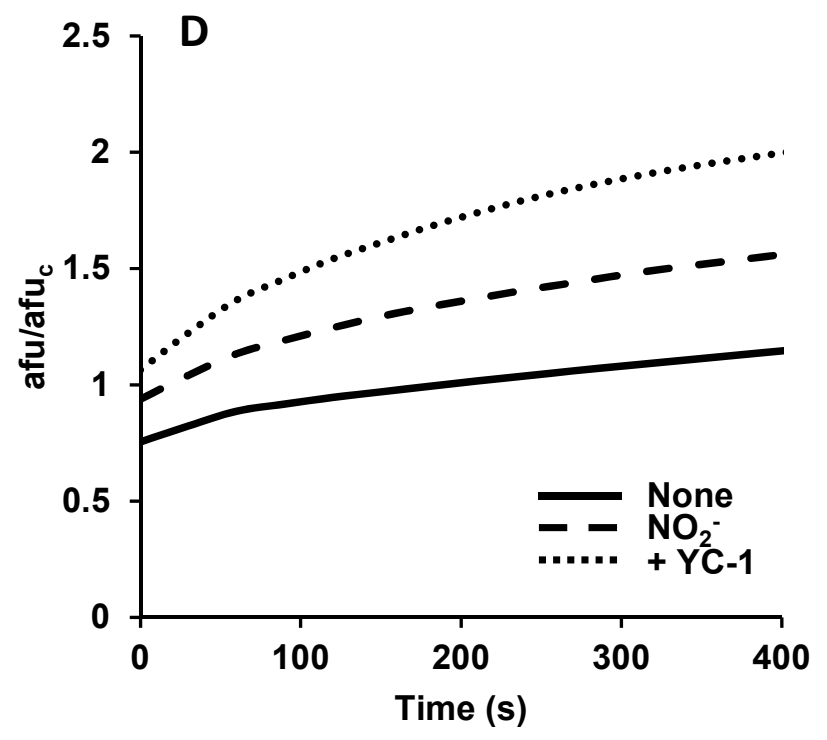

Fig 3.2: Effect of $\mathrm{YC}-1$ on nitrite reduction to NO: Rat aortic smooth muscle cells loaded for 45 min with $10 \mu \mathrm{M} \mathrm{Cu}_{2}$ (FL2E) and treated with (A) Vehicle, (B) $30 \mathrm{mM}$ nitrite and (C) pretreatment with $20 \mu \mathrm{M}$ YC-1 followed by $30 \mathrm{mM}$ nitrite for $10 \mathrm{~min}$. (D) Change in the ratio of arbitrary fluorescence units normalized with average of arbitrary fluorescence units of control $\left(\mathrm{afu} / \mathrm{afu}_{\mathrm{c}}\right)$ for $\mathrm{A}, \mathrm{B}$ and $\mathrm{C}$. 


\subsubsection{Heat treatment and order of the reaction}
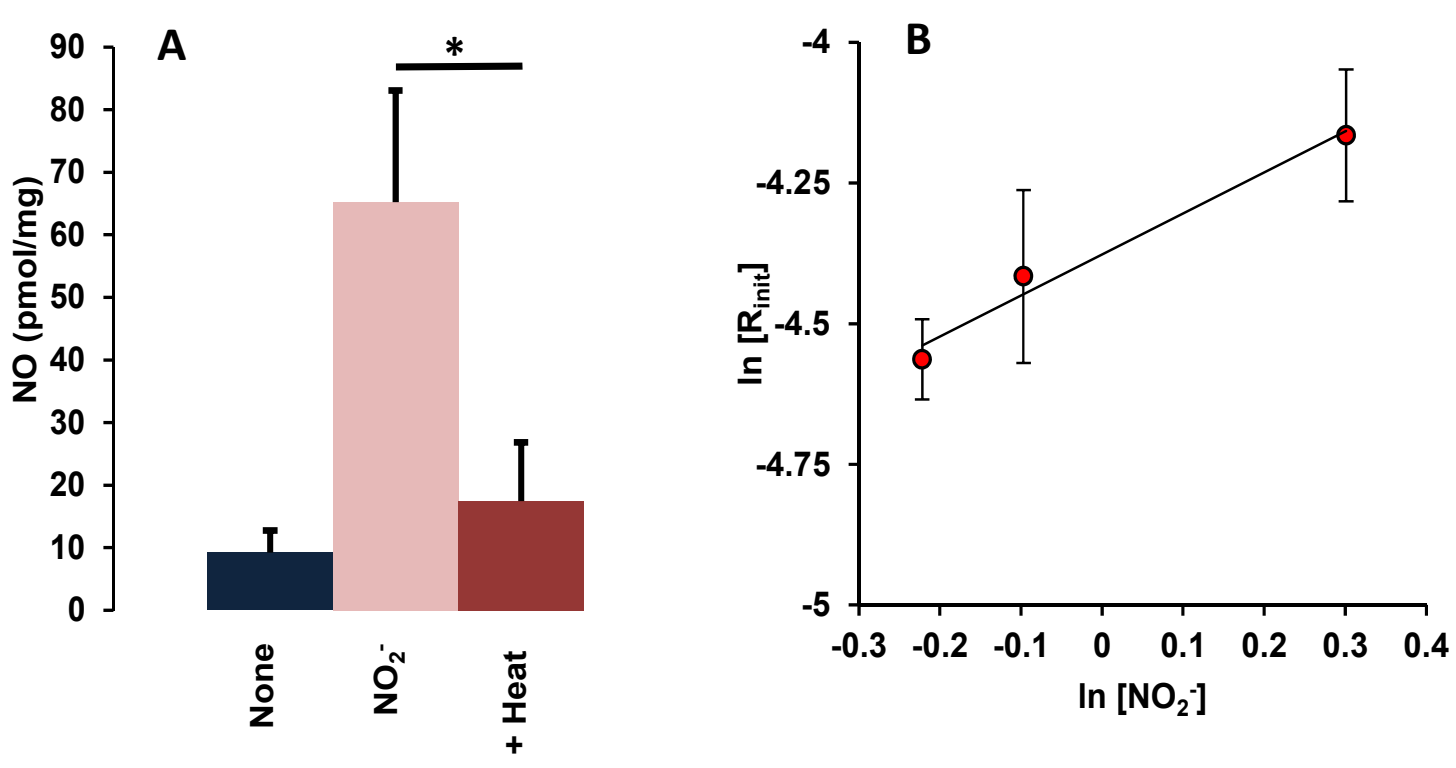

Fig 3.3: (A) Effect of heat on nitrite reduction to NO: Cell lysates were treated with either vehicle, $600 \mu \mathrm{M}$ nitrite or $600 \mu \mathrm{M}$ nitrite after heating the cell lysates in near boiling water for $30 \mathrm{~min}$. (B) Nitrite reduction from three doses of nitrite, 0.6, 0.8 and 2 $\mathrm{mM}$ was measured and the initial rate of nitrite reduction (averaged over first 10 minutes of the experiment) was plotted against nitrite in a $\log -\log$ graph. The slope of the graph is $0.73 \pm 0.3$ thus indicating first order kinetics for the reaction. $(n=3$ and $* p<0.05)$

In Fig 3.3A, the effect of heat on nitrite reduction to NO was monitored by keeping cell lysates at near boiling water for 30 minutes. NO produced was substantially reduced to control levels, thus being an indicator that any non-enzymatic activity did not play a role. To verify the order of the reaction, we measured NO yields from three different nitrite concentrations, $0.6,0.8$ and $2 \mathrm{mM}$. An initial rate of nitrite reduction was measured by analyzing rate of NO formation after the first 10 minutes of introduction of nitrite in the purge vessel. A plot of the initial rate vs. nitrite concentrations as in Fig 3.3B 
shows a slope of $0.73 \pm 0.3$, thus indicating a first order reaction and further elucidating the enzyme dependency of the phenomenon. Considering cell radius to be in the range of $5-10 \mu \mathrm{m}$ and a total of $2 \times 10^{5}$ cells for experimentation, initial rates of nitrite reduction $\mathrm{R}_{\text {init }}$ were calculated in terms of $\mathrm{mM} / \mathrm{min}$ for Fig $3.3 \mathrm{~B}$ and the overall rate constant $\mathrm{k}_{\mathrm{ov}}$ derived thus is $1.26 \times 10^{4} \mathrm{~s}^{-1}$.

\subsubsection{CO and Allopurinol effects on nitrite reduction to NO}

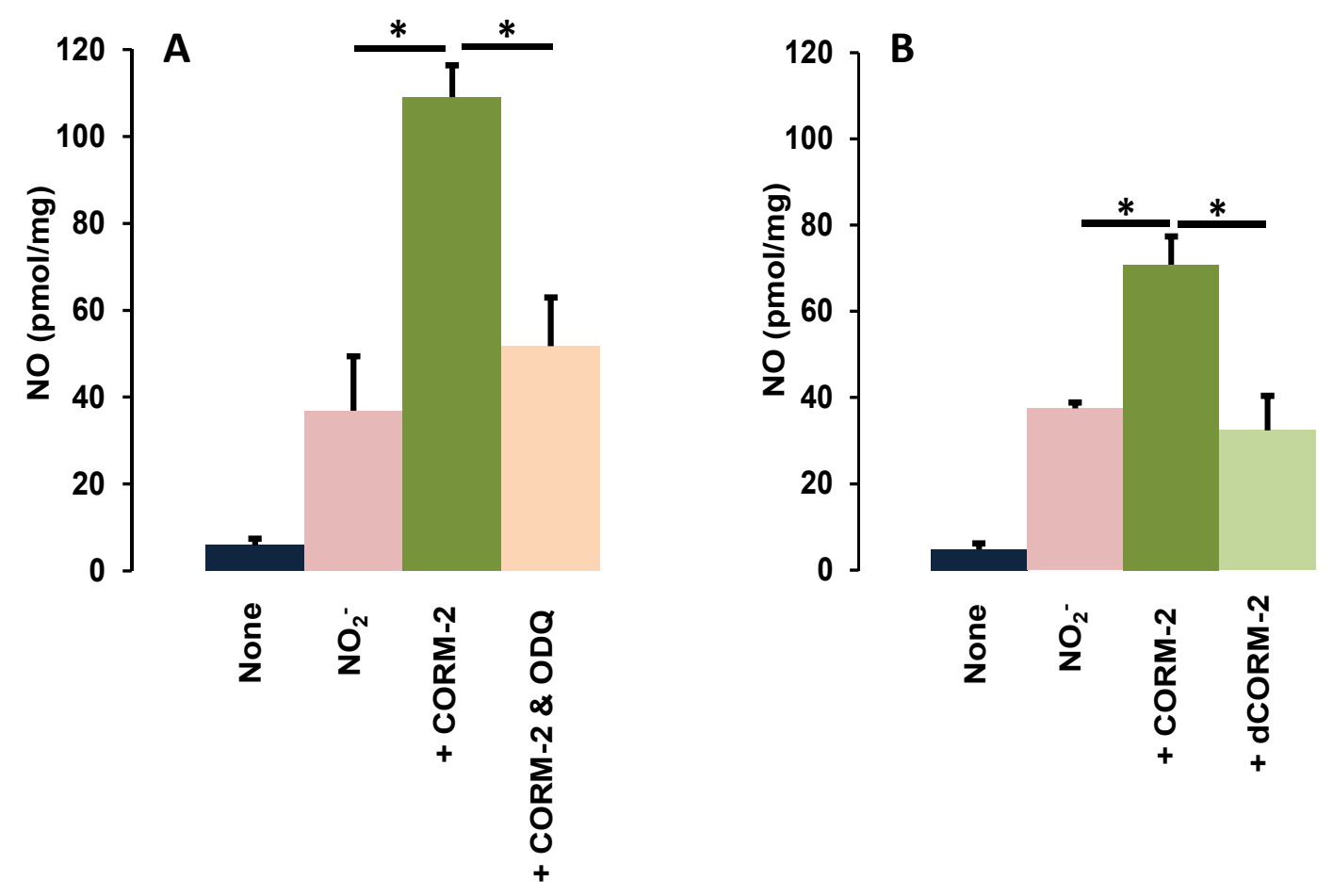



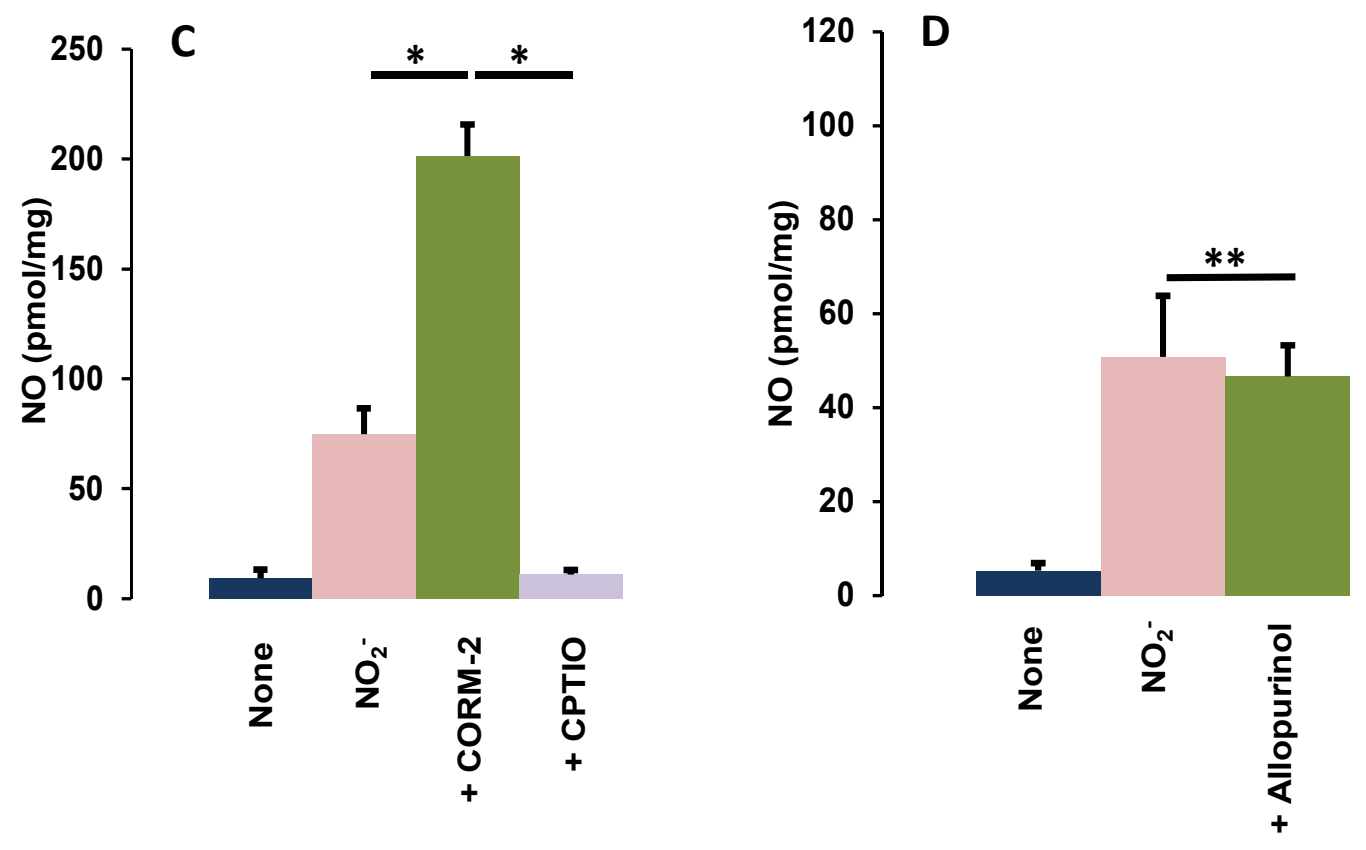

Fig 3.4: Effect of $\mathrm{CO}$ on nitrite reduction to NO: (A) Cell lysates were treated with either vehicle, $600 \mu \mathrm{M}$ nitrite, $600 \mu \mathrm{M}$ nitrite $+50 \mu \mathrm{M}$ CORM-2, and $600 \mu \mathrm{M}$ nitrite $+50 \mu \mathrm{M}$ CORM-2 $+10 \mu \mathrm{M}$ ODQ. (B) Cell lysates were treated with either vehicle, $600 \mu \mathrm{M}$ nitrite, $600 \mu \mathrm{M}$ nitrite $+50 \mu \mathrm{M}$ CORM-2, and $600 \mu \mathrm{M}$ nitrite $+50 \mu \mathrm{M}$ degraded CORM2. (C) Cell lysates were treated with either vehicle, $600 \mu \mathrm{M}$ nitrite $+50 \mu \mathrm{M}$ CORM-2 or $600 \mu \mathrm{M}$ nitrite $+50 \mu \mathrm{M}$ CORM-2 $+600 \mu \mathrm{M}$ CPTIO. (D) Effect of allopurinol on nitrite reduction to NO: Cell lysates were treated with either vehicle, $600 \mu \mathrm{M}$ nitrite, or $600 \mu \mathrm{M}$ nitrite $+100 \mu \mathrm{M}$ allopurinol for $10 \mathrm{~min}$ and $\mathrm{NO}$ measured by chemiluminescence. $(\mathrm{n}=3$ and $\left.{ }^{*} \mathrm{p}<0.05,{ }^{* *} \mathrm{p}>0.05\right)$

$\mathrm{CO}$ is a known sGC activator and therefore we tested the effect of a $\mathrm{CO}$ donor CORM-2 [117] on nitrite reduction. Cell lysates were exposed to $600 \mu \mathrm{M}$ nitrite in the presence and absence of $50 \mu \mathrm{M}$ CORM- 2 and the NO produced was analyzed by chemiluminescence. We observed that at least $600 \mu \mathrm{M}$ nitrite was required to detect measurable levels of NO (Fig 3.4A). In the presence of nitrite plus CORM-2 there was a 
2-3 fold increase in the NO generation (Fig 3.4A). The mediation of $\mathrm{sGC}$ in CO-induced NO generation was tested with ODQ. It significantly attenuated the nitrite plus CORM-2 induced NO production and thus demonstrating that $\mathrm{sGC}$ is mostly likely acting as nitrite reductase. As depicted in Fig 3.4B, degraded CORM-2 failed to activate NO generation showing that increased NO production from CORM-2 treatment was due to CO release. The chemiluminescence NO signal in these experiments was verified with the CPTIO treatment. As shown in Fig 3.4C, the rise in signal in response to nitrite plus CORM-2 treatment was abolished after CPTIO pretreatment. XOR inhibitor allopurinol $(100 \mu \mathrm{M})$ had no effect on the nitrite initiated NO formation (Fig 3.4D) in cell lysates showing that in SMCs XOR does not act as nitrite reductase. The abolishment of chemiluminescence signal by C-PTIO also showed that the increased signal due to nitrite and CORM-2 is the result of $\mathrm{NO}$ generation. 


\subsection{4 $\mathrm{O}_{2}$ dependence of nitrite reduction and transport}
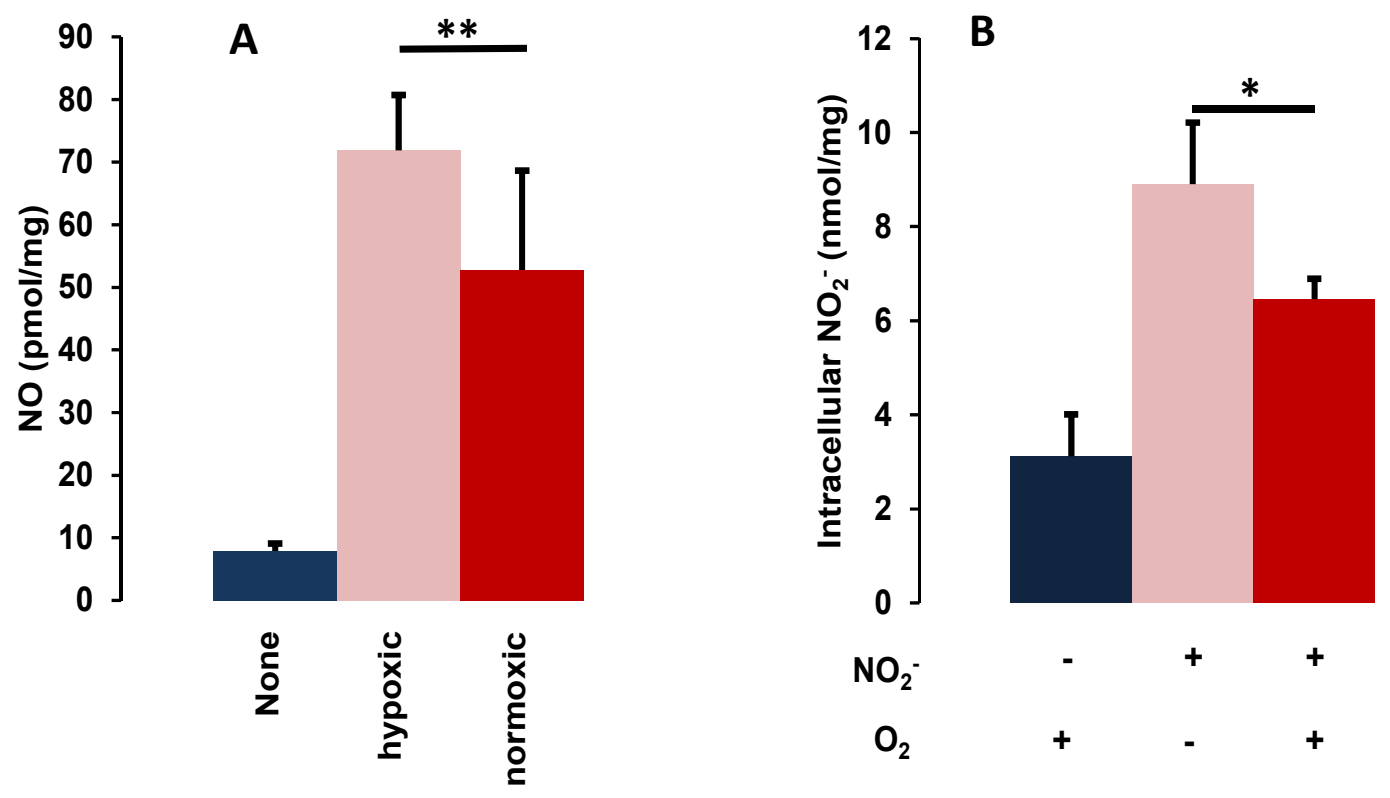

Fig 3.5: (A) Effect of oxygen on nitrite reduction to NO: Cell lysates were treated with $600 \mu \mathrm{M}$ nitrite either after purging with helium for $15 \mathrm{~min}$ (hypoxic) or with compressed air (normoxic). (B) Nitrite transport kinetics: Nitrite was added to cell cultures and intracellular nitrite measured by chemiluminescence upon cell lysis at different time intervals ( $\mathrm{n}=3$ ). (C) Cells were treated with either vehicle, $600 \mu \mathrm{M}$ nitrite (normoxia), or $600 \mu \mathrm{M}$ nitrite (hypoxia) $\left(\mathrm{n}=3\right.$ and $\left.{ }^{*} \mathrm{p}<0.05, * * \mathrm{p}>0.05\right)$.

sGC activity is known to be insensitive to $\mathrm{O}_{2}$ binding and we wanted to verify the effect of $\mathrm{O}_{2}$ levels on nitrite reduction to $\mathrm{NO}$ in SMCs. As illustrated in Fig 3.5A, nitrite reduction to NO was not influenced by hypoxic conditions and thus documenting sGC catalyzed nitrite reduction was independent of $\mathrm{O}_{2}$ binding. We also analyzed nitrite transport under hypoxic conditions. This showed a moderate increase in intracellular nitrite as in Fig 3.5B 


\subsubsection{Cellular nitrite transport via anion channels}
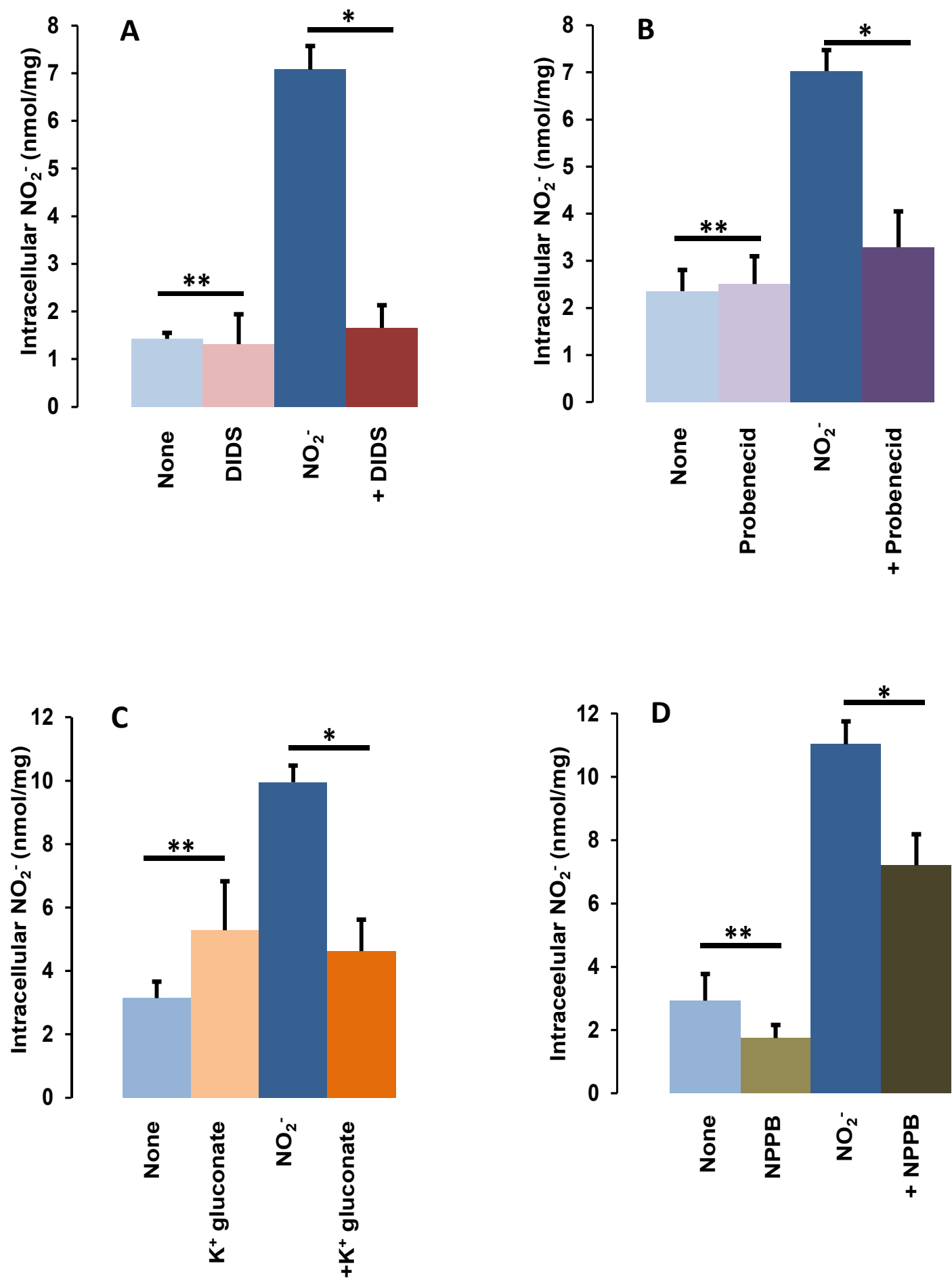
Fig 3.6 (cont.): Intracellular nitrite measurements by chemiluminescence: (A) Cell cultures were treated with either vehicle, $100 \mu \mathrm{M}$ DIDS, $600 \mu \mathrm{M}$ nitrite or $100 \mu \mathrm{M}$ DIDS $+600 \mu \mathrm{M}$ nitrite for $10 \mathrm{~min}$ and cell lysates used for nitrite measurements. (B) Cell cultures were treated with either vehicle, $75 \mu \mathrm{M}$ probenecid, $600 \mu \mathrm{M}$ nitrite, or $600 \mu \mathrm{M}$ nitrite $+75 \mu \mathrm{M}$ probenecid and cell lysates used for nitrite measurements. (C) Cell cultures were treated with either vehicle, $50 \mathrm{mM} \mathrm{K}^{+}$gluconate, $600 \mu \mathrm{M}$ nitrite or $600 \mu \mathrm{M}$ nitrite $+50 \mathrm{mM} \mathrm{K}{ }^{+}$gluconate for $10 \mathrm{~min}$ and cell lysates used for nitrite measurements. (D) Cell cultures were treated with either vehicle, $10 \mu \mathrm{M} \mathrm{NPPB}, 600 \mu \mathrm{M}$ nitrite, or 10 $\mu \mathrm{M}$ NPPB $+600 \mu \mathrm{M}$ nitrite for $10 \mathrm{~min}$ and cell lysates used for nitrite measurements. (n $=3$ and $* \mathrm{p}<0.05, * * \mathrm{p}>0.05)$

We studied the nitrite transport mechanism using different anion channel blockers. DIDS is a potent inhibitor of $\mathrm{Cl}^{-}: \mathrm{HCO}_{3}{ }^{-}$transport channels including AE-2 on rat VSMCs $[110,118]$. Cells were treated with nitrite in the presence and absence of 100 $\mu \mathrm{M}$ DIDS and intracellular nitrite levels measured by chemiluminescence. DIDS completely inhibited nitrite influx (Fig 3.6A) and thus showing that AE2 may be mediating nitrite transport in SMCs. The chemiluminescene signal was completeletely abolished upon sulfanilamide pretreatment showing insignificant contribution of nitrosothiols towards nitrite levels (data not shown). Since SMCs are shown to possess urate transport channels [111], which are a member of organic anion transport family, we speculate that nitrite could be using these channels. As shown in Fig 3.6B, urate transporter inhibitor, probenecid $(75 \mu \mathrm{M})$ significantly blocked the cellular nitrite uptake. Similar inhibitions were observed with $\mathrm{K}+$ gluconate (organic anion transport inhibitor) and NPPB (chloride channel blocker) as shown in Fig 3.6C and Fig 3.6D respectively. Take together these data demonstrate that nitrite uses a number of anion channels for its uptake by SMCs. 


\subsubsection{Competitive inhibition of nitrite reduction and transport by nitrate}
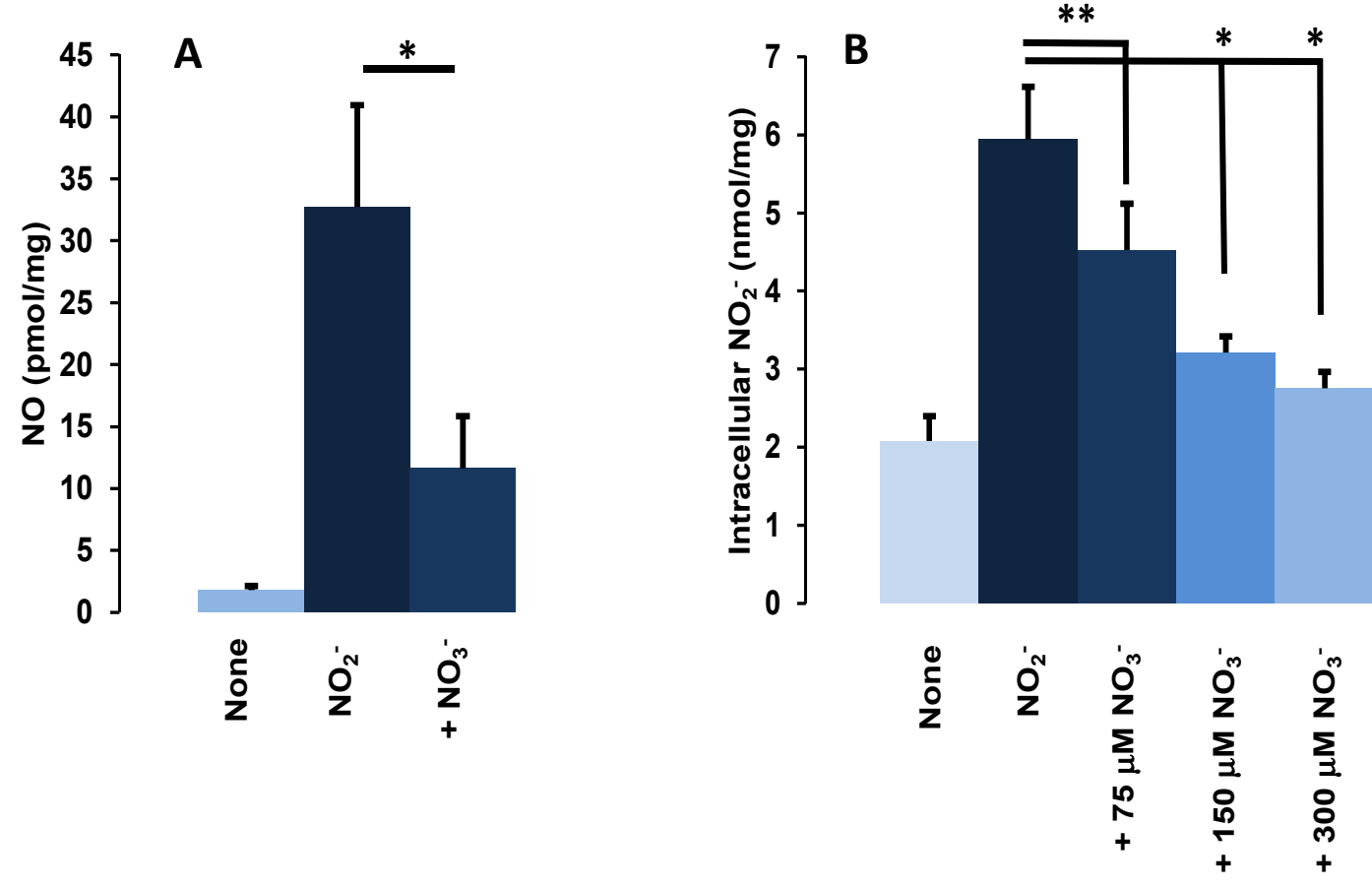

Fig 3.7: Effect of nitrate on nitrite reduction and nitrite transport. (A) Cell lysates were treated with either vehicle, $600 \mu \mathrm{M}$ nitrite, or $600 \mu \mathrm{M}$ nitrite $+300 \mu \mathrm{M}$ nitrate. (B) Cell cultures were treated with $600 \mu \mathrm{M}$ nitrite in the absence and presence of increasing concentration of nitrate for $10 \mathrm{~min}$ and intracellular nitrite measured by chemiluminescence upon cell lysis $(\mathrm{n}=3$ and $* \mathrm{p}<0.05, * * \mathrm{p}>0.05)$

Because of their structural similarity, nitrate could be modulating nitrite transport and subsequent reduction. Therefore, cell lysates were pretreated with $300 \mu \mathrm{M}$ nitrate prior to nitrite addition and NO measurements by chemiluminescence. We observed that nitrate significantly attenuated nitrite reduction (Fig 3.7A) and thus showing that nitrate competes with nitrite for sGC binding and reduction. We also investigated whether nitrate blocks cellular nitrite uptake. As shown in Fig 3. 7B, nitrate dose-dependently blocked nitrite uptake. 


\subsection{Discussion}

Nitrite reduction to NO by heme and molybdenum containing macromolecules has been widely documented in both normoxic and hypoxic environments. Since the ultimate biological target of NO produced is its receptor sGC and subsequent dilation, NO has to traverse the vasculature without being consumed along the way. In the last decade, various competing hypotheses have been proposed to demonstrate sufficient levels of NO reaching sGC in smooth muscle cells and effect vasorelaxation. However, a convincing hypothesis has not yet emerged that satisfies all possible caveats. One such proposal could be if SMCs produce NO locally so that it binds to its target without having to overcome various scavengers like oxyhemoglobin and superoxide. We have carried out experiments to determine the nitrite reduction to NO by $\mathrm{sGC}$ in cultured rat aortic SMCs. The cell lysates effectively produced measurable levels of NO after addition of nitrite, at concentrations comparable to that used by others $[48,119]$. The results illustrate that nitrite reduction to NO could be inhibited by known sGC activity blockers (ODQ) and elevated by its known specific activators ( $\mathrm{CO}$ and $\mathrm{YC}-1)$. Additionally, nitrite reduction was abolished upon boiling the cell lysate demonstrating the participation of an enzymatic activity - but not nitrite disproportionation - in NO formation. These observations indicate that $\mathrm{sGC}$ may serve as a local source of $\mathrm{NO}$ to mediate relaxation of the vascular smooth muscle. Although several early reports had documented nitrite's participation in the activation of $\mathrm{sGC}$ to synthesize cGMP $[36,120]$ but sGC may act as nitrite reductase was not speculated. Recent accumulated evidence points to sGC's possible mediation in nitrite induced protection against ischemia/reperfusion injury [105] and vessel relaxation following nitrite ${ }^{-}$reduction [48]. But detailed investigations were 
not conducted to find the cellular origin of $\mathrm{sGC} /$ nitrite reductase activity and the effects of sGC specific modulators were not attempted.

While nitrite metabolism is most active under hypoxia, it is widely believed to be inert at neutral $\mathrm{pH}$ and normoxic conditions. sGC activity generating cGMP was documented to be independent of $\mathrm{O}_{2}$ levels [121-124]. Thus, our finding that $\mathrm{O}_{2}$ tension had no effect on nitrite reduction is in support of this sGC property. This observation implied that even if most of $\mathrm{NO}$ is scavenged by oxyHb in normoxic conditions, sGC may still metabolize nitrite and effect vasodilation. Moreover, nitrite reduction in both normoxia and hypoxia was recently observed in heart and liver tissues, the rate of which was much faster as compared to that in blood [125]. Whereas earlier work has illustrated tissue XOR as a potent nitrite reductase [126], it did not reduce nitrite in our studies. Hence in rat aortic SMCs the sGC appears to be the major source of nitrite reduction. This interpretation was supported by the observations made in rat aortic tissue [48]. Alternatively, it is possible that XOR activity is lost in passaged cells used in the present investigations.

Since reactions of nitrite with sGC are localized to the cytosol, it is imperative to know the transport mechanism of nitrite across the cell membrane. There is very limited knowledge about nitrite transport in any of the mammalian system. Our experiments with channel blockers showed that nitrite mainly uses anion channels to traverse the SMC membrane. These include urate, $\mathrm{Cl}^{-}: \mathrm{HCO}^{-}$, organic anion and chloride transporters. Among the blockers tested, DIDS acted as a potent inhibitor of nitrite transport showing that AE2 could be the major nitrite transporter. It was also observed that in the presence 
of DIDS the intracellular nitrite accumulation was reduced showing that DIDS inhibits its influx but not efflux. In contrast, DIDS was shown to block nitrite export in human RBCs [112]. This difference could be due to participation of different isoforms of AE: SMC are known to possess AE2 transporter [110] while RBC having AE1 transporter [127]. Uric acid facilitates vascular SMC proliferation and it uses urate transporter to enter the cells and in particular URAT1 is demonstrated to control renal urate excretion [111]. These anion transporters may have additional physiological functions, as shown here, in nitrite transport and facilitate increased cellular NO production. It would be of great significance to examine the modulation of vascular nitrite transport in physiological and pathophysiological conditions.

Since nitrite reduction is not controlled by $\mathrm{O}_{2}$ levels, it raises the important question of how nitrite reduction is modulated in SMCs. Our experiments illustrated that nitrate not only competes with nitrite for reduction but also efficiently blocks nitrite transport at near physiological concentrations. This observation has wide pathophysiological implications as increased nitrate production in certain conditions may attenuate nitrite reduction and relaxation. In the absence of known nitrate reductases it may accumulate in plasma and tissues reaching higher concentrations. For example, serum nitrate levels were elevated in women with pre-eclampsia, which based on our findings, can be explained as serum nitrate inhibiting the relaxation mediated by physiological nitrite reduction. Also, under oxidative stress there could be increased reaction of $\mathrm{NO}$ and $\mathrm{O}_{2}^{-}$forming nitrate via $\mathrm{ONOO}^{-}$. Vaziri et al [128] have measured increased iNOS, eNOS expression and elevated plasma NOx levels in pre-hypertensive 
SHR. The initially increased NOx levels may play a role in later development of hypertension in this model.

In summary, our investigations demonstrate that sGC catalyzes the nitrite reduction in smooth muscle, independent of $\mathrm{O}_{2}$ levels, and nitrite uses different anion transporters to traverse the cell membrane. Thus, sGC may serve as a local source of NO for smooth muscle relaxation. Both nitrite reduction and its membrane transport are inhibited by nitrate, an observation that has important pathological implications. 
Chapter 4: Computational modeling of NO and NO oxidative species in the microcirculation: Reducing nitrite to $\mathrm{NO}$ in the smooth muscle cells vs. arteriolar lumen

\subsection{Abstract}

Sufficient availability of nitric oxide (NO) in the smooth muscles of blood vessels is important for its function as the proposed endothelium derived relaxing factor. NO may be preserved through the formation of $\mathrm{NO}_{2}{ }^{-}$anions or nitrosothiols which have a longer half-life than NO in the circulation. This provides the possibility to transport NO to a distant location. A 2D axisymmetric diffusion model was used to observe NO and NO oxidative species transport and to test the potential contribution of $\mathrm{NO}_{2}{ }^{-}$and nitrosothiols to smooth muscle NO levels according to data derived in previous research. With physiological concentrations of $\mathrm{NO}_{2}^{-}(10 \mu \mathrm{M}-20 \mu \mathrm{M})$ in the smooth muscle tissue, sufficient $\mathrm{NO}$ is generated to affect blood vessel tone. $\mathrm{NO}_{2}{ }^{-}$reduction was found to be more efficient when occurring in the tissue as compared to the lumen. NO oxidase activity in the tissue regions was found to be an important factor for generating smooth muscle levels of $\mathrm{NO}_{2}^{-}$. Results suggest that the major nitrosating mechanism in vivo is anaerobic and nitrosothiols may deliver minor amounts of $\mathrm{NO}$ through a $\mathrm{Cu}^{+}$dependent enzyme activity.

\subsection{Introduction}

After the discovery of NO as the endothelial derived relaxing factor [1, 49], NO has been found to play a role in maintaining blood pressure [6], vascular tone [129], vascular permeability [130], adhesion and aggregation of platelets [131, 132] and SMC proliferation [133]. One of the major functions of NO in the circulation is to act as a soluble Guanylate Cyclase (sGC) activator, producing enough cyclic guanosine mono 
phosphate (cGMP) to ensure smooth muscle relaxation $[1,49,50,134]$. Critical for this is maintenance of sufficient availability of NO in the smooth muscle. Disruption of this availability can lead to pathophysiological conditions such as atherosclerosis, renal failure, high blood pressure and diabetes related vascular complications. In the vasculature, NO levels are mainly regulated by NO production by various nitric oxide synthase enzymes, and NO consumption by hemoglobin $(\mathrm{Hb})$ in blood and various heme enzymes in tissues such as myoglobin [21,22].

The ability of NO to perform its normal physiological functions inspite of the presence of NO sinks in the system has been attributed to either inhibition of NO consumption by red blood cells (RBCs) [27, 32, 34, 135-139] or to the conversion of NO to more stable adducts such as nitrite anions or nitrosothiols, which then release NO either locally or downstream $[39,140]$. Many theoretical investigations have investigated these scenarios $[23,26,32,141-146]$. Unfortunately, no models have studied the transport of $\mathrm{NO}$ oxidation derivatives such as $\mathrm{NO}_{2}, \mathrm{~N}_{2} \mathrm{O}_{3}$, nitrite, nitrate and nitrosothiols in arterioles. In this study nitrite reduction by smooth muscles will be modeled. We will test whether NO generation in the smooth muscle is sufficient to affect blood vessel tone. In addition, tissue nitrite concentrations are reported to be approximately $10 \mu \mathrm{M}$ [42], the mechanisms of generation for which are unknown. For nitrite generation simple autoxidation of $\mathrm{NO}$ in the system, acceleration of NO oxidation in hydrophobic compartments of the tissue [147], ferricytochrome c based acceleration of NO oxidation in tissues [148], cytochrome c oxidase based oxidation of NO [149] and acceleration of 
NO oxidation in plasma by a NO oxidase enzyme ceruloplasmin [150] will be used to derive lumen and SMC levels of nitrite.

Our study will also test mechanisms of nitrosothiol formation. Of all the thiols, glutathione (GSH) will be chosen as it is an important candidate for the formation of its respective nitrosothiol (S-nitrosoglutathione, GSNO) owing to high concentrations of GSH and long half-life of GSNO in vivo (0.5 - $10 \mathrm{mM}$ of GSH as per Meister et al. [53] and a GSNO half-life of 5.5 hours compared to $0.1-15 \mathrm{~s}$ for NO [4]). GSNO poduction through generation of the GS radical by oxidation of GSH with $\mathrm{NO}_{2}$ with the kinetics described in chapter 3 of this work and through the process of ferricytochrome c reduction will be done [151], [93]. The ability of GSNO to deliver NO will be also be tested through a $\mathrm{Cu}^{+}$dependent GSNO lyase activity.

\subsection{Methods}

\subsubsection{Model Geometry}

NO production in an arteriole of $50 \mu \mathrm{m}$ internal diameter and an adjacent arteriolar wall and tissue layer of a thickness of $75 \mu \mathrm{m}$ was modeled as a series of concentric cylinders. The domain comprised of eight distinct regions. RBCs flow in the core of the lumen (LC) in the innermost region of the domain. A cell free layer (CF) was considered near the arteriolar wall. The arteriolar wall consists of an endothelial cell (EC) layer, interstitial gap (IG) and a smooth muscle (SMC) layer. Outside the arteriolar wall, a hypothetical neuronal layer (NL) was considered [152], followed by a non-perfused tissue region (NPT) and a capillary perfused tissue region (PT). Geometry followed in the model is described in table 4.1 


\subsubsection{Common modeling equations and boundary conditions}

An unsteady reaction - diffusion equation is formulated to simulate transport for NO and other NO oxidation intermediates in the radial direction. Axial and angular gradients of any NO species are considered negligible.

$\frac{\partial C_{X}}{\partial t}=D_{X} \frac{1}{r} \frac{\partial}{\partial r}\left(r \frac{\partial C_{X}}{\partial r}\right)-R_{X}+Q_{x}$

where $\mathrm{C}_{\mathrm{x}}$ is the concentration of species $\mathrm{X}$ : $\mathrm{NO}, \mathrm{NO}_{2}, \mathrm{~N}_{2} \mathrm{O}_{3}, \mathrm{NO}_{2}{ }^{-}, \mathrm{NO}_{3}{ }^{-}, \mathrm{GSNO}, \mathrm{GS}$, $\mathrm{O}_{2}, \mathrm{O}_{2}{ }^{-}$or $\mathrm{ONOO}^{-} . \mathrm{D}_{\mathrm{x}}$ is the diffusivity of the species $\mathrm{X}, \mathrm{R}_{\mathrm{x}}$ is the consumption rate of the species in a particular region, $\mathrm{Q}_{\mathrm{x}}$ is the production rate of the species, $\mathrm{t}$ is time and $\mathrm{r}$ is radial distance.

Assumption of a partition coefficient of unity and continuity of concentration and flux at the interfaces yield the following boundary conditions:

$$
\begin{aligned}
& \left.\left.D_{X} \frac{\partial C_{X}}{\partial r}\right]_{r=R_{i}^{-}}=D_{X} \frac{\partial C_{X}}{\partial r}\right]_{r=R_{i}^{+}} \\
& \left.\left.J_{i j}=P_{m}\left[C_{x}\right]_{r=R_{i}^{-}}-C_{x}\right]_{r=R_{i}^{+}}\right\rfloor
\end{aligned}
$$

where $i$ and $j$ are adjacent regions and $\mathrm{R}_{\mathrm{i}}$ is the distance of the interface between regions $i$ and $j$ from the central axis of the arteriole. $\mathrm{J}_{\mathrm{ij}}$ is the flux of the species at interface $\mathrm{ij}$ and $\mathrm{P}_{\mathrm{m}}$ is the membrane permeability of the species at interface assumed infinite for all species. 


\subsubsection{Modeling NO consumption and SGC activation}

Modeling of NO consumption and generation in each compartment and sGC consumption and activation in the smooth muscle was followed from Tsoukias et al. [24]. NO consumption in autoxidation was broken up into constitutive reactions and NO consumption in nitrosation schemes of GSH were added to the model. These reactions are mentioned in table 4.2. The list of parameters used in the model and concentrations held constant during the stimulations are mentioned in table 4.3.

Table 4.1: Model geometry and concentrations held at steady state

\begin{tabular}{|l|l|l|l|}
\hline Symbol & Description & Values & Units \\
\hline $\mathrm{R}_{\mathrm{lc}}$ & Radius at lumen core & 20.5 & $\mu \mathrm{m}$ \\
\hline $\mathrm{R}_{\mathrm{cf}}$ & Radius at cell free layer & 25 & $\mu \mathrm{m}$ \\
\hline $\mathrm{R}_{\mathrm{ec}}$ & Radius at endothelial cell layer & 25.5 & $\mu \mathrm{m}$ \\
\hline $\mathrm{R}_{\mathrm{g}}$ & Radius at interstitial gap & 26 & $\mu \mathrm{m}$ \\
\hline $\mathrm{R}_{\mathrm{sm}}$ & Radius at smooth muscle layer & 32 & $\mu \mathrm{m}$ \\
\hline $\mathrm{R}_{\mathrm{nerve}}$ & Radius at end of nerve fiber & 34 & $\mu \mathrm{m}$ \\
\hline $\mathrm{R}_{\mathrm{nt}}$ & Radius at end of non-perfused tissue & 64 & $\mu \mathrm{m}$ \\
\hline $\mathrm{R}_{\mathrm{cap}}$ & Radius at end of capillary layer & 100 & $\mu \mathrm{m}$ \\
\hline
\end{tabular}

Table 4.2: Chemical equations simulated in the model

\begin{tabular}{|l|l|l|l|}
\hline$\#$ & Equation & Rate constant & Ref \\
\hline 1 & $2 \mathrm{NO}+\mathrm{O}_{2} \stackrel{k_{1}}{\longrightarrow} 2 \mathrm{NO}_{2}$ & $\mathrm{k}_{1}=2.9 \times 10^{6} \mathrm{M}^{-2} \mathrm{~s}^{-1}$ & {$[76,77]$} \\
& & $\mathrm{k}_{1 \mathrm{t}}=29 \times 10^{6} \mathrm{M}^{-2} \mathrm{~s}^{-1}$ & {$[147]^{*}$} \\
\hline 2 & $\mathrm{NO}+\mathrm{NO}_{2} \underset{k_{-2}}{\stackrel{k_{2}}{\longrightarrow} N_{2} \mathrm{O}_{3}}$ & $\mathrm{k}_{2}=1.1 \times 10^{9} \mathrm{M}^{-1} \mathrm{~s}^{-1}$ & {$[78]$} \\
& & $\mathrm{k}_{-2}=8.1 \times 10^{4} \mathrm{~s}^{-1}$ & {$[78]$} \\
\hline 3 & $\mathrm{~N}_{2} \mathrm{O}_{3}+\mathrm{H}_{2} \mathrm{O} \stackrel{k_{3}}{\longrightarrow} 2 \mathrm{NO}_{2}^{-}+2 \mathrm{H}^{+}$ & $\mathrm{k}_{3}=1470 \mathrm{~s}^{-1}$ & {$[75]^{* *}$} \\
\hline
\end{tabular}




\begin{tabular}{|c|c|c|c|}
\hline 4 & $\begin{array}{l}\mathrm{NO}_{2}+G S H \stackrel{k_{4}}{\longrightarrow} N O_{2}^{-}+G S+H^{+} \\
N_{2}+G S^{-} \stackrel{k_{4 \prime \prime}}{\longrightarrow} N O_{2}^{-}+G S\end{array}$ & $\mathrm{k}_{4}=1.15 \times 10^{7} \mathrm{M}^{-1} \mathrm{~s}^{-1}$ & $\begin{array}{l}\text { Ch. } 2 \\
\text { See [74] }\end{array}$ \\
\hline 5 & $G S+N O \stackrel{k_{5}}{\longrightarrow} G S N O$ & $\mathrm{k}_{5}=3 \times 10^{9} \mathrm{M}^{-1} \mathrm{~s}^{-1}$ & [79] \\
\hline 6 & $G S H \underset{k_{-6}}{\stackrel{k_{6}}{\leftrightarrow}} G S^{-}+H^{+}$ & $\begin{array}{l}\mathrm{k}_{6}=63 \mathrm{~s}^{-1} \\
\mathrm{k}_{-6}=1 \times 10^{9} \mathrm{M}^{-1} \mathrm{~s}^{-1}\end{array}$ & $\begin{array}{l}{[80]} \\
{[80]^{* * *}}\end{array}$ \\
\hline 7 & $G S^{\circ}+G S N O \stackrel{k_{7}}{\longrightarrow} G S S G+N O$ & $\mathrm{k}_{7}=1.7 \times 10^{9} \mathrm{M}^{-1} \mathrm{~s}^{-1}$ & [83] \\
\hline 8 & $2 G S \stackrel{k_{8}}{\longrightarrow} G S S G$ & $\mathrm{k}_{8}=1.5 \times 10^{9} \mathrm{M}^{-1} \mathrm{~s}^{-1}$ & {$[153]$} \\
\hline 9 & $\mathrm{NO}_{2}+G S \stackrel{k_{9}}{\longrightarrow} \mathrm{GSNO}_{2}$ & $\mathrm{k}_{9}=3 \times 10^{9} \mathrm{M}^{-1} \mathrm{~s}^{-1}$ & {$[154]$} \\
\hline 10 & $\mathrm{NO}+\mathrm{O}_{2}^{-} \stackrel{k_{10}}{\longrightarrow} \mathrm{ONOO}^{-}$ & $\mathrm{k}_{10}=1.9 \times 10^{10} \mathrm{M}^{-1} \mathrm{~s}^{-1}$ & {$[155]$} \\
\hline 11 & $2 \mathrm{NO}_{2} \underset{k_{-11}}{\stackrel{k_{11}}{\leftrightarrow}} N_{2} \mathrm{O}_{4}$ & $\begin{array}{l}\mathrm{k}_{11}=4.5 \times 10^{9} \mathrm{M}^{-1} \mathrm{~s}^{-1} \\
\mathrm{k}_{-11}=6.9 \times 10^{3} \mathrm{~s}^{-1}\end{array}$ & $\begin{array}{l}{[156]} \\
{[156]}\end{array}$ \\
\hline 12 & $\mathrm{~N}_{2} \mathrm{O}_{4}+\mathrm{H}_{2} \mathrm{O} \stackrel{k_{12}}{\longrightarrow} \mathrm{NO}_{2}^{-}+\mathrm{NO}_{3}^{-}+2 \mathrm{H}^{+}$ & $\mathrm{k}_{12}=1.0 \times 10^{3} \mathrm{~s}^{-1}$ & {$[157]$} \\
\hline 13 & $2 G S N O+O_{2}^{-}+H^{+} \stackrel{k_{13}}{\longrightarrow} G S S G+2 N_{2}^{-}$ & $\mathrm{k}_{13}=9 \times 10^{8} \mathrm{M}^{-2} \mathrm{~s}^{-1}$ & {$[147]$} \\
\hline 14 & $\mathrm{ONOO}^{-}+\mathrm{H}^{+} \stackrel{k_{14}}{\longrightarrow} \mathrm{NO}_{2}+\mathrm{OH}$ & $\mathrm{k}_{14}=0.23 \mathrm{~s}^{-1}$ & {$[158]$} \\
\hline 15 & $\mathrm{ONOO}^{-}+H^{+} \stackrel{k_{15}}{\longrightarrow} \mathrm{NO}_{3}^{-}+H^{+}$ & $\mathrm{k}_{15}=0.57 \mathrm{~s}^{-1}$ & {$[158]$} \\
\hline 16 & $\mathrm{Cu}^{2+}+\mathrm{NO}+\mathrm{H}_{2} \mathrm{O} \stackrel{k_{16}}{\longrightarrow} \mathrm{NO}_{2}^{-}+2 \mathrm{H}^{+}+\mathrm{Cu}^{+}$ & $\mathrm{k}_{16}=5.5 \times 10^{-2} \mathrm{~s}^{-1}$ & $\begin{array}{l}{[150,} \\
159]\end{array}$ \\
\hline 17 & $\mathrm{NO}+\mathrm{CytFe}-\mathrm{III}+\mathrm{H}_{2} \mathrm{O} \stackrel{k_{17} \longrightarrow}{\longrightarrow} \mathrm{CytFe}-\mathrm{II}+\mathrm{NO}_{2}^{-}+2 \mathrm{H}$ & $\mathrm{k}_{17}=0.33 \mathrm{~s}^{-1}$ & {$[20]$} \\
\hline 18 & $\mathrm{CytFe}-\mathrm{III}-\mathrm{GSH}+\mathrm{NO} \stackrel{k_{18}}{\longrightarrow} \mathrm{CytFe}-\mathrm{II}+\mathrm{GSNO}+\mathrm{H}$ & $\mathrm{k}_{18}=4.2 \times 10^{-3} \mathrm{~s}^{-1}$ & [92] \\
\hline 19 & $\mathrm{NO}_{2}^{-}+\mathrm{Fe}-\mathrm{II}+\mathrm{H}^{+} \stackrel{k_{19}}{\longrightarrow} \mathrm{NO}+\mathrm{Fe}-\mathrm{III}+\mathrm{OH}^{-}$ & $\mathrm{k}_{19}=1.3 \times 10^{-2} \mathrm{~s}^{-1}$ & Ch. 3 \\
\hline
\end{tabular}

* accelerated NO autoxidation in hydrophobic components in the tissues. 
** Calculated from a blood phosphate concentration of $1-2 \mathrm{mM}$ and explanation given in [75].

$* * * \mathrm{pH}=7.4$

Table 4.3: Other rate constants and physical parameters used in the model

\begin{tabular}{|c|c|c|c|c|}
\hline Symbol & Description & Values & Units & Ref \\
\hline $\mathrm{D}$ & NO diffusivity & $3.3 \times 10^{-9}$ & $\mathrm{~m}^{2} / \mathrm{s}$ & {$[160]$} \\
\hline $\mathrm{D}_{\mathrm{GSNO}}$ & GSNO diffusivity & $1.8 \times 10^{-10}$ & $\mathrm{~m}^{2} / \mathrm{s}$ & [147] \\
\hline $\mathrm{D}_{\mathrm{NO} 2}$ & $\mathrm{NO}_{2}$ diffusivity & $4.67 \times 10^{-10}$ & $\mathrm{~m}^{2} / \mathrm{s}$ & text \\
\hline $\mathrm{D}_{\mathrm{N} 2 \mathrm{O} 3}$ & $\mathrm{~N}_{2} \mathrm{O}_{3}$ diffusivity & $4.67 \times 10^{-10}$ & $\mathrm{~m}^{2} / \mathrm{s}$ & text \\
\hline $\mathrm{D}_{\mathrm{NO} 2-}$ & $\mathrm{NO}_{2}^{-}$diffusivity & $4.1 \times 10^{-10}$ & $\mathrm{~m}^{2} / \mathrm{s}$ & [161] \\
\hline $\mathrm{D}_{\mathrm{NO} 3-}$ & $\mathrm{NO}_{3}{ }^{-}$diffusivity & $4.2 \times 10^{-10}$ & $\mathrm{~m}^{2} / \mathrm{s}$ & {$[161]$} \\
\hline $\mathrm{D}_{\mathrm{O} 2-}$ & $\mathrm{O}_{2}^{-}$diffusivity & $2.8 \times 10^{-9}$ & $\mathrm{~m}^{2} / \mathrm{s}$ & [162] \\
\hline $\mathrm{D}_{\mathrm{ONOO}-}$ & $\mathrm{ONOO}^{-}$diffusivity & $2.6 \times 10^{-9}$ & $\mathrm{~m}^{2} / \mathrm{s}$ & [162] \\
\hline $\mathrm{D}_{\mathrm{O} 2}$ & $\mathrm{O}_{2}$ diffusivity & $2 \times 10^{-9}$ & $\mathrm{~m}^{2} / \mathrm{s}$ & [163] \\
\hline $\mathrm{k}_{20}$ & Rate constant for 6-sGC formation & $2 \times 10^{9}$ & $\mathrm{M}^{-1} \mathrm{~s}^{-1}$ & [24] \\
\hline $\mathrm{k}_{-20}$ & Rate constant for 6-sGC dissociation & 15 & $\mathrm{~s}^{-1}$ & [24] \\
\hline $\mathrm{k}_{21}$ & Rate constant for 5 -sGC formation & $6.4 \times 10^{-3}$ & $\mathrm{~s}^{-1}$ & [24] \\
\hline $\mathrm{k}_{-21}$ & Rate constant for 5 -sGC dissociation & $0.1 \times 10^{-3}$ & $\mathrm{~s}^{-1}$ & {$[24]$} \\
\hline $\mathrm{k}_{22}$ & $\begin{array}{l}\text { Rate constant for NO dependent } 5- \\
\text { sGC formation }\end{array}$ & $4.2 \times 10^{6}$ & $\mathrm{M}^{-1} \mathrm{~s}^{-1}$ & [24] \\
\hline $\mathrm{k}_{\mathrm{D}}$ & $\mathrm{NO}-$ sGC dissociation constant & 0.01 & $\mathrm{~s}^{-1}$ & [24] \\
\hline $\mathrm{k}_{\mathrm{bl}}$ & $\begin{array}{l}\text { Rate constant for NO consumption in } \\
\text { blood }\end{array}$ & $\begin{array}{l}750- \\
6400\end{array}$ & $\mathrm{~s}^{-1}$ & [24] \\
\hline $\mathrm{k}_{\mathrm{bl}, \mathrm{per}}$ & $\begin{array}{l}\text { Rate constant for } \mathrm{ONOO}^{-} \\
\text {consumption in blood }\end{array}$ & 30 & $\mathrm{~s}^{-1}$ & {$[164]$} \\
\hline $\mathrm{k}_{\text {app }}$ & $\begin{array}{l}\text { Apparent NO consumption in } \\
\text { capillaries }\end{array}$ & $10-25.9$ & $\mathrm{~s}^{-1}$ & [165] \\
\hline $\mathrm{k}_{\mathrm{bl}, \mathrm{NO} 2-}$ & $\begin{array}{l}\text { Rate constant for } \mathrm{NO}_{2}^{-} \text {consumption } \\
\text { in blood }\end{array}$ & $6.3 \times 10^{-3}$ & $\mathrm{~s}^{-1}$ & text \\
\hline $\mathrm{k}_{\mathrm{bl}, \mathrm{NO} 3-}$ & $\begin{array}{l}\text { Rate constant for } \mathrm{NO}_{3}{ }^{-} \text {consumption } \\
\text { in blood }\end{array}$ & $2.96 \times 10^{-5}$ & $\mathrm{~s}^{-1}$ & text \\
\hline $\mathrm{k}_{\mathrm{bl}, \mathrm{GSNO}}$ & $\begin{array}{l}\text { Rate constant for GSNO consumption } \\
\text { in blood }\end{array}$ & $3.5 \times 10^{-5}$ & $\mathrm{~s}^{-1}$ & text \\
\hline $\mathrm{k}_{\mathrm{per}, \mathrm{NO}}$ & $\begin{array}{l}\text { Rate constant for peroxynitrite } \\
\text { consumption by NO }\end{array}$ & $9.1 \times 10^{4}$ & $\mathrm{M}^{-1} \mathrm{~s}^{-1}$ & [166] \\
\hline $\mathrm{k}_{\mathrm{cytO}, \mathrm{NO} 2-}$ & $\begin{array}{l}\text { Rate constant for } \mathrm{NO}_{2}^{-} \text {generation by } \\
\text { cytochrome } \mathrm{c} \text { oxidase }\end{array}$ & 0.233 & $\mathrm{~s}^{-1}$ & [149] \\
\hline $\mathrm{k}_{\mathrm{NO} 3-}$ & Rate constant for $\mathrm{NO}_{3}^{-}$generation in & $0.6 \times \mathrm{k}_{\mathrm{bl}}$ & $\mathrm{s}^{-1}$ & text \\
\hline
\end{tabular}




\begin{tabular}{|c|c|c|c|c|}
\hline & blood & & & \\
\hline $\mathrm{V}_{\max } / \mathrm{K}_{\mathrm{m}}$ & GSNO transport constant & $1 \times 10^{-2}$ & $\mathrm{~s}^{-1}$ & [147] \\
\hline $\mathrm{Q}_{\mathrm{NO}, \max }$ & $\begin{array}{l}\text { Maximum NO generation at } \\
\text { boundaries }\end{array}$ & $2.65 \times 10^{-8}$ & $\mathrm{~mol} /\left(\mathrm{m}^{2} \times \mathrm{s}\right)$ & $\begin{array}{l}{[160,} \\
167]\end{array}$ \\
\hline $\mathrm{Q}_{\text {cap }}$ & $\begin{array}{l}\text { Apparent NO production rate in the } \\
\text { capillaries }\end{array}$ & $4.82 \times 10^{-7}$ & $\mathrm{M} \cdot \mathrm{s}^{-1}$ & {$[165]$} \\
\hline $\mathrm{Q}_{\mathrm{O} 2-\max }$ & Maximum rate of $\mathrm{O}_{2}^{-}$generation & $5 \times 10^{-6}$ & $M \cdot s^{-1}$ & {$[162]$} \\
\hline Het & Hematocrit & 0.45 & & \\
\hline $\mathrm{K}_{\mathrm{m}, \mathrm{eNOS}}$ & $\begin{array}{l}\text { O2 concentration for half maximum } \\
\text { eNOS activity. }\end{array}$ & 7.7 & $\mu \mathrm{M}$ & {$[168]$} \\
\hline $\mathrm{K}_{\mathrm{m}, \mathrm{nNOS}}$ & $\begin{array}{l}\mathrm{O}_{2} \text { concentration for half maximum } \\
\text { nNOS activity. }\end{array}$ & 23.2 & $\mu \mathrm{M}$ & {$[168]$} \\
\hline $\mathrm{K}_{\mathrm{m}, \mathrm{GSNO}}$ & $\begin{array}{l}\text { Km for copper lyase based GSNO } \\
\text { reduction }\end{array}$ & 12.4 & $\mu \mathrm{M}$ & [169] \\
\hline $\mathrm{V}_{\mathrm{m}, \mathrm{GSNO}}$ & $\begin{array}{l}\text { Vmax for copper lyase based GSNO } \\
\text { reduction }\end{array}$ & 3.68 & $\mu \mathrm{M} \cdot \mathrm{s}^{-1}$ & [169] \\
\hline $\mathrm{R}_{\mathrm{O} 2 \mathrm{ec}}$ & Consumption of $\mathrm{O}_{2}$ in endothelium & 54 & $\mu \mathrm{M} \cdot \mathrm{s}^{-1}$ & [162] \\
\hline $\mathrm{R}_{\mathrm{O} 2 \mathrm{v}(\max )}$ & Consumption of $\mathrm{O}_{2}$ in vascular wall & 5 & $\mu \mathrm{M} \cdot \mathrm{s}^{-1}$ & {$[162]$} \\
\hline $\mathrm{R}_{\mathrm{O} 2 \mathrm{t}(\max )}$ & Consumption of $\mathrm{O}_{2}$ in tissue & 50 & $\mu \mathrm{M} \cdot \mathrm{s}^{-1}$ & [162] \\
\hline $\mathrm{R}_{\mathrm{ec}, \mathrm{NO} 3-}$ & $\begin{array}{l}\text { Rate for } \mathrm{NO}_{3}{ }^{-} \text {consumption in } \\
\text { endothelium }\end{array}$ & $2.2 \times 10^{2}$ & $\mathrm{nM} \cdot \mathrm{s}^{-1}$ & {$[170]$} \\
\hline $\mathrm{R}_{\mathrm{ec}, \mathrm{NO} 2-}$ & Rate for $\mathrm{NO}_{2}^{-}$release by endothelium & $3.3 \times 10^{2}$ & $\mathrm{pM} \cdot \mathrm{s}^{-1}$ & {$[170]$} \\
\hline $\mathrm{C}_{\mathrm{O} 2}$ & $\mathrm{O}_{2}$ concentration in the lumen core & 78.5 & $\mu \mathrm{M}$ & \\
\hline $\mathrm{C}_{\mathrm{GSH}}$ & $\begin{array}{l}\text { Glutathione concentration from } \\
\text { endothelium to tissue }\end{array}$ & 5 & $\mathrm{mM}$ & \\
\hline $\mathrm{C}_{\mathrm{SOD}}$ & Superoxide Dismutase concentration & 1 & $\mu \mathrm{M}$ & \\
\hline $\mathrm{C}_{\mathrm{sGC}}$ & $\begin{array}{l}\text { sGC concentration in the smooth } \\
\text { muscle layer }\end{array}$ & 100 & $\mathrm{nM}$ & \\
\hline $\mathrm{C}_{\mathrm{sm}, \mathrm{NO} 2-}$ & $\mathrm{NO}_{2}{ }^{-}$concentration in SMC layer & $10-20$ & $\mu \mathrm{M}$ & \\
\hline
\end{tabular}

\subsection{3 $\mathrm{O}_{2}$ diffusion and consumption}

For $\mathrm{O}_{2}$ diffusion and consumption, the same equations as Eq. $(4.1 \mathrm{a}-4.1 \mathrm{c})$ were considered. Concentration of $\mathrm{O}_{2}$ was calculated by the relation $\mathrm{C}_{\mathrm{O} 2}=\alpha \times \mathrm{P}_{\mathrm{O} 2}$ where $\alpha$ is solubility of $\mathrm{O}_{2}$ in the tissue $\left(1.34 \mu \mathrm{M} /\right.$ Torr [171]) and $\mathrm{P}_{\mathrm{O} 2}$ is the partial pressure of $\mathrm{O}_{2}$ in tissue. A constant $\mathrm{P}_{\mathrm{O} 2}$ of $58.59 \mathrm{~mm} \mathrm{Hg}$ was selected for the $\mathrm{LC}$ and the $\mathrm{CF}$ regions [141], which is equivalent to a $\mathrm{C}_{02}$ of $78.5 \mu \mathrm{M}$ and a $60 \% \mathrm{O}_{2}$ saturation of blood. Endothelium $\mathrm{O}_{2}$ consumption was taken constant and $\mathrm{O}_{2}$ consumption in the arteriolar wall and tissue 
was modeled in a Michaelis-Menten fashion with maximum $\mathrm{O}_{2}$ consumption rates as shown in table 4.3. The equations as used by Buerk et al. [171] were followed:

$$
R_{O_{2}}=\frac{R_{O_{2 \max }} \times C_{O_{2}}}{C_{O_{2}}+A p p K_{m}}
$$

where $\mathrm{R}_{\mathrm{O} 2}$ is the rate of $\mathrm{O}_{2}$ consumption, $\mathrm{R}_{\mathrm{O} 2 \max }$ is the maximum rate of $\mathrm{O}_{2}$ consumption, $\mathrm{C}_{\mathrm{O} 2}$ is the local oxygen concentration and $\mathrm{AppK}_{\mathrm{m}}$ is the $\mathrm{O}_{2}$ concentration at half maximum consumption, which was modeled by

$$
A p p K_{m}=K_{m}\left(1+\frac{N O}{27 n M}\right)
$$

where $\mathrm{K}_{\mathrm{m}}$ is the Michaelis - Menten constant in the absence of NO (1.34 $\mu \mathrm{M}$ determined from an experimental $\mathrm{P}_{\mathrm{O} 2}$ of 1 Torr in the absence of $\left.\mathrm{NO}[172,173]\right)$.

\subsection{4 $\mathrm{NO}_{2}, \mathrm{~N}_{2} \mathrm{O}_{3}$, nitrite and nitrate formation, transport and consumption}

$\mathrm{NO}_{2}$ formation was accelerated in the tissue compartment by taking an NO autoxidation rate constant 10 times what was previously reported [147]. Nitrite formation in the CF layer and the plasma portion of the LC was modeled by the action of ceruloplasmin at rate constant that was calculated from the reported ceruloplasmin concentration $5 \mu \mathrm{M}$ by Shiva et al. [150] and a similar reaction of $\mathrm{Cu}^{2+}$ ions and NO in aqueous solutions reported by Tran et al. [159]. In the tissue, nitrite formation was modeled through the hydration reaction of an NO - ferricytochrome c complex at a rate constant reported by Sharpe et al. [20] and extrapolated for a ferricytochrome c concentration of $2 \mathrm{mM}$. $\mathrm{NO}_{2}$ radical was consumed through oxidation of GSH and the formation of $\mathrm{N}_{2} \mathrm{O}_{3}$, whereas $\mathrm{N}_{2} \mathrm{O}_{3}$ was consumed by hydrolysis. Nitrite steady state in the 
lumen was achieved by assuming a nitrite half-life in blood of about 110 seconds [174],

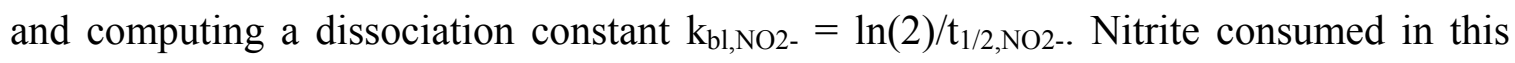
manner in the blood was assumed to produce NO. Nitrite reduction was also modeled in the SMC layer using a rate constant of $1.3 \times 10^{-2} \mathrm{~s}^{-1}$ as obtained in chapter 3 of this study. This was extended to the rest of the tissue compartments (EC, IG, NL and NPT) to obtain steady state therein, under the assumption that a nearly identical magnitude of nitrite reduction exists. Nitrate generation in blood was computed through a rate constant $\mathrm{k}_{\mathrm{NO3}-}$ based on saturation of blood (60\%). Nitrate steady state was achieved by assuming a nitrate half-life in blood of about 5.5 hours, and computing a dissociation constant $\mathrm{k}_{\mathrm{bl}, \mathrm{NO} O-}$ $=\ln (2) / t_{1 / 2, \mathrm{NO} 3 .}$. Diffusivity of nitrite and nitrate was assumed for the values of $\mathrm{NaNO}_{2}$ and $\mathrm{KNO}_{3}$ derived in pork tissue [161]. Although nitrite and nitrate are not believed to diffuse freely through cell membranes, these diffusivities were modeled to approximate nitrite and nitrate transport occurring through passive as well as channel mediated mechanisms. Diffusivity of $\mathrm{NO}_{2}$ in water was estimated from the diffusivity in water obtained by Chen et al. [175]. The property of inverse proportionality of diffusivity to viscosity of medium was used to calculate the diffusivities of $\mathrm{NO}_{2}$ in blood as follows:

$$
\frac{D_{b}}{D_{w}}=\frac{\eta_{w}}{\eta_{b}}
$$

where $D_{b}$ is diffusivity in blood, $D_{w}$ is the diffusivity in water, $\eta_{w}$ is the viscosity in water and $\eta_{\mathrm{b}}$ is the viscosity in blood. By using blood and water viscosities at $37^{\circ} \mathrm{C}(3$ and 0.7 $\mathrm{mPa} \cdot \mathrm{s}$ [176] respectively), $\mathrm{NO}_{2}$ diffusivity in blood was extrapolated from that in water 
$\left(2 \times 10^{-9} \mathrm{~m}^{2} / \mathrm{s}\right)$ to come to a value of $4.67 \times 10^{-10} \mathrm{~m}^{2} / \mathrm{s} . \mathrm{N}_{2} \mathrm{O}_{3}$ diffusivity was not available and therefore assumed to be the same as $\mathrm{NO}_{2}$.

\subsubsection{GSNO formation, transport and consumption}

The diffusion of GSNO and transport was followed as described by Shin et al. [147]. In chapter 2 of this work, we showed that GSNO formation was negligible through the $\mathrm{N}_{2} \mathrm{O}_{3}$ route. Consequently, GSNO formation was compared between two mechanisms: 1) a $\mathrm{NO}_{2}$ radical based nitrosation scheme as has been described in Chapter 2 of this work and 2) the process of ferricytochrome c reduction as has been described by Basu et al [151] and Broniowska et al [93]. According to the proposed mechanism for the $2^{\text {nd }}$ pathway, GSH binds first to ferricytochrome c followed by the binding of NO which reduces the ferric heme to ferrous state and releases GSNO. The observed kinetics of such a process indicate a first order reaction rate constant of $1.05 \times 10^{-3} \mathrm{~s}^{-1}$ for the formation of GSNO by the reduction of ferricytochrome c-GSH complex $(50 \mu \mathrm{M})$ with NO. The concentration of ferricytochrome c-GSH complex was considered constant. GSNO steady state was achieved by assuming a GSNO half-life in blood of about 5.5 hours, and computing a dissociation constant $\mathrm{k}_{\mathrm{bl}, \mathrm{GSNO}}=\ln (2) / \mathrm{t}_{1 / 2, \mathrm{GSNO}}$. NO release from GSNO reduction [169] was not implemented for the first phase of simulations attempting to model GSNO formation to see the extent of GSNO formed by these mechanisms independent of any consumption. This was implemented with distinct simulations by using a $\mathrm{V}_{\mathrm{m}, \mathrm{GSNO}}$ and $\mathrm{K}_{\mathrm{m}, \mathrm{GSNO}}$ mentioned in table 4.3 using constant GSNO concentrations based on reported levels of S-nitroso compounds in vascular tissue (40 nM, [42]). 


\subsubsection{Superoxide formation and scavenging}

Superoxide $\left(\mathrm{O}_{2}^{-}\right)$generation was modeled using the following relation from Buerk et al. [162] using the same assumptions of dependency on $\mathrm{O}_{2}$ and $\mathrm{NO}$ concentrations.

$$
Q_{O_{2}^{0^{-}}}=Q_{O_{2 \max }^{0^{-}}}\left(\frac{C_{O_{2}}}{C_{O_{2}}+A p p K_{m}}\right)
$$

Superoxide disumutase (SOD) was held constant at $1 \mu \mathrm{M}$ for the entire width of the tissue region (EC to PT). $\mathrm{O}_{2}{ }^{-}$and $\mathrm{NO}$ and $\mathrm{O}_{2}{ }^{-}$and GSNO interactions were modeled as mentioned in table 4.1 .

\subsubsection{Numerical methods}

The transport was modeled as partial differential equations on finite element modeling software package COMSOL 3.5 (Stockholm, Sweden) to analyze the transport of NO and other oxidative intermediates in the circulation. The time step was $0.1 \mathrm{~s}$ and the model was simulated for a period of 100 seconds. The relative tolerance for convergence was 0.001 while the absolute tolerance was 0.0001 . An extra fine mesh was used for all simulations, and partial differential equations were solved using a SParse Object Oriented Linear Equations Solver (SPOOLES).

\subsection{Results}

\subsubsection{Generating NO from SMC nitrite}

Smooth muscle cell nitrite has been reported to range from $10 \mu \mathrm{M}$ to $20 \mu \mathrm{M}[41$, 42]. To test NO generation within the SMC layer, concentrations of nitrite in the layer were varied between these ranges and held constant for the duration of the simulations. All other sources of NO were knocked out from the model, with NO consumption by arteriolar and capillary blood left as NO sinks. The rate constants related to these $\left(\mathrm{k}_{\text {blood }}\right.$ 
and $\mathrm{k}_{\mathrm{app}}$ ) were varied between their respective values for $\mathrm{RBC}$ permeabilities between 0.1 to $40 \mathrm{~cm} / \mathrm{s}$ which are probable limits for RBC permeabilities as suggested by Tsoukias et al [28]. NO consumption through sGC, and all other reactions in Table 4.1 were left unaltered. The resultant NO cross-profile plots generated are presented in Fig 4.1A - B. Peak NO generated in the SMC ranged from $1.5 \mathrm{nM}$ to $3.5 \mathrm{nM}$. This amount of NO might affect blood vessel tone given reported values for the $\mathrm{K}_{\mathrm{m}}$ of sGC from a few $\mathrm{nM}$ to hundreds of nM. Thus, physiological concentrations of nitrite might have an actual relevance in blood vessel vasodilation and examination of accumulation of such levels of nitrite might be an objective worth pursuing.
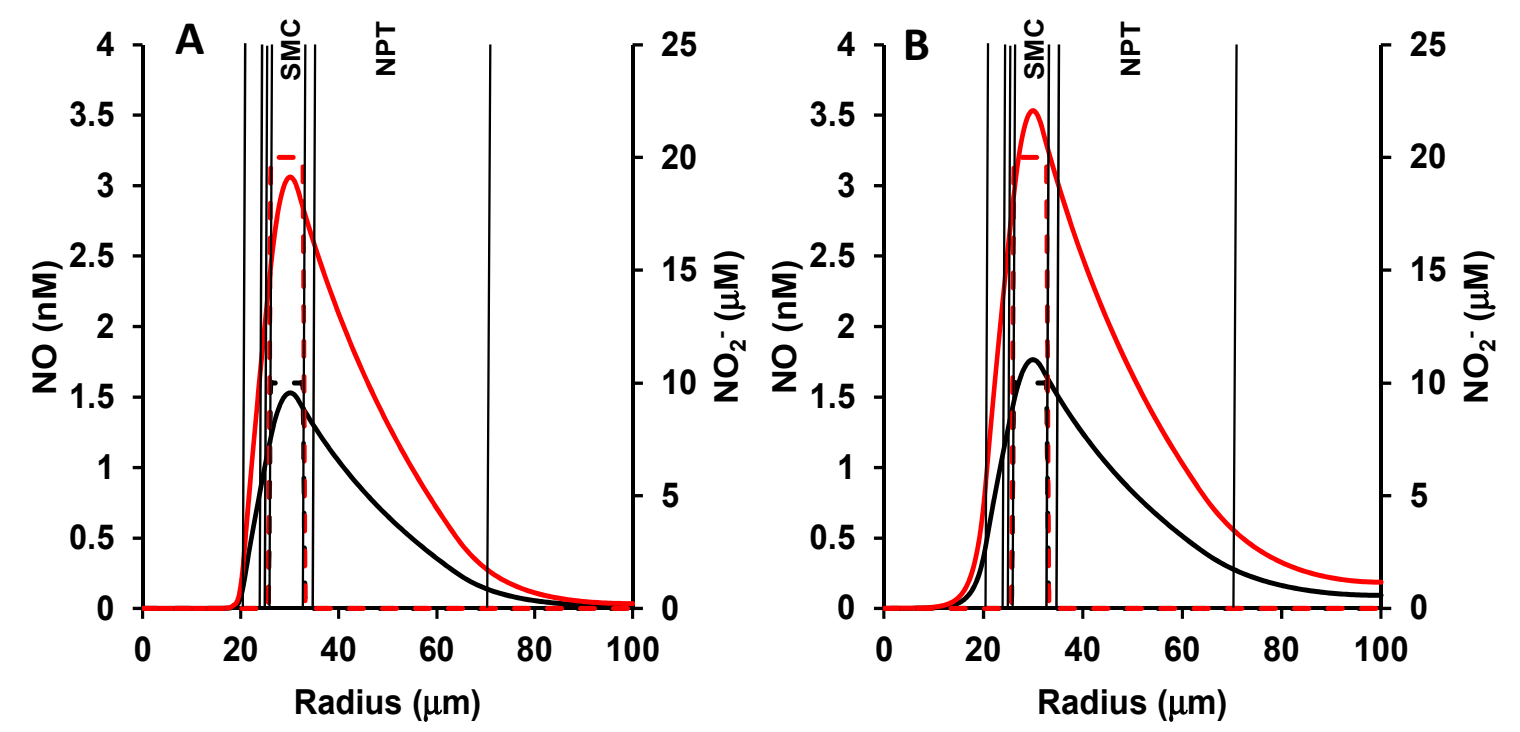

Fig 4.1: NO generated under steady state physiological nitrite conditions with NO consumption by blood and capillaries intact (A) NO from $10 \mu \mathrm{M}$ SMC nitrite (black line) and $20 \mu \mathrm{M} \mathrm{SMC}$ nitrite (red line) for first order NO consumption in blood at an RBC permeability of $40 \mathrm{~cm} / \mathrm{s}$ and (B) NO from $10 \mu \mathrm{M} \mathrm{SMC} \mathrm{nitrite} \mathrm{(black} \mathrm{line)} \mathrm{and} 20 \mu \mathrm{M}$ 
SMC nitrite (red line) for first order NO consumption in blood at an RBC permeability of $0.1 \mathrm{~cm} / \mathrm{s}$. Dashed lines in both instances indicate chosen constant $\mathrm{NO}_{2}{ }^{-}$concentrations.

\subsubsection{Production of physiological nitrite and nitrate}

Nitrate production was modeled by interaction of $\mathrm{NO}$ with oxyhemoglobin in the blood. Nitrite production was modeled by NO oxidation and enzymatic reactions in both blood and tissue compartments (EC - PT layers). Incorporating diffusivities of nitrate and nitrite mentioned in table 4.3 gives radial profiles of nitrite and nitrate as shown in A. The simulations estimate nitrate concentrations in the blood quite accurately $(21 \mu \mathrm{M}$ as compared to $28 \mu \mathrm{M}$ [177]) and hence were not altered further. Nitrite concentrations in the blood achieved mammalian levels (100s of nM [178]), however vascular tissue nitrite concentrations were far lower (normal levels: 10 to $20 \mu \mathrm{M}$ ). As shown in Fig $4.2 \mathrm{~B}$, diffusivities of nitrite have to be about 100 times or more lower than reported previously $\left(4.1 \times 10^{-12} \mathrm{~m}^{2} / \mathrm{s}\right.$ as compared to $4.1 \times 10^{-10} \mathrm{~m}^{2} / \mathrm{s}$ as suggested by Pinotti et al. [161]) to give a better fit to both tissue nitrite and lumen nitrite concentrations. 

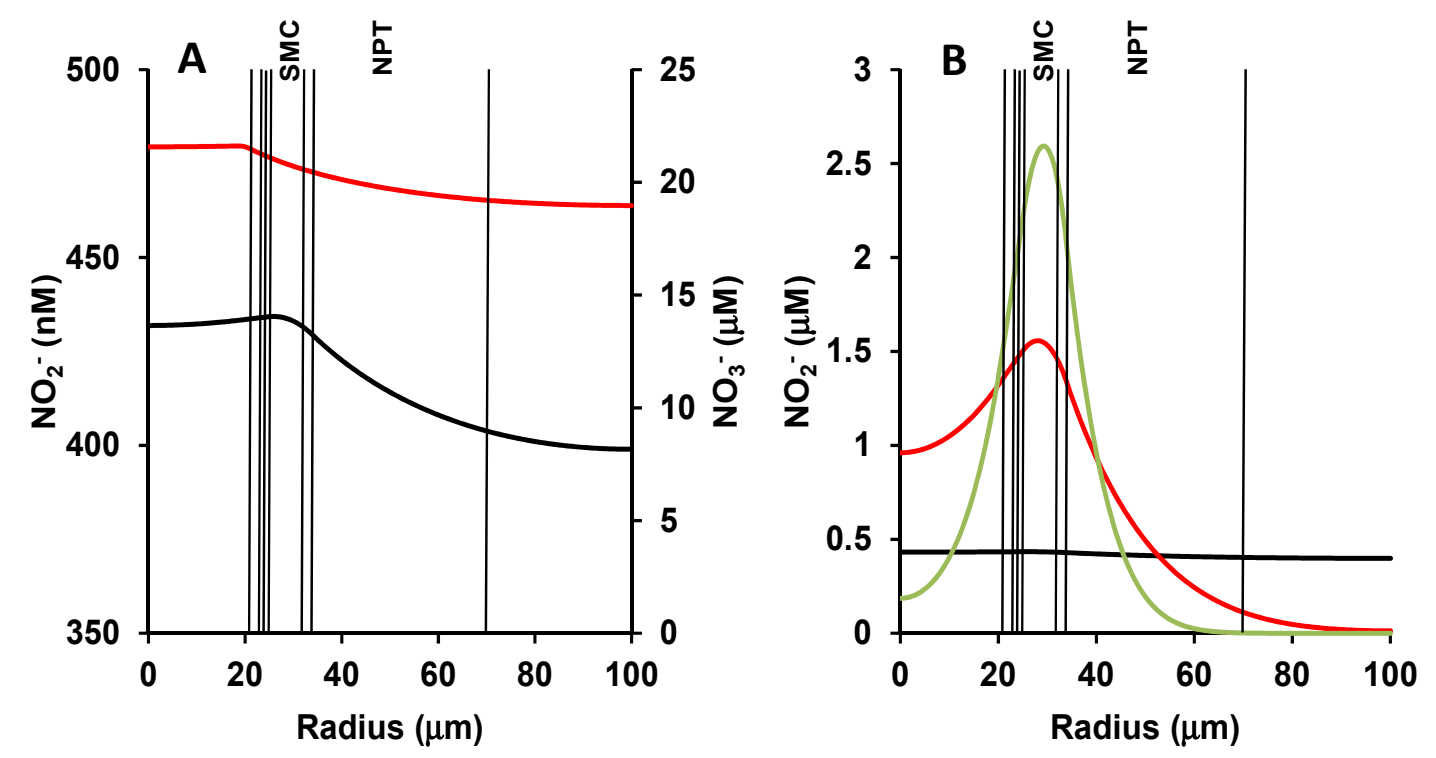

Fig 4.2: A: Radial profiles of nitrite (black line) and nitrate (red line) in the modeled region. B: Radial profiles of nitrite under control (black line), 50 times less (red line) and 100 times less (green line) nitrite diffusivities.

\subsubsection{NO from nitrite infused in blood vessels}

In most cases where nitrite reduction to NO is desired, nitrite was infused in the lumen of blood vessels. To observe significant vasodilation, hundreds of $\mu \mathrm{M}$ nitrite has to be supplied. To examine the impact of this, a constant nitrite of $200 \mu \mathrm{M}-5 \mathrm{mM}$ was introduced into the LC and CF layers of blood flow. Two extreme conditions were considered, one with nitrite reduced solely in the blood region (diffusion to the tissue was suspended) and the other in which nitrite in the blood region diffuses efficiently and equilibrates with tissue nitrite levels. The ability of RBCs to generate GSNO in the lumen was also analyzed for its capacity to transport NO generated from nitrite supplied in the lumen (Fig $4.3 \mathrm{~B}$ ) and only pM levels of GSNO were found to be made. In the second 
scenario of nitrite equilibration across arteriolar wall, a dose of $200 \mu \mathrm{M}$ nitrite was sufficient to give substantial vasodilation (NO produced in SMC layer was approximately $40 \mathrm{nM}$; Fig $4.3 \mathrm{C}$ ). From the simulations, it could be said that nitrite supplied in the lumen in ranges of a few $\mathrm{mM}$ is just as effective for controlling blood vessel tone as physiological nitrite in the SMC.
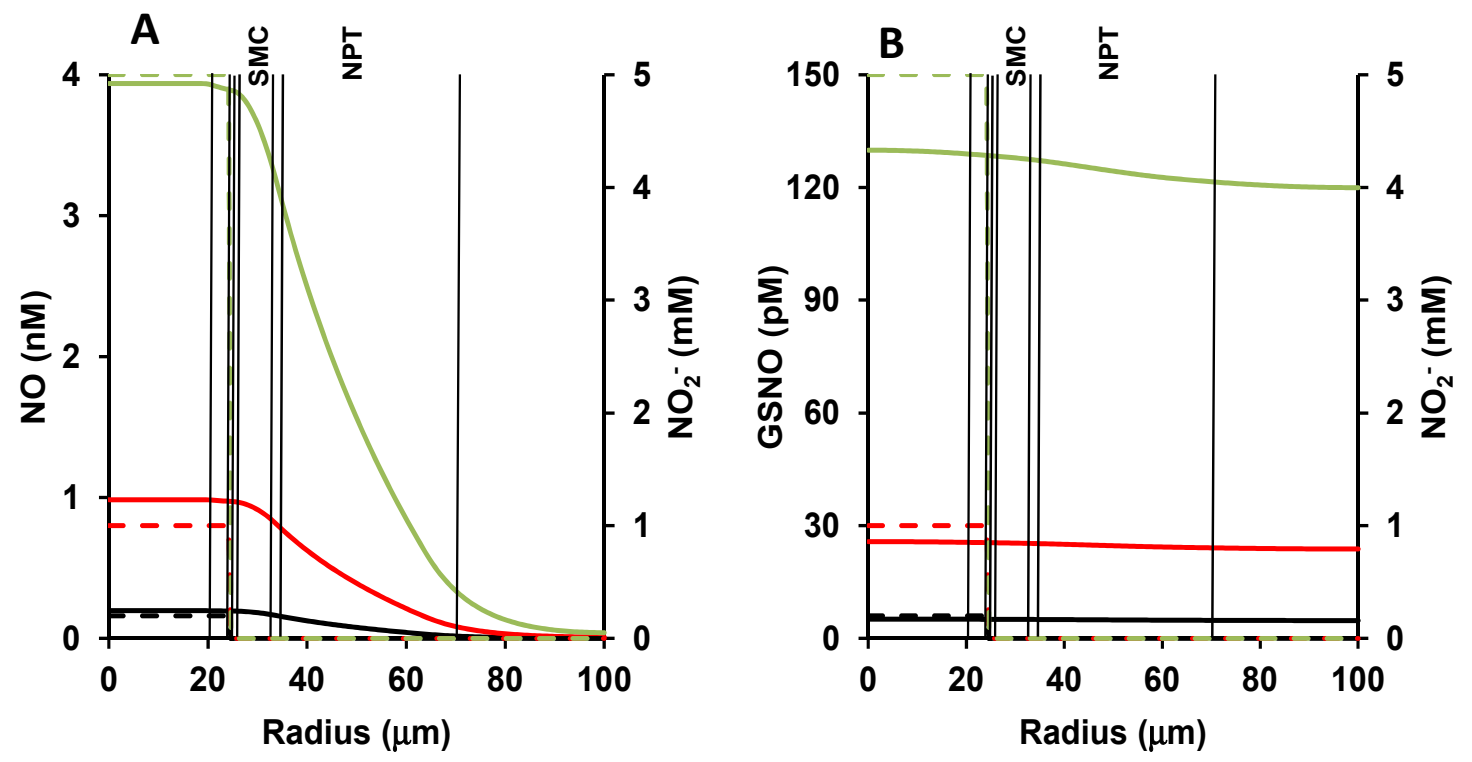


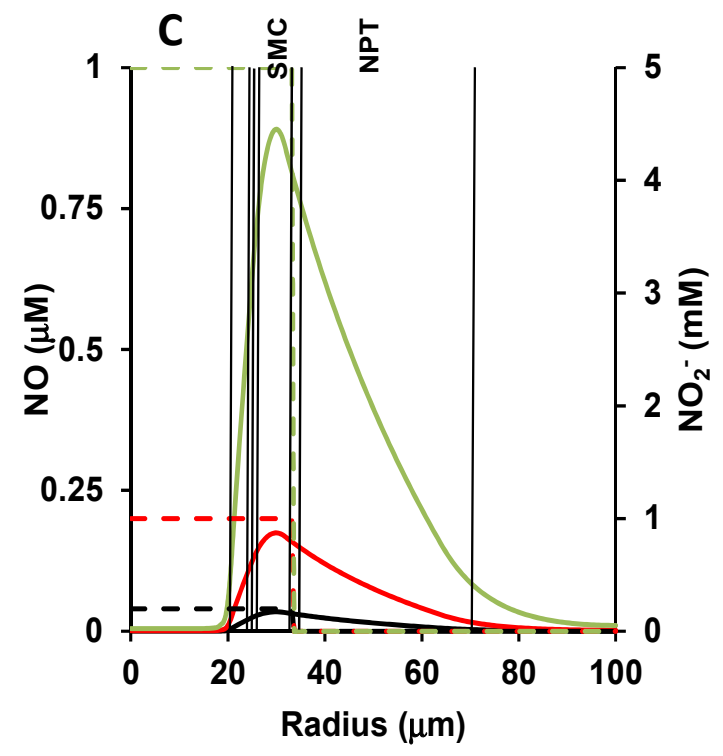

Fig 4.3: Supplying nitrite in the lumen A: NO generation solely by lumen nitrite for 200 $\mu \mathrm{M}$ (black line), $1 \mathrm{mM}$ (red line) and $5 \mathrm{mM}$ (green line) nitrite. B: GSNO generated solely by lumen nitrite for $200 \mu \mathrm{M}$ (black line), $1 \mathrm{mM}$ (red line) and $5 \mathrm{mM}$ (green line) nitrite. C: NO generation by lumen nitrite and SMC layer for $200 \mu \mathrm{M}$ (black line), $1 \mathrm{mM}$ (red line) and $5 \mathrm{mM}$ (green line) with equilibration across the arteriolar wall. Dashed lines in $\mathrm{A}, \mathrm{B}$ and $\mathrm{C}$ indicate chosen constant $\mathrm{NO}_{2}{ }^{-}$concentrations.

\subsubsection{Determining GSH nitrosation mechanism and NO released from GSNO}

Fig 4.4A shows the results of testing GSH nitrosation mechanism in terms of radial profiles of GSNO. The results show that GSNO produced without an anerobic scheme (red line) is much lower than GSNO produced with an anaerobic scheme (red line). Fig 4.4 B shows the NO produced by various constant GSNO levels (20 nM - 60 $\mathrm{nM}$ ) in the tissue for blood NO consumption rate constants corresponding to high permeabilities for RBCs $(40 \mathrm{~cm} / \mathrm{s})$. 

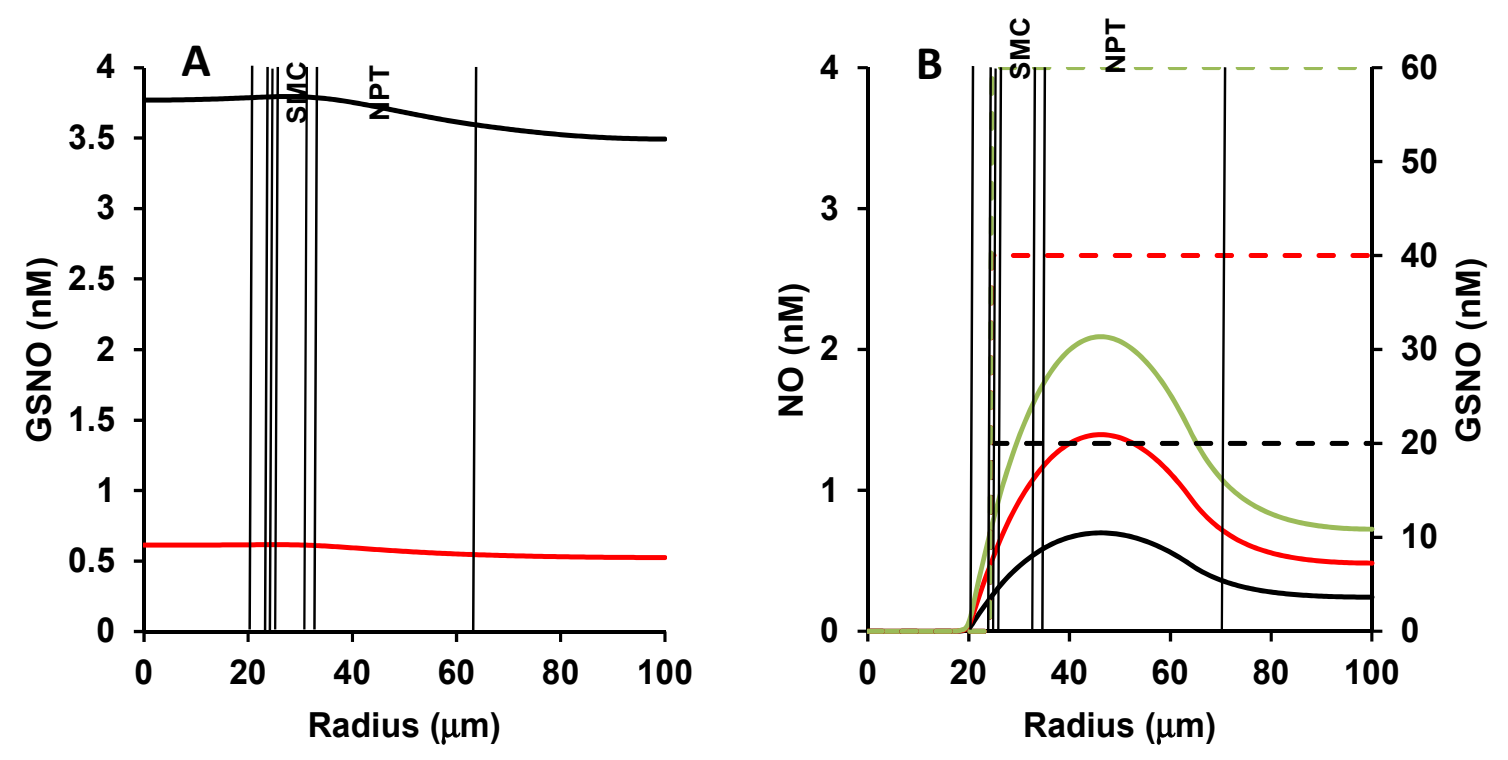

Fig 4.4: Change in GSNO concentration in the radial direction. A: through both pathways of nitrosation (red line) and without cytochrome $\mathrm{C}$ based GSNO production (black line) B: NO produced through constant GSNO concentrations: $20 \mathrm{nM}$ (black line), $40 \mathrm{nM}$ (red line) and $60 \mathrm{nM}$ (green line). Dashed lines in B indicate chosen constant GSNO concentrations.

\subsection{Discussion}

Earlier in chapter 3 of this work, we observed the hypothesis that sGC could reduce nitrite to NO. This appears to be a promising scheme for nitrite to act as an NO storage form, if nitrite can be converted to NO right at the site where its donor is present, the efficiency of transporting NO could be greatly increased. However, we had not studied whether NO produced through this mechanism is sufficient to control blood vessel tone. In this work, we expanded the NO biotransport model in the arteriole as explained by Tsoukias et al. [24] to include various NO oxidative intermediates, related physics to the extent possible, and nitrosation chemistry for the formation of GSNO. Using this model and the rate constant for nitrite reduction by SMC lysates obtained in 
chapter 3, we allowed the generation of NO under constant SMC nitrite alone and subjected NO produced to a theoretical analysis of sGC activation and $\mathrm{NO}$ consumption in vivo proposed by Tsoukias et al [24]. A few limitations exist in our study for instance the overall rate constant $\mathrm{k}_{\mathrm{ov}}$ in the smooth muscle that was calculated in chapter 3 and used here was determined in passaged cells whereas in primary cells or in intact vessels, this reaction might be more potent than observed here. Besides, any competitive inhibition from nitrate as was discussed in chapter 3 was not examined here for want of more verifications. Physiologically, nitrate in the tissues will be much higher than nitrite and it could be possible that the prevalent nitrate in smooth muscle layer could impede this reaction to some extent.

We next attempted to arrive at physiological concentrations of nitrate and nitrite in both arteriolar lumen and tissue. Our nitrate concentrations were able to closely approximate lumen nitrate concentrations and we were able to achieve half of reported vascular tissue nitrate concentrations. Current transport data was however not able to simulate vascular tissue nitrite concentrations appropriately. From our simulations, we propose that nitrite diffusivities in tissue have to be at least 100 times lower than previously reported. Pharmacological and physiological nitrite was also tested for NO formation and these were found to be inadequate in terms of $\mathrm{NO}$ generation in the smooth muscle layer except under ischemic conditions when complete diffusion of nitrite as $\mathrm{HNO}_{2}$ into the smooth muscle region is possible.

Another controversial issue that we sought to resolve in our model was the formation of nitrosothiols. Much work has been done in vitro on mechanisms causing 
nitrosation. Some have suggested the dominance of $\mathrm{N}_{2} \mathrm{O}_{3}$ in the nitrosation scheme, while others have suggested $\mathrm{NO}_{2}$ radical as the nitrosating intermediate, while in a recent work Basu et al. [151] have suggested a ferricytochrome $\mathrm{c}$ based nitrosation scheme. Our simulations show an indication that anaerobic nitrosation schemes have a greater potential to nitrosate thiols than the $\mathrm{NO}_{2}$ radical. However, our simulations are far from reported GSNO levels (100 $\mathrm{nM}$ in blood and $40 \mathrm{nM}$ in vascular tissue). It is likely that there are other anaerobic schemes of GSNO formation in vivo that are yet to be explored.

NO release from GSNO is a hotly debated topic, and in some cell based experiments, nitrite and nitrate have been shown to account for only $40 \%$ of products from an exposure of cells to GSNO [179] with intracellular nitrite retention only $1 \%$ of initial GSNO exposure, and therefore the likelihood of GSNO being a major NO producing agent in the circulation might be minimal. Nevertheless, we took constant GSNO concentrations in the tissue region and provide hypothetical scenarios for NO formation from GSNO as described by Gordge et al. [169] and we observe 0.8 to $2 \mathrm{nM}$ of NO being produced which might be capable of controlling blood vessel tone.

In conclusion, we have four major findings from this study. First, that physiological levels of nitrite in the smooth muscle region might be a partial contributor to smooth muscle NO. Secondly, smooth muscle nitrite might be locally generated and nitrite diffusivity in tissue should be low enough to allow nitrite retention. Third, pharmacological nitrite concentrations barely have any impact on smooth muscle NO except if reduced in tissue and fourth, $\mathrm{NO}_{2}$ is not an important nitrosating intermediate in vivo and other anaerobic schemes should be prominent players in nitrosation. 


\section{Chapter 5: Summary}

Nitric oxide (NO) has been known for its role of regulating vascular tone for a few decades. Its production has been found to be due to the presence of NOS enzymes in the vasculature. In the vicinity of NO production, there are what are called "sinks" according to biotransport sciences in the form of $\mathrm{Hb}$ in blood, other heme species in tissues, oxygen and various oxidase enzymes. Inspite of these, $\mathrm{NO}$ is able to be transported to the smooth muscle to activate its known biological receptor, the enzyme soluble Guanylate Cyclase. This problem is known in the field as NO paradox. Two mechanisms are proposed to resolve the NO paradox, one prevention of consumption of $\mathrm{NO}$ by $\mathrm{Hb}$ encapsulation in RBCs and two, generation of $\mathrm{NO}$ conserving species in the vasculature that may transport NO to a location distal to where it is produced. We sought to work towards that in our studies by observing prevention of $\mathrm{NO}$ consumption in $\mathrm{Hb}$ vesicles, which can be considered as 'lumps' of Hb encapsulated by phospholipid membranes and for the formation of NO conserving species such as nitrosothiols and nitrite and the ability of these to produce NO.

Our study involving nitrosation intermediates revealed an $\mathrm{NO}$ dependent $\mathrm{EC}_{50}$. It could thus be said that under continuous clamped NO delivery from intermediate half-life $\mathrm{NO}$ donors such as PAPA/NO and DEA/NO, $\mathrm{NO}_{2}$ is the more important nitrosating intermediate between $\mathrm{N}_{2} \mathrm{O}_{3}$ and $\mathrm{NO}_{2}$. Analyses from a pseudo steady state approximation using $\mathrm{NO}_{2}$ as the only nitrosating intermediate and a complex mathematical model of several chemical equations fitted our experimental data, thus further validating our experimental data. 
Next, we observed the possibility of recovering NO from nitrite by sGC and associated modulating factors. Recovering NO from nitrite at $\mathrm{sGC}$ appears promising since NO can be generated right where it is needed and thus the throughput of a probable system where NO signals endocrinally can improve dramatically. Towards this end, we cultured smooth muscle cells and observed nitrite reduction by whole cells and smooth muscle cell lysates. We were able to discern using agonists and antagonists that sGC could be a prominent nitrite reducing agent. Later, we analyzed nitrite transporting channels through the application of several anion channel blockers and found that nitrite transport takes place through the mediation of existing anion channels on smooth muscle cells. We were also able to observe the impacts of nitrate on nitrite reduction and transport and our studies have revealed that nitrate can significantly impact both. This would be an interesting area to explore for future enthusiasts in the field of nitrite reductase metalloproteins as it can significantly impact the throughput of any nitrite reductase based NO recovery system.

Lastly, we prepared a simple diffusion model to study the transport of NO oxidative species in a $50 \mu \mathrm{m}$ diameter arteriole as a means to test some of our experimental findings. We observed that reported levels of smooth muscle nitrite if held constant can deliver a low amplitude sustained NO level that might contribute towards a physiologically significant NO levels. We were able to model physiological nitrate concentrations to a fair approximation, while we suggested lower diffusivities for nitrite in tissue to allow for better fit with physiological data. We also showed that NO generated from nitrite delivery in arteriolar lumen is negligible compared to tissue nitrite 
and the prominent mechanisms for GSNO formation in- vivo are anaerobic. Future work in the field of NO paradox might involve further experimentation on intra layer nitrite and nitrate transport in arteriolar tissue, the $\mathrm{NO}$ - nitrate - nitrite cycle therein and several metalloproteins the importance of which has yet to be explored in the NO cycle (such as cytoglobin and different members of the cytochrome family). Thus, while it does not claim to have solved the "NO Paradox", the work presented in this dissertation has certainly made some bold steps in new directions. 


\section{REFERENCES}

1. Ignarro, L.J., et al., Endothelium-derived relaxing factor produced and released from artery and vein is nitric oxide. Proc Natl Acad Sci U S A, 1987. 84(24): p. 9265-9.

2. Bredt, D.S. and S.H. Snyder, Nitric oxide mediates glutamate-linked enhancement of cGMP levels in the cerebellum. Proc Natl Acad Sci U S A, 1989. 86(22): p. 9030-3.

3. Stuehr, D.J. and M.A. Marletta, Mammalian nitrate biosynthesis: mouse macrophages produce nitrite and nitrate in response to Escherichia coli lipopolysaccharide. Proc Natl Acad Sci U S A, 1985. 82(22): p. 7738-42.

4. Beckman, J.S. and W.H. Koppenol, Nitric oxide, superoxide, and peroxynitrite: the good, the bad, and ugly. Am J Physiol, 1996. 271(5 Pt 1): p. C1424-37.

5. Liu, Q. and S.S. Gross, Binding sites of nitric oxide synthases, in Methods in Enzymology, P. Lester, Editor. 1996, Academic Press. p. 311-324.

6. Moncada, S., R.M. Palmer, and E.A. Higgs, Nitric oxide: physiology, pathophysiology, and pharmacology. Pharmacol Rev, 1991. 43(2): p. 109-42.

7. Iganarro L. J., Signal Transduction Mechanisms Involving Nitric Oxide. Biochemical Pharmacology, 1991. 41: p. 485-490.

8. Twort, C.H. and C. van Breemen, Cyclic guanosine monophosphate-enhanced sequestration of $\mathrm{Ca} 2+$ by sarcoplasmic reticulum in vascular smooth muscle. Circ Res, 1988. 62(5): p. 961-4.

9. Waldman, S.A. and F. Murad, Cyclic GMP synthesis and function. Pharmacol Rev, 1987. 39(3): p. 163-96.

10. Hathaway, D.R., et al., Vascular smooth muscle. A review of the molecular basis of contractility. Circulation, 1991. 83(2): p. 382-90.

11. Bellamy, T.C., J. Wood, and J. Garthwaite, On the activation of soluble guanylyl cyclase by nitric oxide. Proceedings of the National Academy of Sciences, 2002. 99(1): p. 507-510.

12. Condorelli, P. and S.C. George, In vivo control of soluble guanylate cyclase activation by nitric oxide: a kinetic analysis. Biophys J, 2001. 80(5): p. 2110-9. 
13. Russwurm, M., et al., Functional properties of a naturally occurring isoform of soluble guanylyl cyclase. Biochem J, 1998. 335 ( Pt 1): p. 125-30.

14. Zhao, Y., et al., A molecular basis for nitric oxide sensing by soluble guanylate cyclase. Proc Natl Acad Sci U S A, 1999. 96(26): p. 14753-8.

15. Gordin, V.A. and A.A. Nedospasov, NO catastrophes in vivo as a result of micellar catalysis. FEBS Lett, 1998. 424(3): p. 239-42.

16. Liu, X., et al., Accelerated reaction of nitric oxide with $\mathrm{O} 2$ within the hydrophobic interior of biological membranes. Proc Natl Acad Sci U S A, 1998. 95(5): p. 2175-9.

17. Rafikova, O., R. Rafikov, and E. Nudler, Catalysis of S-nitrosothiols formation by serum albumin: the mechanism and implication in vascular control. Proc Natl Acad Sci U S A, 2002. 99(9): p. 5913-8.

18. Shiva S., W.X., Ringwood L. A., Xu X., Yuditskaya S., Annavajjhala V., Miyajima H., Hogg N., Harris Z. L., Gladwin M. T.,, Ceruloplasmin is a NO oxidase and nitrite synthase that determines endocrine NO homeostasis. Nat Chem Biol, 2006. 2: p. 486-493.

19. Orii, Y. and H. Shimada, Reaction of cytochrome $\mathrm{c}$ with nitrite and nitric oxide. A model of dissimilatory nitrite reductase. Journal of biochemistry, 1978. 84(6): p. $1542-1552$.

20. Sharpe, M.A. and C.E. Cooper, Reactions of nitric oxide with mitochondrial cytochrome c: a novel mechanism for the formation of nitroxyl anion and peroxynitrite. Biochem J, 1998. 332 ( Pt 1): p. 9-19.

21. Brunori, M., Nitric oxide, cytochrome-c oxidase and myoglobin. Trends Biochem Sci, 2001. 26(1): p. 21-3.

22. Ortega Mateo, A. and A. Amaya Aleixandre de, Nitric oxide reactivity and mechanisms involved in its biological effects. Pharmacol Res, 2000. 42(5): p. 421-7.

23. Lancaster, J.R., Jr., Simulation of the diffusion and reaction of endogenously produced nitric oxide. Proc Natl Acad Sci U S A, 1994. 91(17): p. 8137-41.

24. Tsoukias, N.M., M. Kavdia, and A.S. Popel, A theoretical model of nitric oxide transport in arterioles: frequency- vs. amplitude-dependent control of cGMP formation. Am J Physiol Heart Circ Physiol, 2004. 286(3): p. H1043-56. 
25. Butler, A.R., I.L. Megson, and P.G. Wright, Diffusion of nitric oxide and scavenging by blood in the vasculature. Biochim Biophys Acta, 1998. 1425(1): p. $168-76$.

26. Vaughn, M.W., L. Kuo, and J.C. Liao, Effective diffusion distance of nitric oxide in the microcirculation. Am J Physiol, 1998. 274(5 Pt 2): p. H1705-14.

27. Liu, X., et al., Diffusion-limited reaction of free nitric oxide with erythrocytes. J Biol Chem, 1998. 273(30): p. 18709-13.

28. Tsoukias, N.M. and A.S. Popel, Erythrocyte consumption of nitric oxide in presence and absence of plasma-based hemoglobin. Am J Physiol Heart Circ Physiol, 2002. 282(6): p. H2265-77.

29. Huxley, V.H. and H. Kutchai, The effect of the red cell membrane and a diffusion boundary layer on the rate of oxygen uptake by human erythrocytes. J Physiol, 1981. 316: p. 75-83.

30. Coin, J.T. and J.S. Olson, The rate of oxygen uptake by human red blood cells. J Biol Chem, 1979. 254(4): p. 1178-90.

31. Vaughn, M.W., et al., Erythrocytes possess an intrinsic barrier to nitric oxide consumption. J Biol Chem, 2000. 275(4): p. 2342-8.

32. Vaughn, M.W., et al., Erythrocyte consumption of nitric oxide: competition experiment and model analysis. Nitric Oxide, 2001. 5(1): p. 18-31.

33. Huang, K.T., et al., Modulation of nitric oxide bioavailability by erythrocytes. Proc Natl Acad Sci U S A, 2001. 98(20): p. 11771-6.

34. Deonikar, P. and M. Kavdia, Extracellular diffusion and permeability effects on NO-RBCs interactions using an experimental and theoretical model. Microvasc Res, 2010. 79(1): p. 47-55.

35. Sakai, H., et al., Encapsulation of concentrated hemoglobin solution in phospholipid vesicles retards the reaction with $\mathrm{NO}$, but not $\mathrm{CO}$, by intracellular diffusion barrier. J Biol Chem, 2008. 283(3): p. 1508-17.

36. Ignarro, L.J., et al., Mechanism of vascular smooth muscle relaxation by organic nitrates, nitrites, nitroprusside and nitric oxide: evidence for the involvement of Snitrosothiols as active intermediates. J Pharmacol Exp Ther, 1981. 218(3): p. 73949. 
37. Stamler, J.S., et al., S-nitrosylation of proteins with nitric oxide: synthesis and characterization of biologically active compounds. Proc Natl Acad Sci U S A, 1992. 89(1): p. 444-8.

38. Satoh, S., et al., Involvement of L-type-like amino acid transporters in Snitrosocysteine-stimulated noradrenaline release in the rat hippocampus. J Neurochem, 1997. 69(5): p. 2197-205.

39. Jia, L., et al., S-nitrosohaemoglobin: a dynamic activity of blood involved in vascular control. Nature, 1996. 380(6571): p. 221-226.

40. Zhang, Y. and N. Hogg, The mechanism of transmembrane S-nitrosothiol transport. Proc Natl Acad Sci U S A, 2004. 101(21): p. 7891-6.

41. Cosby, K., et al., Nitrite reduction to nitric oxide by deoxyhemoglobin vasodilates the human circulation. Nat Med, 2003. 9(12): p. 1498-505.

42. Rodriguez, J., et al., Chemical nature of nitric oxide storage forms in rat vascular tissue. Proc Natl Acad Sci U S A, 2003. 100(1): p. 336-41.

43. Millar, T.M., et al., Xanthine oxidoreductase catalyses the reduction of nitrates and nitrite to nitric oxide under hypoxic conditions. FEBS Lett, 1998. 427(2): p. 225-8.

44. Millar, T.M., C.R. Stevens, and D.R. Blake, Xanthine oxidase can generate nitric oxide from nitrate in ischaemia. Biochem Soc Trans, 1997. 25(3): p. 528S.

45. Zweier, J.L., A. Samouilov, and P. Kuppusamy, Non-enzymatic nitric oxide synthesis in biological systems. Biochim Biophys Acta, 1999. 1411(2-3): p. 25062 .

46. Zweier, J.L., et al., Enzyme-independent formation of nitric oxide in biological tissues. Nat Med, 1995. 1(8): p. 804-9.

47. Doyle, M.P., et al., Kinetics and mechanism of the oxidation of human deoxyhemoglobin by nitrites. J Biol Chem, 1981. 256(23): p. 12393-8.

48. Alzawahra, W.F., et al., Heme proteins mediate the conversion of nitrite to nitric oxide in the vascular wall. Am J Physiol Heart Circ Physiol, 2008. 295(2): p. H499-508.

49. Furchgott, R.F. and J.V. Zawadzki, The obligatory role of endothelial cells in the relaxation of arterial smooth muscle by acetylcholine. Nature, 1980. 288(5789): p. $373-6$. 
50. Palmer, R.M., A.G. Ferrige, and S. Moncada, Nitric oxide release accounts for the biological activity of endothelium-derived relaxing factor. Nature, 1987. 327(6122): p. 524-6.

51. Eich, R.F., et al., Mechanism of NO-induced oxidation of myoglobin and hemoglobin. Biochemistry, 1996. 35(22): p. 6976-83.

52. Herold, S., M. Exner, and T. Nauser, Kinetic and mechanistic studies of the NO*mediated oxidation of oxymyoglobin and oxyhemoglobin. Biochemistry, 2001. 40(11): p. 3385-95.

53. Meister, A. and M.E. Anderson, GLUTATHIONE. Annual Review of Biochemistry, 1983. 52: p. 711-760.

54. Keshive, M., et al., Kinetics of S-nitrosation of thiols in nitric oxide solutions. Chem Res Toxicol, 1996. 9(6): p. 988-93.

55. Kharitonov, V.G., A.R. Sundquist, and V.S. Sharma, Kinetics of nitrosation of thiols by nitric oxide in the presence of oxygen. J Biol Chem, 1995. 270(47): p. 28158-64.

56. Wink, D.A., et al., Reactions of the bioregulatory agent nitric oxide in oxygenated aqueous media: determination of the kinetics for oxidation and nitrosation by intermediates generated in the NO/O2 reaction. Chem Res Toxicol, 1993. 6(1): p. $23-7$.

57. Wink, D.A., et al., Reaction kinetics for nitrosation of cysteine and glutathione in aerobic nitric oxide solutions at neutral $\mathrm{pH}$. Insights into the fate and physiological effects of intermediates generated in the $\mathrm{NO} / \mathrm{O} 2$ reaction. Chem Res Toxicol, 1994. 7(4): p. 519-25.

58. Jourd'heuil, D., F.L. Jourd'heuil, and M. Feelisch, Oxidation and nitrosation of thiols at low micromolar exposure to nitric oxide. Evidence for a free radical mechanism. J Biol Chem, 2003. 278(18): p. 15720-6.

59. Keszler, A., Y. Zhang, and N. Hogg, Reaction between nitric oxide, glutathione, and oxygen in the presence and absence of protein: How are S-nitrosothiols formed? Free Radic Biol Med, 2010. 48(1): p. 55-64.

60. Nedospasov, A.A., Is N2O3 the main nitrosating intermediate in aerated nitric oxide (NO) solutions in vivo? If so, where, when, and which one? J Biochem Mol Toxicol, 2002. 16(3): p. 109-20.

61. Schrammel, A., et al., S-nitrosation of glutathione by nitric oxide, peroxynitrite, and $\bullet \mathrm{NO} / \mathrm{O} 2 \cdot-$. Free Radical Biology and Medicine, 2003. 34(8): p. 1078-1088. 
62. Field, L., et al., An unusually stable thionitrite from N-acetyl-D,L-penicillamine; $\mathrm{X}$-ray crystal and molecular structure of 2-(acetylamino)-2-carboxy-1,1dimethylethyl thionitrite. Journal of the Chemical Society, Chemical Communications, 1978(6): p. 249-250.

63. Williams, D.L., S-nitrosothiols and role of metal ions in decomposition to nitric oxide. Methods Enzymol, 1996. 268: p. 299-308.

64. Fang, K., et al., Reductive assays for S-nitrosothiols: implications for measurements in biological systems. Biochem Biophys Res Commun, 1998. 252(3): p. 535-40.

65. Gaston, B., et al., Bronchodilator S-nitrosothiol deficiency in asthmatic respiratory failure. Lancet, 1998. 351(9112): p. 1317-9.

66. Gorren, A.C., et al., Decomposition of S-nitrosoglutathione in the presence of copper ions and glutathione. Arch Biochem Biophys, 1996. 330(2): p. 219-28.

67. Samouilov, A. and J.L. Zweier, Development of chemiluminescence-based methods for specific quantitation of nitrosylated thiols. Anal Biochem, 1998. 258(2): p. 322-30.

68. Saville, B., A scheme for the colorimetric determination of microgram amounts of thiols. Analyst, 1958. 83(993): p. 670-672.

69. Griffiths, C., et al., A new and simple method for delivering clamped nitric oxide concentrations in the physiological range: application to activation of guanylyl cyclase-coupled nitric oxide receptors. Mol Pharmacol, 2003. 64(6): p. 1349-56.

70. Keefer, L.K., et al., "NONOates" (1-substituted diazen-1-ium-1,2-diolates) as nitric oxide donors: Convenient nitric oxide dosage forms, in Methods in Enzymology, P. Lester, Editor. 1996, Academic Press. p. 281-293.

71. Maragos, C.M., et al., Complexes of .NO with nucleophiles as agents for the controlled biological release of nitric oxide. Vasorelaxant effects. Journal of Medicinal Chemistry, 1991. 34(11): p. 3242-3247.

72. Li, Q. and J.R. Lancaster Jr, Calibration of nitric oxide flux generation from diazeniumdiolate NO donors. Nitric Oxide, 2009. 21(1): p. 69-75.

73. Thomas, D.D., et al., Guide for the use of nitric oxide (NO) donors as probes of the chemistry of NO and related redox species in biological systems, in Methods in Enzymology, L.P. Enrique Cadenas, Editor. 2002, Academic Press. p. 84-105. 
74. Ford, E., M.N. Hughes, and P. Wardman, Kinetics of the reactions of nitrogen dioxide with glutathione, cysteine, and uric acid at physiological $\mathrm{pH}$. Free Radical Biology and Medicine, 2002. 32(12): p. 1314-1323.

75. Goldstein, S. and G. Czapski, Mechanism of the Nitrosation of Thiols and Amines by Oxygenated $\cdot \mathrm{NO}$ Solutions: the Nature of the Nitrosating Intermediates. Journal of the American Chemical Society, 1996. 118(14): p. 3419-3425.

76. Goldstein, S. and G. Czapski, Kinetics of Nitric Oxide Autoxidation in Aqueous Solution in the Absence and Presence of Various Reductants. The Nature of the Oxidizing Intermediates. Journal of the American Chemical Society, 1995. 117(49): p. 12078-12084.

77. Czapski, G. and S. Goldstein, The role of the reactions of $\cdot \mathrm{NO}$ with superoxide and oxygen in biological systems: A kinetic approach. Free Radical Biology and Medicine, 1995. 19(6): p. 785-794.

78. Schwartz, S.E., Trace atmospheric constituents: properties, transformations, and fates. Related Information: Wiley Series in Advances in Environmental Science and Technology Vol. 12. 1983. Medium: X; Size: Pages: 560.

79. Madej, E., et al., Thiyl radicals react with nitric oxide to form S-nitrosothiols with rate constants near the diffusion-controlled limit. Free Radical Biology and Medicine, 2008. 44(12): p. 2013-2018.

80. Wardman P., Evaluation of the "radical sink" hypothesis from a chemical-kinetic viewpoint. J Radioanal Nucl Chem, 1998. 232: p. 23-27.

81. Lancaster, J.R., Nitroxidative, Nitrosative, and Nitrative Stress: Kinetic Predictions of Reactive Nitrogen Species Chemistry Under Biological Conditions. Chemical Research in Toxicology, 2006. 19(9): p. 1160-1174.

82. Wardman, P. and C. von Sonntag, Kinetic factors that control the fate of thiyl radicals in cells. Methods Enzymol, 1995. 251: p. 31-45.

83. Wood, P.D., B. Mutus, and R.W. Redmond, The Mechanism of Photochemical Release of Nitric Oxide from S-Nitrosoglutathione. Photochemistry and Photobiology, 1996. 64(3): p. 518-524.

84. Carroll, R.T., et al., 4-Hydroxy-2,2,6,6-tetramethylpiperidine-1-oxyl (Tempol) Inhibits Peroxynitrite-Mediated Phenol Nitration. Chemical Research in Toxicology, 2000. 13(4): p. 294-300.

85. Hogg, N., R.J. Singh, and B. Kalyanaraman, The role of glutathione in the transport and catabolism of nitric oxide. FEBS Letters, 1996. 382(3): p. 223-228. 
86. Koshiishi, I., T. Takajo, and K. Tsuchida, Regulation of S-thiolation and Snitrosylation in the thiol/nitric oxide system by radical scavengers. Nitric Oxide, 2007. 16(3): p. 356-361.

87. Goss, S.P., et al., Reactions of *NO, *NO2 and peroxynitrite in membranes: physiological implications. Free Radic Res, 1999. 31(6): p. 597-606.

88. Nedospasov, A.A., Competition involving biogenic NO. Biochemistry (Mosc), 1998. 63(7): p. 744-65.

89. Thomas, D.D., et al., Heme proteins and nitric oxide (NO): the neglected, eloquent chemistry in NO redox signaling and regulation. Antioxid Redox Signal, 2003. 5(3): p. 307-17.

90. HOOPER, D.C., et al., Uric acid, a peroxynitrite scavenger, inhibits CNS inflammation, blood-CNS barrier permeability changes, and tissue damage in a mouse model of multiple sclerosis. The FASEB Journal, 2000. 14(5): p. 691-698.

91. Rubbo, H., et al., Nitric Oxide Inhibition of Lipoxygenase-Dependent Liposome and Low-Density Lipoprotein Oxidation: Termination of Radical Chain Propagation Reactions and Formation of Nitrogen-Containing Oxidized Lipid Derivatives. Archives of Biochemistry and Biophysics, 1995. 324(1): p. 15-25.

92. Basu, S., et al., A novel role for cytochrome c: Efficient catalysis of S-nitrosothiol formation. Free Radical Biology and Medicine, 2010. 48(2): p. 255-263.

93. Broniowska, K.A., et al., Cytochrome c-mediated formation of S-nitrosothiol in cells. Biochem J, 2012. 442(1): p. 191-7.

94. Bosworth, C.A., et al., Dinitrosyliron complexes and the mechanism(s) of cellular protein nitrosothiol formation from nitric oxide. Proceedings of the National Academy of Sciences, 2009. 106(12): p. 4671-4676.

95. Inoue, K., et al., Nitrosothiol Formation Catalyzed by Ceruloplasmin. Journal of Biological Chemistry, 1999. 274(38): p. 27069-27075.

96. Luchsinger, B.P., et al., Routes to S-nitroso-hemoglobin formation with heme redox and preferential reactivity in the $\beta$ subunits. Proceedings of the National Academy of Sciences, 2003. 100(2): p. 461-466.

97. Weichsel, A., et al., Heme-assisted S-nitrosation of a proximal thiolate in a nitric oxide transport protein. Proceedings of the National Academy of Sciences of the United States of America, 2005. 102(3): p. 594-599. 
98. Tiso, M., et al., Human neuroglobin functions as a redox-regulated nitrite reductase. J Biol Chem. 286(20): p. 18277-89.

99. Shiva, S., et al., Deoxymyoglobin is a nitrite reductase that generates nitric oxide and regulates mitochondrial respiration. Circ Res, 2007. 100(5): p. 654-61.

100. Zhang, Z., et al., Generation of nitric oxide by a nitrite reductase activity of xanthine oxidase: a potential pathway for nitric oxide formation in the absence of nitric oxide synthase activity. Biochem Biophys Res Commun, 1998. 249(3): p. 767-72.

101. Li, H., T.K. Kundu, and J.L. Zweier, Characterization of the magnitude and mechanism of aldehyde oxidase-mediated nitric oxide production from nitrite. $\mathrm{J}$ Biol Chem, 2009. 284(49): p. 33850-8.

102. Aamand, R., et al., Generation of nitric oxide from nitrite by carbonic anhydrase: a possible link between metabolic activity and vasodilation. Am J Physiol Heart Circ Physiol, 2009. 297(6): p. H2068-74.

103. Castello, P.R., et al., Mitochondrial cytochrome oxidase produces nitric oxide under hypoxic conditions: implications for oxygen sensing and hypoxic signaling in eukaryotes. Cell Metab, 2006. 3(4): p. 277-87.

104. Li, H., et al., Characterization of the mechanism of cytochrome P450 reductasecytochrome P450-mediated nitric oxide and nitrosothiol generation from organic nitrates. J Biol Chem, 2006. 281(18): p. 12546-54.

105. Duranski, M.R., et al., Cytoprotective effects of nitrite during in vivo ischemiareperfusion of the heart and liver. J Clin Invest, 2005. 115(5): p. 1232-40.

106. Webb, A., et al., Reduction of nitrite to nitric oxide during ischemia protects against myocardial ischemia-reperfusion damage. Proc Natl Acad Sci U S A, 2004. 101(37): p. 13683-8.

107. Huang, Z., et al., Enzymatic function of hemoglobin as a nitrite reductase that produces NO under allosteric control. J Clin Invest, 2005. 115(8): p. 2099-107.

108. Rassaf, T., et al., Nitrite reductase function of deoxymyoglobin: oxygen sensor and regulator of cardiac energetics and function. Circ Res, 2007. 100(12): p. 1749-54.

109. Cruickshank, S.F., L.M. Baxter, and R.M. Drummond, The Cl(-) channel blocker niflumic acid releases $\mathrm{Ca}(2+)$ from an intracellular store in rat pulmonary artery smooth muscle cells. Br J Pharmacol, 2003. 140(8): p. 1442-50. 
110. Brosius, F.C., 3rd, et al., AE anion exchanger mRNA and protein expression in vascular smooth muscle cells, aorta, and renal microvessels. Am J Physiol, 1997. 273(6 Pt 2): p. F1039-47.

111. Price, K.L., et al., Human vascular smooth muscle cells express a urate transporter. J Am Soc Nephrol, 2006. 17(7): p. 1791-5.

112. Vitturi, D.A., et al., Regulation of nitrite transport in red blood cells by hemoglobin oxygen fractional saturation. Am J Physiol Heart Circ Physiol, 2009. 296(5): p. H1398-407.

113. Chen, W., H. Tong, and H. Liu, Effects of nitrate on nitrite toxicity to Microcystis aeruginosa. Mar Pollut Bull, 2012. 64(6): p. 1106-11.

114. McQuade, L.E., et al., Visualization of nitric oxide production in the mouse main olfactory bulb by a cell-trappable copper(II) fluorescent probe. Proc Natl Acad Sci U S A. 107(19): p. 8525-30.

115. Feelisch, M., et al., Concomitant S-, N-, and heme-nitros(yl)ation in biological tissues and fluids: implications for the fate of NO in vivo. FASEB J, 2002. 16(13): p. 1775-85.

116. Bradford, M.M., A rapid and sensitive method for the quantitation of microgram quantities of protein utilizing the principle of protein-dye binding. Anal Biochem, 1976. 72: p. 248-54.

117. Motterlini, R., et al., Carbon Monoxide-Releasing Molecules. Circulation Research, 2002. 90(2): p. e17-e24.

118. Humphreys, B.D., et al., Functional characterization and regulation by $\mathrm{pH}$ of murine AE2 anion exchanger expressed in Xenopus oocytes. Am J Physiol, 1994. 267(5 Pt 1): p. C1295-307.

119. Feelisch, M., et al., Tissue processing of nitrite in hypoxia: an intricate interplay of nitric oxide-generating and -scavenging systems. J Biol Chem, 2008. 283(49): p. 33927-34.

120. Mittal, C.K., W.P. Arnold, and F. Murad, Characterization of protein inhibitors of guanylate cyclase activation from rat heart and bovine lung. J Biol Chem, 1978. 253(4): p. 1266-71.

121. Deinum, G., et al., Binding of nitric oxide and carbon monoxide to soluble guanylate cyclase as observed with Resonance raman spectroscopy. Biochemistry, 1996. 35(5): p. 1540-7. 
122. Schelvis, J.P., et al., Resonance raman characterization of the heme domain of soluble guanylate cyclase. Biochemistry, 1998. 37(46): p. 16289-97.

123. Stone, J.R. and M.A. Marletta, Soluble Guanylate Cyclase from Bovine Lung: Activation with Nitric Oxide and Carbon Monoxide and Spectral Characterization of the Ferrous and Ferric States. Biochemistry, 1994. 33(18): p. 5636-5640.

124. Zhao Y., B.P.E., Ballou D. P., Marletta M. A., A molecular basis for nitric oxide sensing by soluble guanylate cyclase. Proc. Natl. Acad. Sci. USA, 1999. 96: p. 14753-14758.

125. Li, H., et al., Nitric oxide production from nitrite occurs primarily in tissues not in the blood: critical role of xanthine oxidase and aldehyde oxidase. J Biol Chem, 2008. 283(26): p. 17855-63.

126. Alef, M.J., et al., Nitrite-generated NO circumvents dysregulated arginine/NOS signaling to protect against intimal hyperplasia in Sprague-Dawley rats. J Clin Invest. 121(4): p. 1646-56.

127. Shingles, R., M.H. Roh, and R.E. McCarty, Direct measurement of nitrite transport across erythrocyte membrane vesicles using the fluorescent probe, 6methoxy-N-(3-sulfopropyl) quinolinium. J Bioenerg Biomembr, 1997. 29(6): p. 611-6.

128. Vaziri, N.D., Z. Ni, and F. Oveisi, Upregulation of renal and vascular nitric oxide synthase in young spontaneously hypertensive rats. Hypertension, 1998. 31(6): p. $1248-54$.

129. Kelm, M., et al., Role of nitric oxide in the regulation of coronary vascular tone in hearts from hypertensive rats. Maintenance of nitric oxide-forming capacity and increased basal production of nitric oxide. Hypertension, 1995. 25(2): p. 186-93.

130. Fukumura, D., et al., Role of nitric oxide in tumor microcirculation. Blood flow, vascular permeability, and leukocyte-endothelial interactions. Am J Pathol, 1997. 150(2): p. 713-25.

131. Radomski, M.W., R.M. Palmer, and S. Moncada, Modulation of platelet aggregation by an L-arginine-nitric oxide pathway. Trends Pharmacol Sci, 1991. 12(3): p. $87-8$.

132. Radomski, M.W., et al., Platelet adhesion to human vascular endothelium is modulated by constitutive and cytokine induced nitric oxide. Cardiovasc Res, 1993. 27(7): p. 1380-2. 
133. Marks, D.S., et al., Inhibition of neointimal proliferation in rabbits after vascular injury by a single treatment with a protein adduct of nitric oxide. J Clin Invest, 1995. 96(6): p. 2630-8.

134. Arnold, W.P., et al., Nitric oxide activates guanylate cyclase and increases guanosine 3':5'-cyclic monophosphate levels in various tissue preparations. Proc Natl Acad Sci U S A, 1977. 74(8): p. 3203-7.

135. Azarov, I., et al., Mechanisms of slower nitric oxide uptake by red blood cells and other hemoglobin-containing vesicles. J Biol Chem, 2011. 286(38): p. 33567-79.

136. Deonikar, P. and M. Kavdia, An integrated computational and experimental model of nitric oxide-red blood cell interactions. Ann Biomed Eng, 2010. 38(2): p. 357-70.

137. Han, T.H., et al., Erythrocyte nitric oxide transport reduced by a submembrane cytoskeletal barrier. Biochim Biophys Acta, 2005. 1723(1-3): p. 135-42.

138. Liao, J.C., et al., Intravascular flow decreases erythrocyte consumption of nitric oxide. Proc Natl Acad Sci U S A, 1999. 96(15): p. 8757-61.

139. Liu, X., et al., Nitric oxide uptake by erythrocytes is primarily limited by extracellular diffusion not membrane resistance. J Biol Chem, 2002. 277(29): p. 26194-9.

140. Crawford, J.H., et al., Hypoxia, red blood cells, and nitrite regulate NO-dependent hypoxic vasodilation. Blood, 2006. 107(2): p. 566-74.

141. Chen, X., et al., A model of $\mathrm{NO} / \mathrm{O} 2$ transport in capillary-perfused tissue containing an arteriole and venule pair. Ann Biomed Eng, 2007. 35(4): p. 517-29.

142. Chen, X., et al., The influence of radial RBC distribution, blood velocity profiles, and glycocalyx on coupled NO/O2 transport. J Appl Physiol, 2006. 100(2): p. 482-92.

143. Huang, K.T., Z. Huang, and D.B. Kim-Shapiro, Nitric oxide red blood cell membrane permeability at high and low oxygen tension. Nitric Oxide, 2007. 16(2): p. 209-16.

144. Kavdia, M. and A.S. Popel, Wall shear stress differentially affects NO level in arterioles for volume expanders and Hb-based O2 carriers. Microvasc Res, 2003. 66(1): p. 49-58. 
145. Kavdia, M., N.M. Tsoukias, and A.S. Popel, Model of nitric oxide diffusion in an arteriole: impact of hemoglobin-based blood substitutes. Am J Physiol Heart Circ Physiol, 2002. 282(6): p. H2245-53.

146. Tsoukias, N.M., Nitric oxide bioavailability in the microcirculation: insights from mathematical models. Microcirculation, 2008. 15(8): p. 813-34.

147. Shin, H.Y. and S.C. George, Microscopic modeling of NO and Snitrosoglutathione kinetics and transport in human airways. J Appl Physiol, 2001. 90(3): p. 777-88.

148. Orii, Y. and H. Shimada, Reaction of cytochrome $\mathrm{c}$ with nitrite and nitric oxide. A model of dissimilatory nitrite reductase. J Biochem, 1978. 84(6): p. 1542-52.

149. Pearce, L.L., et al., The catabolic fate of nitric oxide: the nitric oxide oxidase and peroxynitrite reductase activities of cytochrome oxidase. J Biol Chem, 2002. 277(16): p. 13556-62.

150. Shiva, S., et al., Ceruloplasmin is a NO oxidase and nitrite synthase that determines endocrine NO homeostasis. Nat Chem Biol, 2006. 2(9): p. 486-93.

151. Basu, S., et al., A novel role for cytochrome c: Efficient catalysis of S-nitrosothiol formation. Free Radic Biol Med, 2010. 48(2): p. 255-63.

152. Kavdia, M. and A.S. Popel, Contribution of nNOS- and eNOS-derived NO to microvascular smooth muscle NO exposure. Journal of Applied Physiology, 2004. 97(1): p. 293-301.

153. Hoffman, M.Z. and E. Hayon, Pulse radiolysis study of sulfhydryl compounds in aqueous solution. The Journal of Physical Chemistry, 1973. 77(8): p. 990-996.

154. Kirsch, M., et al., Inhibition of Peroxynitrite-Induced Nitration of Tyrosine by Glutathione in the Presence of Carbon Dioxide through both Radical Repair and Peroxynitrate Formation. Chemistry - A European Journal, 2001. 7(15): p. 33133320.

155. Kissner, R., et al., Formation and Properties of Peroxynitrite as Studied by Laser Flash Photolysis, High-Pressure Stopped-Flow Technique, and Pulse Radiolysis. Chemical Research in Toxicology, 1997. 10(11): p. 1285-1292.

156. Broszkiewicz R. K., The pulse radiolysis study of $\mathrm{NaNO}_{2}$ and $\mathrm{NaNO}_{3}$ solutions. Bull. Acad. Pol. Sci. Sedr. Sci. Chim., 1976. 24: p. 221-229.

157. Schwartz S. E., W.W.H., Kinetics of reactive dissolution of nitrogen oxide in aqueous solution. Adv. Environ. Sci. Technol., 1983. 12: p. 1-116. 
158. Coddington, J.W., J.K. Hurst, and S.V. Lymar, Hydroxyl Radical Formation during Peroxynitrous Acid Decomposition. Journal of the American Chemical Society, 1999. 121(11): p. 2438-2443.

159. Tran, D., et al., Investigation of the Nitric Oxide Reduction of the Bis(2,9Dimethyl-1,10-phenanthroline) Complex of Copper(II) and the Structure of [Cu(dmp)2(H2O)](CF3SO3)2. Inorganic Chemistry, 1998. 37(10): p. 2505-2511.

160. Malinski, T., et al., Diffusion of nitric oxide in the aorta wall monitored in situ by porphyrinic microsensors. Biochem Biophys Res Commun, 1993. 193(3): p. 1076-82.

161. Pinotti, A., et al., Diffusion of Nitrite and Nitrate Salts in Pork Tissue in the Presence of Sodium Chloride. Journal of Food Science, 2002. 67(6): p. 21652171.

162. Buerk, D.G., K. Lamkin-Kennard, and D. Jaron, Modeling the influence of superoxide dismutase on superoxide and nitric oxide interactions, including reversible inhibition of oxygen consumption. Free Radic Biol Med, 2003. 34(11): p. 1488-503.

163. Truskey, G.A., F. Yuan, and D.F. Katz, Transport Phenomena in Biological Systems. 2009: Pearson Prentice Hall.

164. Savill, N.J., R. Weller, and J.A. Sherratt, Mathematical modelling of nitric oxide regulation of rete peg formation in psoriasis. J Theor Biol, 2002. 214(1): p. 1-16.

165. Tsoukias, N.M. and A.S. Popel, A model of nitric oxide capillary exchange. Microcirculation, 2003. 10(6): p. 479-95.

166. Pfeiffer, S., et al., Metabolic fate of peroxynitrite in aqueous solution. Reaction with nitric oxide and $\mathrm{pH}$-dependent decomposition to nitrite and oxygen in a 2:1 stoichiometry. J Biol Chem, 1997. 272(6): p. 3465-70.

167. Vaughn M. W., H.K., Kuo L., Liao J. C.,, Effective diffusion distance of nitric oxide in the microcirculation. Am J Physiol Heart Circ Physiol, 1998. 274: p. H1705-H1714.

168. Rengasamy, A. and R.A. Johns, Determination of Km for oxygen of nitric oxide synthase isoforms. J Pharmacol Exp Ther, 1996. 276(1): p. 30-3.

169. Gordge, M.P., et al., Role of a copper (I)-dependent enzyme in the anti-platelet action of S-nitrosoglutathione. Br J Pharmacol, 1996. 119(3): p. 533-8. 
170. Jansson, E.A., et al., A mammalian functional nitrate reductase that regulates nitrite and nitric oxide homeostasis. Nat Chem Biol, 2008. 4(7): p. 411-7.

171. Buerk, D.G., Can we model nitric oxide biotransport? A survey of mathematical models for a simple diatomic molecule with surprisingly complex biological activities. Annu Rev Biomed Eng, 2001. 3: p. 109-43.

172. Costa, L.E., G. Mendez, and A. Boveris, Oxygen dependence of mitochondrial function measured by high-resolution respirometry in long-term hypoxic rats. Am J Physiol, 1997. 273(3 Pt 1): p. C852-8.

173. Richmond, K.N., et al., Critical of skeletal muscle in vivo. American Journal of Physiology - Heart and Circulatory Physiology, 1999. 277(5): p. H1831-H1840.

174. Kelm, M., Nitric oxide metabolism and breakdown. Biochim Biophys Acta, 1999. 1411(2-3): p. 273-89.

175. Chen, L., J.-W. Lin, and C.-L. Yang, Absorption of NO2 in a packed tower with $\mathrm{Na} 2 \mathrm{SO} 3$ aqueous solution. Environmental Progress, 2002. 21(4): p. 225-230.

176. Kestin, J., M. Sokolov, and W.A. Wakeham, Viscosity of liquid water in the range -8 [degree]C to 150 [degree]C. Journal of Physical and Chemical Reference Data, 1978. 7(3): p. 941-948.

177. Kleinbongard, P., et al., Plasma nitrite concentrations reflect the degree of endothelial dysfunction in humans. Free Radic Biol Med, 2006. 40(2): p. 295-302.

178. Pelletier, M.M., et al., The measurement of blood and plasma nitrite by chemiluminescence: pitfalls and solutions. Free Radic Biol Med, 2006. 41(4): p. 541-8.

179. Zeng, H., N.Y. Spencer, and N. Hogg, Metabolism of S-nitrosoglutathione by endothelial cells. Am J Physiol Heart Circ Physiol, 2001. 281(1): p. H432-9.

180. Goldstein, S. and G. Czapski, Reactivity of Peroxynitrite versus Simultaneous Generation of $\bullet \mathrm{NO}$ and $\mathrm{O} 2 \cdot-$ toward NADH. Chemical Research in Toxicology, 2000. 13(8): p. 736-741.

181. Bonini, M.G. and O. Augusto, Carbon dioxide stimulates the production of thiyl, sulfinyl, and disulfide radical anion from thiol oxidation by peroxynitrite. J Biol Chem, 2001. 276(13): p. 9749-54.

182. Luo, D., S.W. Smith, and B.D. Anderson, Kinetics and mechanism of the reaction of cysteine and hydrogen peroxide in aqueous solution. J Pharm Sci, 2005. 94(2): p. 304-16. 
183. Jourd'heuil, D., et al., Reaction of superoxide and nitric oxide with peroxynitrite. Implications for peroxynitrite-mediated oxidation reactions in vivo. J Biol Chem, 2001. 276(31): p. 28799-805.

184. Santos, C.X., M.G. Bonini, and O. Augusto, Role of the carbonate radical anion in tyrosine nitration and hydroxylation by peroxynitrite. Arch Biochem Biophys, 2000. 377(1): p. 146-52.

185. Buxton, G.V., et al., Critical Review of rate constants for reactions of hydrated electrons, hydrogen atoms and hydroxyl radicals ([center-dot] $\mathrm{OH} /[$ centerdot]O[sup - ] in Aqueous Solution. Journal of Physical and Chemical Reference Data, 1988. 17(2): p. 513-886.

186. Merényi, G., et al., Mechanism and Thermochemistry of Peroxynitrite Decomposition in Water. The Journal of Physical Chemistry A, 1999. 103(29): p. 5685-5691.

187. Behar, D., et al., Acid dissociation constant and decay kinetics of the perhydroxyl radical. The Journal of Physical Chemistry, 1970. 74(17): p. 3209-3213.

188. Tamba, M., G. Simone, and M. Quintiliani, Interactions of thiyl free radicals with oxygen: a pulse radiolysis study. Int J Radiat Biol Relat Stud Phys Chem Med, 1986. 50(4): p. 595-600. 


\section{APPENDICES}

Appendix A1: Glutathiyl Radical as an Intermediate in the Glutathione Nitrosation

(The following appendix was published as supplement along with Chapter 2)

Kumpal Madrasi ${ }^{1}$, Mahesh S. Joshi ${ }^{1}$, Tushar Gadkari ${ }^{1}$, Konstantinos Kavallieratos ${ }^{2}$ and Nikolaos Tsoukias ${ }^{1}$

${ }^{1}$ Department of Biomedical Engineering, Florida International University, Miami FL 33174

${ }^{2}$ Department of Chemistry and Biochemistry, Florida International University, Miami, FL 33199

Table A1.1: Detailed set of equations involved in the nitrosation of GSH are as follows

\begin{tabular}{|c|c|c|c|}
\hline $\begin{array}{l}\text { Reaction } \\
\text { No. }\end{array}$ & Equation & Rate constant & Reference \\
\hline 1 & $2 \mathrm{NO}+\mathrm{O}_{2} \stackrel{k_{1}}{\longrightarrow} 2 \mathrm{NO}_{2}$ & $\mathrm{k}_{1}=2.9 \times 10^{6} \mathrm{M}^{-2} \mathrm{~s}^{-1}$ & [76], [77] \\
\hline 2 & $\mathrm{NO}+\mathrm{NO}_{2} \underset{k_{-2}}{\stackrel{k_{2}}{\leftrightarrow}} N_{2} \mathrm{O}_{3}$ & $\begin{array}{l}\mathrm{k}_{2}=1.1 \times 10^{9} \mathrm{M}^{-1} \mathrm{~s}^{-1} \\
\mathrm{k}_{-2}=8.1 \times 10^{4} \mathrm{~s}^{-1}\end{array}$ & $\begin{array}{l}{[78]} \\
{[78]}\end{array}$ \\
\hline 4 & $\mathrm{~N}_{2} \mathrm{O}_{3}+\mathrm{H}_{2} \mathrm{O} \stackrel{k_{4}}{\longrightarrow} 2 \mathrm{NO}_{2}^{-}+2 \mathrm{H}^{+}$ & $\mathrm{k}_{4}=38130 \mathrm{~s}^{-1}$ & [75] \\
\hline 5 & $\begin{array}{l}\mathrm{NO}_{2}+\mathrm{GSH} \stackrel{k_{5^{\prime}}}{\longrightarrow} \mathrm{NO}_{2}^{-}+G S^{\cdot}+H^{+} \\
\mathrm{NO}_{2}+G S^{-} \stackrel{k_{5^{\prime \prime}}}{\longrightarrow} \mathrm{NO}_{2}^{-}+G S\end{array}$ & $\mathrm{k}_{5}=1.15 \times 10^{7} \mathrm{M}^{-1} \mathrm{~s}^{-}$ & $\begin{array}{l}\text { Estimated } \\
\text { See also } \\
{[74]}\end{array}$ \\
\hline 6 & $G S+N O \stackrel{k_{6}}{\longrightarrow} G S N O$ & $\mathrm{k}_{6}=3 \times 10^{9} \mathrm{M}^{-1} \mathrm{~s}^{-1}$ & [79] \\
\hline 7 & $G S H \underset{k_{-7}}{\stackrel{k_{7}}{\leftrightarrow}} G S^{-}+H^{+}$ & $\begin{array}{l}\mathrm{k}_{7}=63 \mathrm{~s}^{-1} \\
\mathrm{k}_{-7}=0.1 \times 10^{10} \mathrm{M}^{-1} \mathrm{~s}^{-} \\
1\end{array}$ & $\begin{array}{l}{[80]} \\
{[80]^{*}}\end{array}$ \\
\hline 8 & $G S+G S^{-} \underset{k_{-8}}{\stackrel{k_{8}}{\leftrightarrow}} G S S G^{-}$ & $\mathrm{k}_{8}=9.6 \times 10^{6} \mathrm{M}^{-1} \mathrm{~s}^{-1}$ & [81] \\
\hline
\end{tabular}




\begin{tabular}{|c|c|c|c|}
\hline & & $\mathrm{k}_{-8}=1.6 \times 10^{5} \mathrm{~s}^{-1}$ & {$[82]$} \\
\hline 9 & $\mathrm{GSSG}^{-}+\mathrm{O}_{2} \stackrel{k_{9}}{\longrightarrow} G S S G+\mathrm{O}_{2}^{\cdot-}$ & $\mathrm{k}_{9}=5 \times 10^{9} \mathrm{M}^{-1} \mathrm{~s}^{-1}$ & [82] \\
\hline 10 & $G S+G S N O \stackrel{k_{10}}{\longrightarrow} G S S G+N O$ & $\mathrm{k}_{10}=1.7 \times 10^{9} \mathrm{M}^{-1} \mathrm{~s}^{-1}$ & [83] \\
\hline 11 & $2 G S \stackrel{k_{11}}{\longrightarrow} G S S G$ & $\mathrm{k}_{11}=1.5 \times 10^{9} \mathrm{M}^{-1} \mathrm{~s}^{-}$ & [153] \\
\hline 12 & $\mathrm{NO}_{2}+G S \stackrel{k_{12}}{\longrightarrow} \mathrm{GSNO}_{2}$ & $\mathrm{k}_{12}=3 \times 10^{9} \mathrm{M}^{-1} \mathrm{~s}^{-1}$ & [154] \\
\hline 13 & $\mathrm{NO}+\mathrm{O}_{2}^{-} \stackrel{k_{13}}{\longrightarrow} \mathrm{ONOO}^{-}$ & $\begin{array}{l}\mathrm{k}_{13}=1.9 \times 10^{10} \mathrm{M}^{-} \\
{ }^{1} \mathrm{~s}^{-1}\end{array}$ & [155] \\
\hline 14 & $\mathrm{O}_{2}^{\cdot-}+\mathrm{NO}_{2} \stackrel{k_{14}}{\longrightarrow} \mathrm{O}_{2} \mathrm{NOO}^{-}$ & $\mathrm{k}_{14}=4.5 \times 10^{9} \mathrm{M}^{-1} \mathrm{~s}^{-}$ & [180] \\
\hline 15 & $\mathrm{ONOO}^{-}+\mathrm{H}^{+} \stackrel{k_{15}}{\longrightarrow} \mathrm{NO}_{2}+\mathrm{OH}$ & $\mathrm{k}_{15}=0.23 \mathrm{~s}^{-1}$ & [158] \\
\hline 16 & $\mathrm{ONOO}^{-}+H^{+} \stackrel{k_{16}}{\longrightarrow} H^{+}+\mathrm{NO}_{3}^{-}$ & $\mathrm{k}_{16}=0.57 \mathrm{~s}^{-1}$ & [158] \\
\hline 17 & $\mathrm{ONOO}^{-}+\mathrm{GSH} \stackrel{k_{17}}{\longrightarrow} \mathrm{NO}_{2}^{-}+\mathrm{GSOH}$ & $\mathrm{k}_{17}=6.6 \times 10^{2} \mathrm{M}^{-1} \mathrm{~s}^{-}$ & [181] \\
\hline 18 & $G S O H+G S H \stackrel{k_{18}}{\longrightarrow} G S S G+H_{2} O$ & $\begin{array}{l}\mathrm{k}_{18}=7.2 \times 10^{-4} \mathrm{M}^{-} \\
{ }^{1} \mathrm{~s}^{-1}\end{array}$ & [182] \\
\hline 19 & $\mathrm{OH}+\mathrm{O}_{2}^{\cdot-} \stackrel{k_{19}}{\longrightarrow} \mathrm{O}_{2}+\mathrm{OH}^{-}$ & $\mathrm{k}_{19}=1 \times 10^{10} \mathrm{M}^{-1} \mathrm{~s}^{-1}$ & [183] \\
\hline 20 & $\mathrm{OH}+\mathrm{ONOO}^{-} \stackrel{k_{20}}{\longrightarrow} \mathrm{H}^{+}+\mathrm{O}_{2}^{-}+\mathrm{NO}_{2}^{-}$ & $\mathrm{k}_{20}=4.8 \times 10^{9} \mathrm{M}^{-1} \mathrm{~s}^{-}$ & [184] \\
\hline 21 & $\mathrm{OH}+\mathrm{GSH} \stackrel{k_{21}}{\longrightarrow} \mathrm{GS}+\mathrm{H}_{2} \mathrm{O}$ & $\begin{array}{l}\mathrm{k}_{21}=1.4 \times 10^{10} \mathrm{M}^{-} \\
{ }^{1} \mathrm{~s}^{-1}\end{array}$ & [185] \\
\hline
\end{tabular}




\begin{tabular}{|l|l|l|l|}
\hline 22 & $\mathrm{OH}+\mathrm{NO}_{2}^{-} \stackrel{\mathrm{k}_{22}}{\longrightarrow} \mathrm{NO}_{2}+\mathrm{OH}^{-}$ & $\mathrm{k}_{22}=5.3 \times 10^{9} \mathrm{M}^{-1} \mathrm{~s}^{-}$ & {$[186]$} \\
\hline 23 & $\mathrm{OH}+\mathrm{NO} \stackrel{k_{23}}{\longrightarrow} \mathrm{HNO}_{2}$ & $\mathrm{k}_{23}=1.0 \times 10^{10} \mathrm{M}^{-}$ & {$[180]$} \\
& & $\mathrm{s}^{-1}$ & \\
\hline 24 & $2 \mathrm{O}_{2}^{-}+2 \mathrm{H}^{+} \stackrel{\mathrm{k}_{24}}{\longrightarrow} \mathrm{O}_{2}+\mathrm{H}_{2} \mathrm{O}_{2}$ & $\mathrm{k}_{24}=2.5 \times 10^{5} \mathrm{M}^{-1} \mathrm{~s}^{-}$ & {$[187]$} \\
\hline 25 & $2 \mathrm{NO}_{2} \stackrel{k_{25}}{\leftrightarrow} \mathrm{N}_{2} \mathrm{O}_{4}$ & 1 & \\
\hline 26 & $\mathrm{~N}_{2} \mathrm{O}_{4}+\mathrm{H}_{2} \mathrm{O} \stackrel{k_{26}}{\longrightarrow} \mathrm{NO}_{2}^{-}+\mathrm{NO}_{3}^{-}+2 \mathrm{H}^{+}$ & $\mathrm{k}_{26}=1.0 \times 10^{3} \mathrm{~s}^{-1}$ & {$[157]$} \\
\hline
\end{tabular}

$* \mathrm{pH}=7.4$

Table A1.1 summarizes relevant reactions and kinetic constants utilized in a computational analysis of the reaction scheme. Simulations allow to estimate GSH nitrosation rates and to compare the results with the previously derived rate laws (Eq. $2.2 \mathrm{~b}-2.2 \mathrm{~d}$ ) (Fig 23.5). Reaction 2.3 was neglected in the modeling because it showed little impact on the overall results of the model.

Predicted reaction rates based on the complete set of reactions are presented as symbols for different combinations of GSH and NO donor concentrations. Dashed lines show predictions using the rate law for Reactions 2.1, 2.2, $2.4-2.6$ (Eq. 2.2b) and solid lines account also for GSSG formation through Reactions 2.7 - 2.9 (Eq. 2.2c).

At high $[\mathrm{NO}] /[\mathrm{GSH}]$ ratios, GSNO formation rates determined by Eq. $2.2 \mathrm{~b}$ (Dashed lines) are similar to those determined from the complete set of reactions 
(circles), highlighting the importance of Reactions 2.1, 2.2, 2.4 - 2.6 in GSNO formation. At low $[\mathrm{NO}] /[\mathrm{GSH}]$ ratios, Eq. 2.2c (solid lines) better describes systems kinetics suggesting a significant formation of GSSG through Reactions $2.7-2.9$ under these conditions.

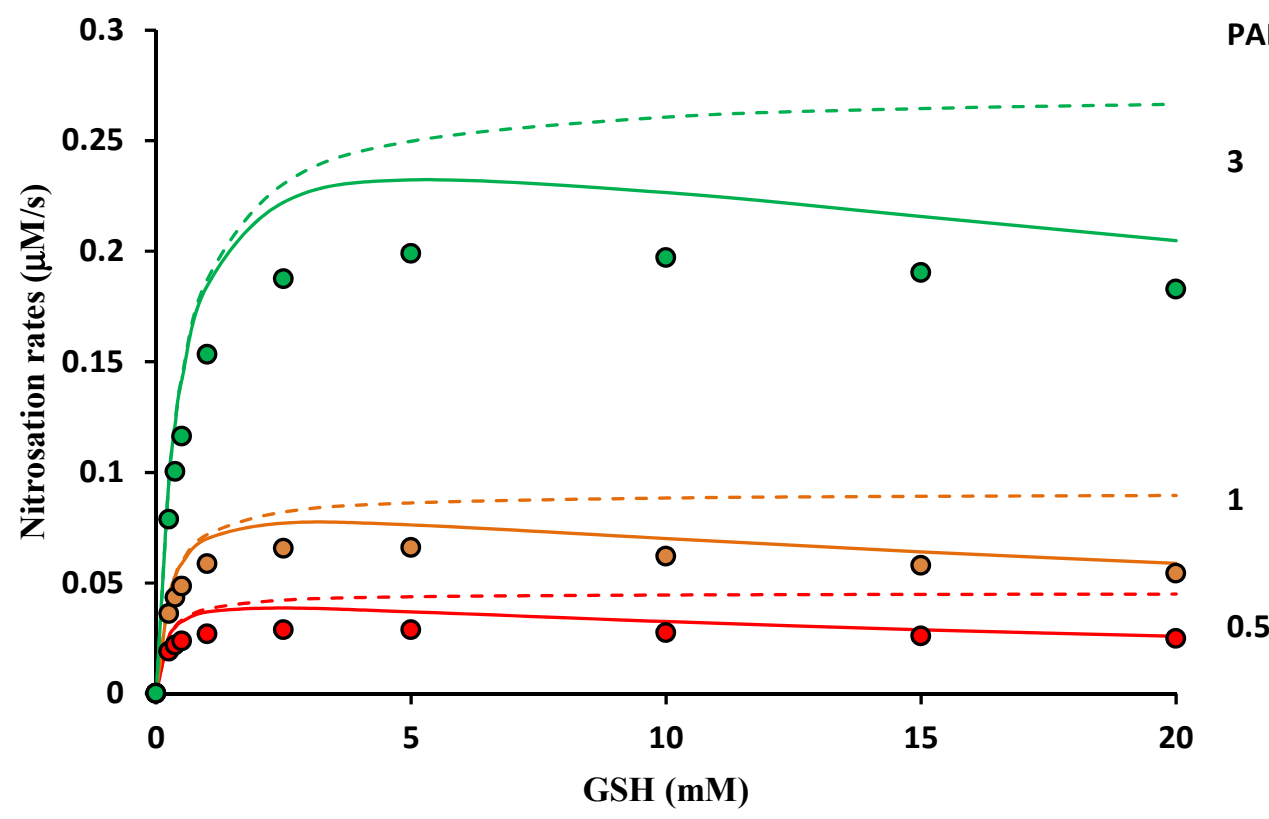

PAPA/NO (mM)

Fig A1.1: Comparison of the outcomes of the new (Eq. 2.2c) and simple (Eq. 2.2b) rate laws and the mathematical model. Dashed line indicates the simple rate law and solid line indicates the new rate law. Circles indicate outcomes of the mathematical model. Red, orange and green are for PAPA/NO concentrations of $0.5,1$ and $3 \mathrm{mM}$ respectively.

The above comparisons indicate that the concentration ratio of $[\mathrm{NO}] /[\mathrm{GSH}]$ is a critical factor in determining nitrosation process. For high ratios, the utilization of GS towards the production of GSSG has a minor impact on GSNO production. However, as the ratio decreases a significant portion of GSH is utilized towards GSSG formation and an actual decrease in GSNO formation rate is predicted as GSH increase above $10^{3} \times$ 
[NO]. In physiological scenarios, conditions that would favor GSSG production are likely, with $\mathrm{NO}$ levels reportedly in the $\mathrm{nM}$ range and $\mathrm{GSH}$ in the $\mathrm{mM}$ range (i.e. $[\mathrm{NO}] /[\mathrm{GSH}]<10^{-3}$ ) would favor GSSG formation. This could provide a pathway for reduced GSNO production in vivo.

\section{Thiyl peroxyl radical}

During the computational modeling of the reaction system, some difference was found in the resulting $\mathrm{EC}_{50}$ values when implementing the formation of thiyl peroxyl radical, GSOO which has been reported in [188] as follows:

$\mathrm{GS}+\mathrm{O}_{2} \leftrightarrow G S O O$

Reaction A1.1

This has been reported to be followed by several reactions [81]. However, GSOO is said to have a characteristic absorption peak at $540 \mathrm{~nm}$ [188], which we did not observe under our experimental conditions. Moreover, the reaction was observed to occur at a $\mathrm{pH}$ of 5.5 [188] whereas in our study we clamped $\mathrm{pH}$ at 7.4. Thus, the formation of the thiyl peroxyl radical and other downstream reactions as was implemented by Lancaster et al [81] was precluded from our analysis. Nevertheless, formation of thiyl peroxyl radical can be of importance in vivo (particularly at low $\mathrm{pH}$ ), since there are a series of downstream reactions that can interfere with GSNO formation:

$$
\begin{array}{ll}
\mathrm{GSOO}+\mathrm{GSNO} \rightarrow \mathrm{GSSG}+\mathrm{O}_{2}+\mathrm{NO} & \text { Reaction A1.2a } \\
\mathrm{GSOO}+\mathrm{NO}_{2} \leftrightarrow \mathrm{GSOONO}_{2} & \text { Reaction A1.2b }
\end{array}
$$


Reactions A1.2a - A1.2d can prove to be significant competitors to the oxidation of GSH by the $\mathrm{NO}_{2}$ radical or to the combination of the GS radical and the NO radical to form GSNO. It remains to be seen whether these reactions have any impact on the status of GSNO formation in vivo. The reaction rate constant for Reaction A1.1 is $2 \times 10^{9}$ $\mathrm{M}^{-1} \mathrm{~s}^{-1}$ and that of Reaction 2.6 is $3 \times 10^{9} \mathrm{M}^{-1} \mathrm{~s}^{-1}$ suggesting that the GSNO formation is faster than that of GSOO. The production of GSOO radical and GSNO in vivo under hypoxic and low $\mathrm{pH}$ conditions needs to be further investigated. 


\section{Appendix A2: Pseudo Steady Approximations}

The equations used in the pseudo steady state approximation in Chapter 2 of the manuscript are as follows:

$$
\begin{aligned}
& 2 \mathrm{NO}+\mathrm{O}_{2} \stackrel{k_{1}}{\longrightarrow} 2 \mathrm{NO}_{2} \\
& \mathrm{NO}_{2}+\mathrm{NO}_{k_{-2}}^{\stackrel{k_{2}}{\longrightarrow}} \mathrm{N}_{2} \mathrm{O}_{3} \\
& \mathrm{GSH}+\mathrm{N}_{2} \mathrm{O}_{3} \stackrel{k_{3}}{\longrightarrow} \mathrm{GSNO}+\mathrm{NO}_{2}^{-}+\mathrm{H}^{+} \\
& \mathrm{N}_{2} \mathrm{O}_{3}+\mathrm{H}_{2} \mathrm{O} \stackrel{k_{4}}{\longrightarrow} 2 \mathrm{NO}_{2}^{-}+2 \mathrm{H}^{+} \\
& \mathrm{NO}_{2}+\mathrm{GSH} \stackrel{k_{5}}{\longrightarrow} \mathrm{GS}+\mathrm{NO}_{2}^{-} \\
& \mathrm{GS}+\mathrm{NO} \stackrel{k_{6}}{\longrightarrow} \mathrm{GSNO}
\end{aligned}
$$

For $\mathrm{N}_{2} \mathrm{O}_{3}$ based nitrosation, only Eq A2.1 - A2.4 are relevant. Attempting to derive PSSA for $\mathrm{N}_{2} \mathrm{O}_{3}$ based nitrosation, we get the following:

$$
\begin{aligned}
& \frac{d[G S N O]}{d t}=k_{3}[G S H]\left[N_{2} O_{3}\right] \\
& \frac{d\left[\mathrm{NO}_{2}\right]}{d t}=2 k_{1}[N O]^{2}\left[O_{2}\right]-k_{2}\left[\mathrm{NO}_{2}\right][N O]+k_{-2}\left[N_{2} O_{3}\right]
\end{aligned}
$$

$\frac{d\left[N_{2} O_{3}\right]}{d t}=k_{2}\left[N O_{2}\right][N O]-k_{-2}\left[N_{2} O_{3}\right]-k_{3}\left[N_{2} O_{3}\right][G S H]-k_{4}\left[N_{2} O_{3}\right]$

Assuming negligible concentrations of $\mathrm{NO}_{2}$ and $\mathrm{N}_{2} \mathrm{O}_{3}$, one can equate the LHS of Eq. A2.8 and Eq. A2.9 as 0, and write for $\mathrm{NO}_{2}$ :

$k_{2}\left[N O_{2}\right][N O]=2 k_{1}[N O]^{2}\left[O_{2}\right]+k_{-2}\left[N_{2} O_{3}\right]$

And for $\mathrm{N}_{2} \mathrm{O}_{3}$, we can write:

$\left[\mathrm{N}_{2} \mathrm{O}_{3}\right]=\frac{k_{2}\left[\mathrm{NO}_{2}\right][\mathrm{NO}]}{k_{-2}+k_{3}[G S H]+k_{4}}$

From Eq. A2.10 and A2.11, one can write: 


$$
\begin{aligned}
& k_{2}\left[N O_{2}\right][N O]=2 k_{1}[N O]^{2}\left[O_{2}\right]+\frac{k_{-2} k_{2}\left[N O_{2}\right][N O]}{k_{-2}+k_{3}[G S H]+k_{4}} \\
& \frac{\left[k_{3}[G S H]+k_{4}\right] k_{2}\left[N O_{2}\right][N O]}{\left[k_{-2}+k_{3}[G S H]+k_{4}\right]}=2 k_{1}[N O]^{2}\left[O_{2}\right]
\end{aligned}
$$

Dividing both the sides by [NO] and cross multiplying, we get:

$$
\left[N O_{2}\right]=\frac{2 k_{1}[N O]\left[O_{2}\right]\left[k_{-2}+k_{3}[G S H]+k_{4}\right]}{k_{2}\left[k_{3}[G S H]+k_{4}\right]}
$$

From Eq. A2.7 and A2.11, one can write:

$$
\frac{d[G S N O]}{d t}=\frac{k_{3}[G S H] \times k_{2}\left[N O_{2}\right][N O]}{\left[k_{-2}+k_{3}[G S H]+k_{4}\right]}
$$

From Eq. A2.14 and A2.15, one can write:

$$
\begin{aligned}
& \frac{d[G S N O]}{d t}=\frac{2 k_{3}[G S H] \times k_{2}[N O]}{\left[k_{-2}+k_{3}[G S H]+k_{4}\right]} \times\left(\frac{k_{1}[N O]\left[O_{2}\right] \times\left[k_{-2}+k_{3}[G S H]+k_{4}\right]}{k_{2}\left[k_{3}[G S H]+k_{4}\right]}\right) \\
& \frac{d[G S N O]}{d t}=\frac{2 k_{1}[N O]^{2}\left[O_{2}\right][G S H]}{[G S H]+\frac{k_{4}}{k_{3}}}
\end{aligned}
$$

which is the final expression for PSSA that is used for $\mathrm{N}_{2} \mathrm{O}_{3}$ based nitrosation.

For a PSSA based approximation of GSNO formation via $\mathrm{NO}_{2}$, we need to use Eq A2.1, A2.2, A2.4, A2.5 and A2.6. Deriving rate laws, we can write the following:

$$
\begin{aligned}
& \frac{d\left[N O_{2}\right]}{d t}=2 k_{1}[N O]^{2}\left[O_{2}\right]-k_{2}\left[N O_{2}\right][N O]+k_{-2}\left[N_{2} O_{3}\right][N O]-k_{5}\left[N O_{2}\right][G S H] \\
& \frac{d\left[N_{2} O_{3}\right]}{d t}=k_{2}\left[N O_{2}\right][N O]-k_{-2}\left[N_{2} O_{3}\right]-k_{4}\left[N_{2} O_{3}\right] \\
& \frac{d[G S]}{d t}=k_{5}\left[N O_{2}\right][G S H]-k_{6}[G S][N O]
\end{aligned}
$$


$\frac{d[G S N O]}{d t}=k_{6}\left[G S^{\prime}\right][N O]$

Assuming negligible concentrations of $\mathrm{NO}_{2}, \mathrm{~N}_{2} \mathrm{O}_{3}$ and GS, one can equate the L.H.S. of Eq. A2.18 - A2.20 as zero. For GS, one can thus write:

$k_{6}\left[G S^{\prime}\right][N O]=k_{5}\left[N O_{2}\right][G S H]$

And so:

$$
\frac{d[G S N O]}{d t}=k_{5}\left[N_{2}\right][G S H]
$$

For $\mathrm{N}_{2} \mathrm{O}_{3}$, we can write:

$\left[N_{2} O_{3}\right]=\frac{k_{2}\left[N O_{2}\right][N O]}{\left[k_{-2}+k_{4}\right]}$

And for $\mathrm{NO}_{2}$, we can write:

$\left[k_{2}[N O]+k_{5}[G S H]\right] \times\left[N O_{2}\right]=2 k_{1}[N O]^{2}\left[O_{2}\right]+k_{-2}\left[N_{2} O_{3}\right]$

Using Eq. (A24) and (A25), we can get:

$$
\begin{aligned}
& {\left[k_{2}[N O]+k_{5}[G S H]\right] \times\left[N O_{2}\right]=2 k_{1}[N O]^{2}\left[O_{2}\right]+\frac{k_{-2} k_{2}\left[N O_{2}\right][N O]}{k_{-2}+k_{4}}} \\
& \frac{\left[k_{-2}+k_{4}\right] \times\left[k_{2}[N O]+k_{5}[G S H]\right] \times\left[N O_{2}\right]-k_{-2} k_{2}\left[N O_{2}\right][N O]}{k_{-2}+k_{4}}=2 k_{1}[N O]^{2}\left[O_{2}\right] \\
& {\left[N O_{2}\right]=\frac{2 k_{1}[N O]^{2}\left[O_{2}\right]\left[k_{-2}+k_{4}\right]}{\left[k_{-2} k_{5}[G S H]+k_{4} k_{2}[N O]+k_{4} k_{5}[G S H]\right]}} \\
& {\left[N O_{2}\right]=\frac{2 k_{1}[N O]^{2}\left[O_{2}\right]\left[k_{-2}+k_{4}\right]}{\left[\left[k_{-2}+k_{4}\right] k_{5}[G S H]+k_{4} k_{2}[N O]\right]}} \\
& {\left[N O_{2}\right]=\frac{2 k_{1}[N O]^{2}\left[O_{2}\right]}{k_{5}[G S H]+\frac{k_{4} k_{2}[N O]}{k_{-2}+k_{4}}}}
\end{aligned}
$$

Therefore, implementing the above equation for $\mathrm{NO}_{2}$ in Eq. (A23), one gets: 


$$
\frac{d[G S N O]}{d t}=\frac{k_{5} \times 2 k_{1}[N O]^{2}\left[O_{2}\right][G S H]}{k_{5}[G S H]+\frac{k_{4} k_{2}[N O]}{k_{-2}+k_{4}}}
$$

And thus,

$$
\frac{d[G S N O]}{d t}=\frac{2 k_{1}[N O]^{2}\left[\mathrm{O}_{2}\right][G S H]}{[G S H]+\frac{k_{4} k_{2}[N O]}{\left[k_{-2}+k_{4}\right] k_{5}}}
$$

Similarly, by taking into account the following reactions:

$$
\begin{aligned}
& G S H \underset{k_{-7}}{\stackrel{k_{7}}{\hookrightarrow}} G S^{-}+H^{+} \\
& G S+G S^{-} \underset{k_{-8}}{\leftrightarrow} G S S G^{-} \\
& G S S G^{-}+O_{2} \stackrel{k_{9}}{\longrightarrow} G S S G+O_{2}^{-} \\
& G S+G S N O \stackrel{k_{10}}{\longrightarrow} G S S G+N O
\end{aligned}
$$

it is easy to derive the following relation from Eq A2.1, A2.2, A2.4, A2.5, A2.6, A2.33 A2.35.

$$
\frac{d[G S N O]}{d t}=\frac{2 k_{1}[N O]^{2}\left[O_{2}\right][G S H]}{[G S H]+\frac{k_{2} k_{4}[N O]}{\left[k_{-2}+k_{4}\right] k_{5}}} \times \frac{k_{6}[N O]}{k_{6}[N O]+\frac{k_{8} k_{7}}{k_{-7}}[G S H]}
$$

and from Eq A2.1, A2.2, A2.4, A2.5, A2.6, A2.33 - A2.36.

$$
\frac{d[G S N O]}{d t}=\frac{2 k_{1}[N O]^{2}\left[O_{2}\right][G S H]}{[G S H]+\frac{k_{2} k_{4}[N O]}{\left[k_{-2}+k_{4}\right] k_{5}}} \times \frac{k_{6}[N O]-k_{10}[G S N O]}{k_{6}[N O]+\frac{k_{8} k_{7}}{k_{-7}}[G S H]+k_{10}[G S N O]}
$$




\section{Purpose}

\section{Appendix A3}

This procedure describes the steps in storage of the cell cultures. The cells in consideration are HAOSMC (Human Aortic Smooth Muscle Cells).

\section{Equipment \& Materials}

\section{Equipment}

HEPA-Filtered Laminar Flow Biological Safety Cabinet (LFBSC)

Incubator $37^{\circ} \mathrm{C}, 5 \% \mathrm{CO}_{2}$

Refrigerator at $2^{\circ} \mathrm{C}$ to $8^{\circ} \mathrm{C}$

Waterbath at $35^{\circ} \mathrm{C}$ to $39^{\circ} \mathrm{C}$

$\underline{\text { Materials }}$

Pipette

Pipette tips

Waste Container (150mL beaker)

$70 \%$ Ethanol

Kimwipes 


\section{Reagents}

\begin{tabular}{|l|l|l|l|}
\hline Description & Catalog \# & Lot \# & Expiration Date \\
\hline Supplemented Media & & & \\
\hline
\end{tabular}

Completed by (Initials/Date) Verified by (Initials/Date)

\section{Technician Signature Log}

\begin{tabular}{|l|l|l|}
\hline Print Name & Signature & Initials \\
\hline & & \\
\hline & & \\
\hline & & \\
\hline & & \\
\hline
\end{tabular}

\section{Procedure}

a. Cryopreserved vials:

Store the cryovials in a liquid nitrogen storage tank immediately upon arrival.

b. Safety Precautions:

Biosafety Level 2 Procedures should be followed. Good aseptic technique should be used during all procedures which include wearing appropriate clothing (i.e.- lab coats, safety glasses and gloves) at all times inside the 
hood and spraying hands with alcohol anytime they are re-entered inside the hood. All work and opening of sterile materials or cell cultures must be done inside a HEPA filtered, laminar flow biological safety cabinet (LFBSC).

c. Hood cleared and cleaned by (Initial/date):

d. Preparation steps before media change

i. Turn on water bath and flow hood.

ii. Remove aliquoted amount of supplemented smooth muscle media from refrigerator and place into the water bath. (Amount of media required depends on the amount of cell cultures needed to be fed.)

\section{Initial cell proliferation:}

a. Take a T-25 flask, add $5 \mathrm{ml}$ of smooth muscle cell growth medium that was placed into the water bath.

b. Remove the cryopreserved vial of HAOSMC from the liquid nitrogen storage tank using proper protection for eyes and hands.

c. Turn the vial cap a quarter turn to release any liquid nitrogen that may be trapped in the threads, then re-tighten the cap.

d. Thaw the cells quickly by placing the lower half of the vial in a $37^{\circ} \mathrm{C}$ water bath for 1 minute.

e. Take the vial out of the water bath and wipe dry. 
f. Decontaminate the vial exterior with $70 \%$ alcohol in a sterile Biological Safety Cabinet.

g. Remove the vial cap carefully. Do not touch the rim of the cap or the vial.

h. Resuspend the cells in the vial by gently pipetting the cell 5 times with a 2 $\mathrm{ml}$ pipette. Cells must not be pipette too vigorously as to cause foaming.

i. Use $500 \mu \mathrm{l}$ (out of a total of $1 \mathrm{ml}$ ) of the volume of the cryopreserved vial and add it to the incubated medium in the flask.

j. Cap the flask and rock gently to evenly distribute the cells.

k. Place the flask in a $37^{0} \mathrm{C}, 5 \% \mathrm{CO}_{2}$ humidified incubator. Loosen the cap to allow gas exchange.

1. After 24 hours, change to fresh smooth muscle growth medium to remove all traces of DMSO.

m. Change smooth muscle cell growth medium every alternate day until the cells reach $60 \%$ confluent.

n. Double smooth muscle cell growth medium volume when the culture is $>$ $60 \%$ confluent or for feedings over weekends/holidays.

o. Harvest the cells of the T-25 flask into two flasks when the HAOSMC reach $80 \%$ confluency. 


\section{Purpose}

\section{Appendix A4}

This procedure describes the steps in changing the media of the cell cultures. The cells in consideration are HAOSMC (Human Aortic Smooth Muscle Cells).

\section{Equipment \& Materials}

Equipment

HEPA-Filtered Laminar Flow Biological Safety Cabinet (LFBSC)

Incubator $37^{\circ} \mathrm{C}, 5 \% \mathrm{CO}_{2}$

Refrigerator at $2^{\circ} \mathrm{C}$ to $8^{\circ} \mathrm{C}$

Waterbath at $35^{\circ} \mathrm{C}$ to $39^{\circ} \mathrm{C}$

$\underline{\text { Materials }}$

Pipette

Pipette tips

Waste Container (150mL beaker)

$70 \%$ Ethanol

Kimwipes 


\section{Reagents}

\begin{tabular}{|l|l|l|l|}
\hline Description & Catalog \# & Lot \# & Expiration Date \\
\hline Supplemented Media & & & \\
\hline
\end{tabular}

Completed by (Initials/Date) Verified by (Initials/Date)

\section{Technician Signature Log}

\begin{tabular}{|l|l|l|}
\hline Print Name & Signature & Initials \\
\hline & & \\
\hline & & \\
\hline & & \\
\hline & & \\
\hline
\end{tabular}

\section{Procedure}

e. Safety Precautions:

Biosafety Level 2 Procedures should be followed. Good aseptic technique should be used during all procedures which include wearing appropriate clothing (i.e.- lab coats, safety glasses and gloves) at all times inside the hood and spraying hands with alcohol anytime they are re-entered inside the hood. All work and opening of sterile materials or cell cultures must 
be done inside a HEPA filtered, laminar flow biological safety cabinet (LFBSC).

f. Hood cleared and cleaned by (Initial/date):

g. Preparation steps before media change

i. Turn on water bath and flow hood.

ii. Remove aliquoted amount of supplemented smooth muscle media from refrigerator and place into the water bath. (Amount of media required depends on the amount of cell cultures needed to be fed.) NOTE: For flasks, the approximate amount of smooth muscle cell media needed follows the ratio of $5 \mathrm{~mL}$ per $25 \mathrm{~cm}^{2}$. For 24 well plates, $1 \mathrm{~mL}$ is needed per well.

iii. Note the confluency of the cultures and record in notebook.

Completed by (Initials/Date) ___ Verified by (Initials/Date)

h. Changing Media (To be completed after supplemented media is warm)

i. Spray down flow hood with $70 \%$ ethanol. Wipe down with kimwipes.

ii. Spray down and place the following contents inside the hood: Cell cultures, waste bucket, aliquoted supplemented media, pipette, and appropriate pipette tips. 
iii. For flasks: Keep in an upright position, loosen the caps but do not completely open them until ready for use. Discard old smooth muscle cell media into the waste bucket by slowly pouring. Be careful not to cause splashing as contamination might occur.

iv. For 24 well plates: Remove old smooth muscle cell media using a sterile pipette. Discard old smooth muscle cell media into the waste bucket.

v. Using a pipette, pull up the appropriate amount of smooth muscle cell media from aliquot and place into the flask or well plate. For the flasks, close the tops tightly.

vi. Place cell cultures back into the incubator.

vii. Remove all materials out of the hood and replace in their appropriate locations.

viii. Spray and wipe down the hood when completed.

ix. Discard of waste into the appropriate waste container.

Completed by (Initials/Date) ___ Verified by (Initials/Date)

i. Further feeding considerations

i. Changing of media should be done every 48 hours. 


\section{Purpose}

\section{Appendix A5}

This procedure describes the steps in harvesting the cell cultures. The cells in consideration are HAOSMC (Human Aortic Smooth Muscle Cells).

\section{Equipment \& Materials}

$\underline{\text { Equipment }}$

HEPA-Filtered Laminar Flow Biological Safety Cabinet (LFBSC)

Incubator $37^{\circ} \mathrm{C}, 5 \% \mathrm{CO}_{2}$

Refrigerator at $2^{\circ} \mathrm{C}$ to $8^{\circ} \mathrm{C}$

Waterbath at $35^{\circ} \mathrm{C}$ to $39^{\circ} \mathrm{C}$

Centrifuge

$\underline{\text { Materials }}$

Pipette

Pipette tips

Waste Container (150mL beaker)

$70 \%$ Ethanol

Kimwipes

Conical tubes 


\section{Reagents}

\begin{tabular}{|l|l|l|l|}
\hline Description & Catalog \# & Lot \# & Expiration Date \\
\hline Supplemented Media & & & \\
\hline PBS & & & \\
\hline Trypsin & & & \\
\hline
\end{tabular}

Completed by (Initials/Date) Verified by (Initials/Date)

\section{Technician Signature Log}

\begin{tabular}{|l|l|l|}
\hline Print Name & Signature & Initials \\
\hline & & \\
\hline & & \\
\hline & & \\
\hline & & \\
\hline
\end{tabular}

\section{Procedure}

j. Safety Precautions:

Biosafety Level 2 Procedures should be followed. Good aseptic technique should be used during all procedures which include wearing appropriate clothing (i.e.- lab coats, safety glasses and gloves) at all times inside the 
hood and spraying hands with alcohol anytime they are re-entered inside the hood. All work and opening of sterile materials or cell cultures must be done inside a HEPA filtered, laminar flow biological safety cabinet (LFBSC).

k. Hood cleared and cleaned by (Initial/date):

1. Preparation steps before harvesting

i. Turn on water bath and flow hood. Remove aliquoted amount of supplemented media and trypsin from refrigerator and place into the water bath.

ii. Note the confluency of the cultures and record in notebook. Refer to notebook

iii. Remove the subculture reagent kit from the $-20^{\circ} \mathrm{C}$ freezer and thaw overnight in a refrigerator.

iv. Make sure all the subculture reagents are thawed. Swirl each bottle gently several times to form homogenous solutions.

v. Store subculture reagents and trypsin at $4{ }^{0} \mathrm{C}$ for future use.

Completed by (Initials/Date) ___ Verified by (Initials/Date)

m. Harvesting of cell cultures (To be completed after the trypsin and supplemented media are warm) 
i. Spray down flow hood with $70 \%$ ethanol. Wipe down with kimwipes.

ii. Spray down and place the following contents inside the hood: Cell cultures, waste bucket, aliquoted supplemented media, aliquoted typsin, PBS, conical tubes with rack, pipette, and appropriate pipette tips.

iii. For flasks:

1. Keep in an upright position, loosen the caps but do not completely open them until ready for use. Discard old media into the waste bucket by slowly pouring. Be careful not to cause splashing as contamination might occur.

2. Add $1 \mathrm{ml}$ trypsin to the flasks. (NOTE: The amount of trypsin added follows the ratio of $1 \mathrm{~mL}$ per $25 \mathrm{~cm}^{2}$.)

3. Gently rock the flasks back and forth for approximately 1 minute being careful not to get any liquid in the filter of the cap.

4. Discard waste by pulling up medium in sterile pipettes.

5. Add trypsin to the flasks (NOTE: Approximate amount of trypsin to be used follows the ratio of $2 \mathrm{~mL}$ per $25 \mathrm{~cm}^{2}$.)

6. Place flasks into the incubator. Check flasks frequently under the microscope to ensure that all cells have lifted off the flask. Timing will vary depending on the confluency. Light tapping on the flask will assist in removing the cells 
from the flask. (NOTE: Do not leave the cells in trypsin for longer time than needed as it will damage the cells)

7. Once cells have been completely lifted off the flask, place back into the hood using proper aseptic techniques described above.

8. To quench the trypsin add the equivalent amount of smooth muscle cell growth media. Gently rock to mix well.

9. Using a pipette of the appropriate volume, remove the cell suspension and place into a conical tube.

10. Rinse once again by adding the same amount of smooth muscle cell growth media used to quench. Rock gently and remove suspension as described in the previous step. (NOTE: As a check, look at the flasks or well plates under a microscope to ensure that all the cells have been removed)

11. Place the conical tubes into the centrifuge and spin for 4 minutes at $1500 \mathrm{rpm}$ at $25^{\circ} \mathrm{C}$.

12. Carefully remove the conical tubes from the centrifuge to avoid disrupting the cell pellet and place into the hood.

13. Discard the supernatant leaving only the cell pellet.

14. Resuspend the cell pellet with an appropriate amount of smooth muscle c growth media. 
15. Cells are now ready for further use. Count the cells with a hemocytometer or cell counter. Inoculate at 10,000 cells per $\mathrm{cm}^{2}$ for rapid growth, or at 6000 cells per $\mathrm{cm}^{2}$ for regular subculturing.

iv. For 24 well plates: Remove old cell growth media using a sterile pipette. Discard old media into the waste bucket.

1. Rinse the wells by adding $0.5 \mathrm{~mL}$ of tryspin to each well.

2. Gently rock the well plates to ensure that the cells have been rinsed sufficiently and any residual media is cleaned.

3. Remove waste as described in step 5.1.3.1.

4. Add trypsin to each well (NOTE: $0.5-1 \mathrm{~mL}$ of trypsin per well is sufficient)

5. Place well plates into the incubator. Check plates frequently under the microscope to ensure that all cells have lifted off. Timing will vary depending on the confluency. (NOTE: Do not leave the cells in trypsin for longer time than needed as it will damage the cells)

6. Once cells have completely lifted off the well plate, place back into the hood using proper aseptic techniques described above.

7. Follow steps 5.4.3.9-5.4.3.16. 
Completed by (Initials/Date) Verified by (Initials/Date)

n. Clean-up:

i. Remove all materials out of the hood and replace in their appropriate locations.

ii. Spray and wipe down the hood when completed.

iii. Discard of waste into the appropriate waste container.

o. Further feeding considerations

i. Changing of media should be done every 48 hours. Refer to the changing media SOP. 
VITA

KUMPAL MADRASI

$2007-2012$

Doctoral Candidate, Department of Biomedical Engineering, Florida International University

$2003-2007$

Bachelor of Engineering, Department of Biomedical Engineering, U.V. Patel College of Engineering, Hemachandracharya North Gujarat University

\section{PUBLICATIONS AND CONFERENCE PROCEEDINGS:}

Kumpal J. Madrasi, Mahesh S. Joshi and Nikolaos Tsoukias. "Kinetics of Nitrosation of GSH using NO donors." Poster presentation at FASEB 2010, Anaheim.

Kumpal J. Madrasi, Nikolaos Tsoukias and Mahesh S. Joshi. "Soluble Guanylate Cyclase catalyzes nitrite reduction to nitric oxide in rat aortic smooth muscle cells." Poster presentation at FASEB 2011, Washington D.C.

Kumpal J. Madrasi, Nikolaos Tsoukias and Mahesh S. Joshi. "Nitrite reduction to NO in rat aortic smooth muscle cells by soluble Guanylate Cyclase." Poster presentation at Nitrite 2011, Atlanta.

Kumpal J. Madrasi, Nikolaos Tsoukias and Mahesh S. Joshi. "sGC in SMC acts as nitrite reductase leading to NO formation.” Poster presentation at FASEB 2012, San Diego.

Kumpal J. Madrasi, Tushar Gadkari, Mahesh S. Joshi, Konstantinos Kavallieratos and Nikolaos Tsoukias. "Glutathiyl radical as an intermediate in glutathione nitrosation" Free Radical Biology and Medicine 53 (2012) 1968-1976.

Kumpal J. Madrasi, Nikolaos Tsoukias and Mahesh S. Joshi. "Nitrite transport and reduction by sGC in smooth muscle cells." (manuscript submitted to Free Radical Biology and Medicine)

Tushar V. Gadkari, Natalie Cortes, Kumpal Madrasi, Nikolaos M. Tsoukias, and Mahesh S. Joshi, "Agmatine Induced NO Dependent Rat Mesenteric Artery Relaxation and its Impairment in Salt-Sensitive Hypertension." (manuscript submitted to American Journal of Hypertension)

Shabnam M. Namin, Kumpal J. Madrasi, David Isaza and Nikolaos Tsoukias. "Theoretical and experimental determination of nitric oxide consumption by red blood cells." Nitric Oxide (manuscript under preparation.) 